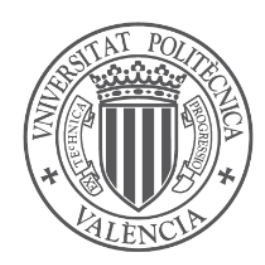

Universitat Politècnica de València

Departamento de Ingeniería Hidráulica y Medio Ambiente Programa de Doctorado de Ingeniería del Agua y Medioambiental

\title{
ON THE USE OF SATELLITE DATA TO CALIBRATE A PARSIMONIOUS ECOHYDROLOGICAL MODEL IN UNGAUGED BASINS
}

AUTHOR: GUIOMAR RUIZ PÉREZ SUPERVISOR: DR. FÉLIX FRANCÉS GARCÍA 

A Ana, 
On the use of satellite data to calibrate a parsimonious ecohydrological model in ungauged basins Doctoral Thesis 
Feel the ocean as it breathes,

shivering teeth.

See the mountains where they meet, smothering me. As the wind fends off the waves, I count down the days heavy stones fear no weather.

And from the rain comes a river running wild that will create an empire for you. Illuminate!

Empire, Of Monster and Men (2015) 
On the use of satellite data to calibrate a parsimonious ecohydrological model in ungauged basins Doctoral Thesis 


\section{ACKNOWLEDGEMENTS}

This doctoral thesis was thanks to a FPI (Formación de Personal Investigador) fellowship supported by the Spanish Ministry. The research leading to this thesis has received funding from the Spanish Ministry of Economy and Competitiveness and FEDER funds, through the research projects INTEGRA ECOTETIS (CGL2011-28776-C02-01) and TETISMED (CGL2014-58127-C3-3-R). The collaboration between Universitat Politècnica de València, Università degli studi della Basilicata and Princeton University was funded by the Spanish Ministry of Economy and Competitiveness through the EEBB-I-15-10262 fellowship.

The MODIS data were obtained through the online Data Pool at the NASA Land Processes Distributed Active Archive Center (LP DAAC), USGS/Earth Resources Observation and Science (EROS) Center, Sioux Falls, South Dakota (https://lpdaac.usgs.gov/get_data). The meteorological data were provided by the Spanish National Weather Agency (AEMET).

Thanks to my supervisor Dr. Félix Francés for the trust and confidence during the last years. Grazie mille Dr. Salvatore Manfreda for being so welcoming and making me to feel at home. Thanks to Dr. Kelly Caylor for his suggestions and guidance during my stay in Princeton University.

Thanks to the Re-Forest research group for their collaboration. Special mention is deserved by Dr. María González-Sanchis and Dr. Antonio D. del Campo.

Thanks to all my colleagues. We built a great working environment and I always found affection and support in our research group. Specially, thanks to Dr. Alicia García-Arias who is much more than a colleague.

Gracias a mi madre por todo su sacrificio. Gracias a mi hermana por estar siempre conmigo. Gracias a mis amigos, a los de siempre y a los que llegasteis luego, por quedaros a mi lado aun estando muy lejos físicamente. Gracias Carmen, tú te merecías una mención especial. 
On the use of satellite data to calibrate a parsimonious ecohydrological model in ungauged basins Doctoral Thesis 


\section{CONTENTS:}

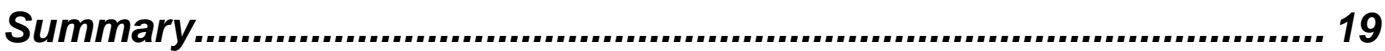

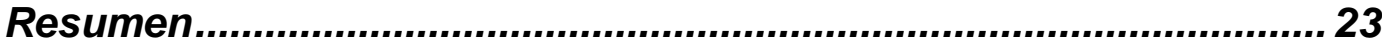

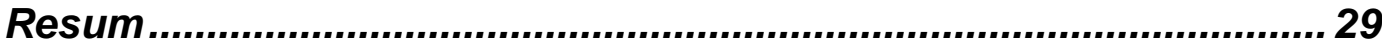

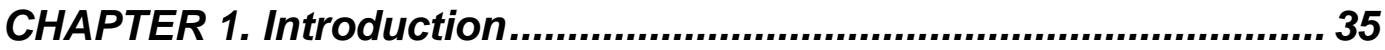

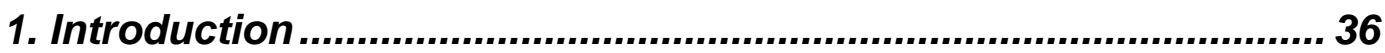

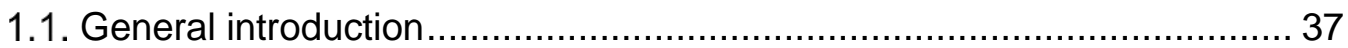

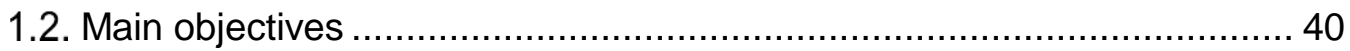

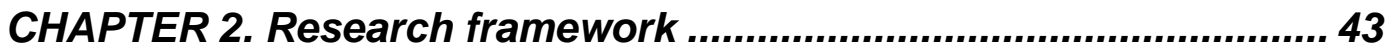

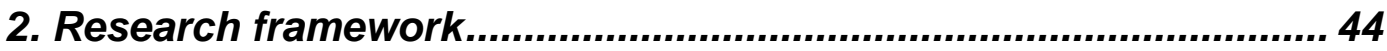

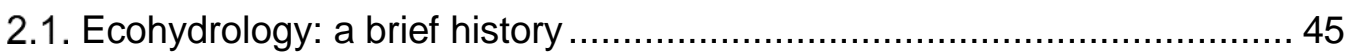

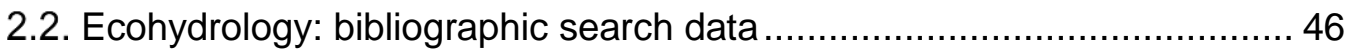

2.3. Plants and water-controlled ecosystems ............................................... 48

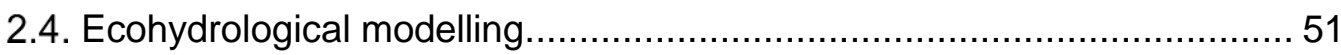

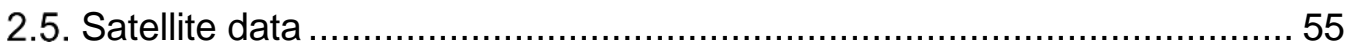

2.5.1. Vegetation and satellite data......................................................... 56

2.5.2. Satellite data and Vegetation Indexes acquisition: MODIS products. 59

2.5.3. Ecohydrological modelling and satellite data .................................... 61

CHAPTER 3. At plot scale: testing the model....................................67

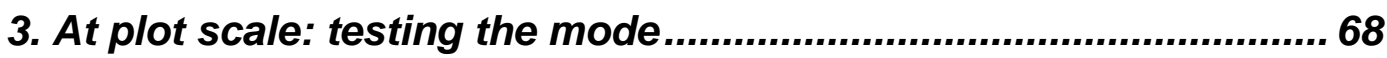

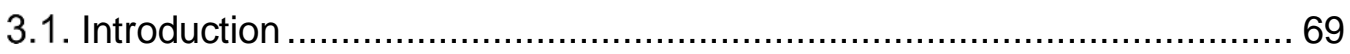

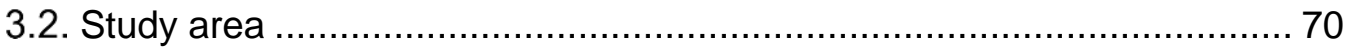

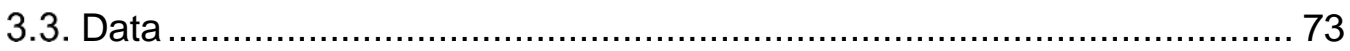

3.3.1. Precipitation and Temperature time series..................................... 73

3.3.2. Transpiration and Soil Water Content time series ............................. 74

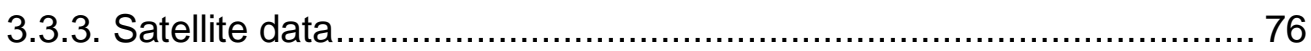

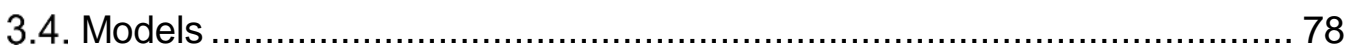




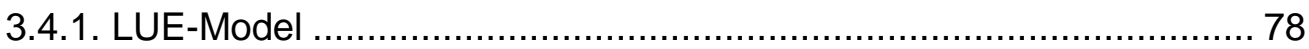

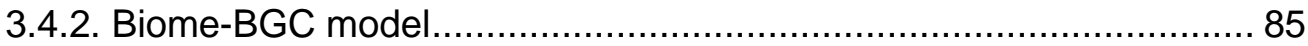

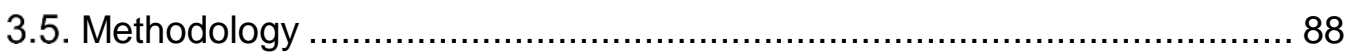

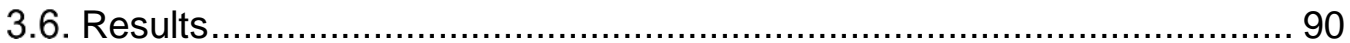

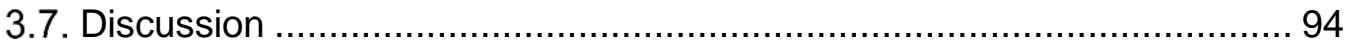

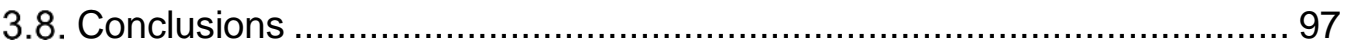

CHAPTER 4. At cathment scale: spatio-temporal modelling ........... 101

4. At catment scale: spatio-temporal modelling............................... 102

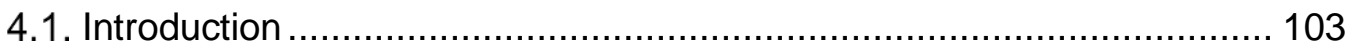

4.2. Study area: Upper Ewaso Ngiro River basin ................................... 104

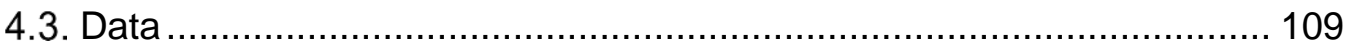

4.4. Model description: TETIS-VEG ..................................................... 110

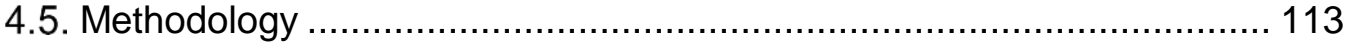

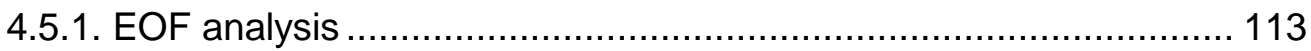

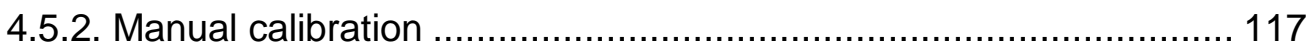

4.5.3. Automatic calibration ............................................................... 119

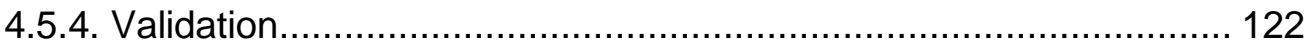

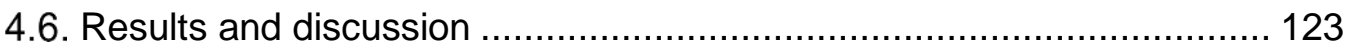

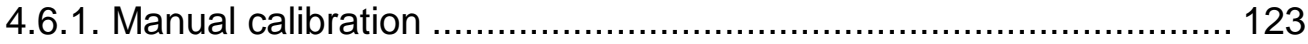

4.6.2. Automatic calibration ................................................................. 126

4.6.3. Satellite validation................................................................ 131

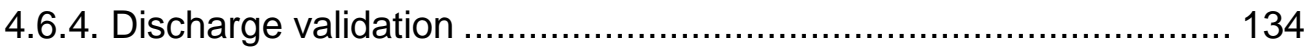

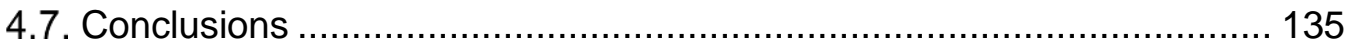

CHAPTER 5. Conclusions .............................................................. 137

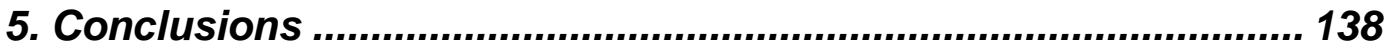

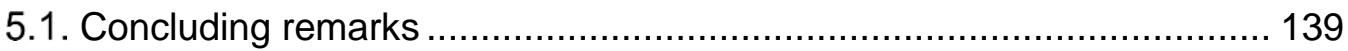

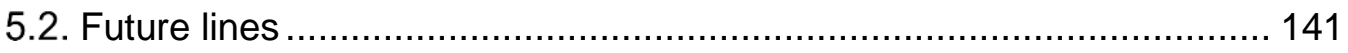

6. Scientific publications derived from this doctoral thesis............. 145 
6.1. Publications in indexed journals (with peer-review) ........................... 145

6.2. Conferences contributions and publications in proceedings ................. 145

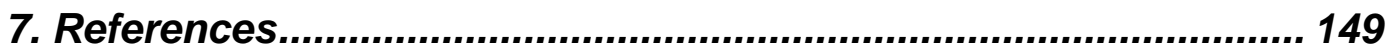


On the use of satellite data to calibrate a parsimonious ecohydrological model in ungauged basins Doctoral Thesis 


\section{LIST OF FIGURES}

Figure 2-1. Published items with the term ecohydrology in the title, abstract and keyword lists from 1991 to 2016

Figure 2-2. Continuum of model terminology according to the level of process detail and understanding within the model. The terminology originated from (1) ecological and (2) hydrological science. Figure extracted from Arnold et al. (2011)

Figure 3-1. Location of the experimental plot study site. Detailed view of the 60 years old Aleppo pine plantation, control plot, used for this work

Figure 3-2. Transpiration measured in field during the observational period from $27 / 03 / 2009$ to $31 / 05 / 2011$

Figure 3-3. SWC measured in field during the observational period from $27 / 03 / 2009$ to $31 / 05 / 2011$ 75

Figure 3-4. NDVI data included in MOD13Q1 and MYD13Q1 products, LAI included in MOD15A2 and MYD15A2, and ET included in MOD16A2 from MODIS (NASA) during the period from 01/01/2000 to 26/12/2012 ................... 77

Figure 3-5. Scheme of the hydrological sub-model (extracted from Pasquato et al., 2015) 79

Figure 3-6. Soil water potential (MPa) at field capacity, permanent wilting point and hygroscopically bound water recommended in the book Plant Ecology (Schulze et al., 2005) for different types of soil and different plants according to their adaptation (drought or moist adapted)

81

Figure 3-7. Biome-BGC detailed model flow chart (extracted from the Theoretically Framework of Biome-BGC, 2010).

Figure 3-8. Comparison between $\mathrm{LAI}_{\mathrm{r}}$ simulated by the model and NDVI from satellite. The shaded areas correspond to the two specific periods with a significant disagreement between simulated $L A l_{r}$ and satellite NDVI

Figure 3-9. Transpiration (lower panel) and SWC (upper panel) measured in field and simulated by both models 92

Figure 3-10. Transpiration (upper panel) and SWC (lower panel) time series simulated by both models (from 2004 to 2012 approximately) 93

Figure 3-11. Linear correlation between transpiration and VPD during the different four groups stablished by Del Campo et al. (2014). R is the Pearson correlation coefficient. 
Figure 3-12. Linear correlation between transpiration and SWC during the different four groups stablished by Del Campo et al. (2014). $\mathrm{R}$ is the Pearson correlation coefficient. 95

Figure 4-1 General map location of the upper Ewaso Ngiro River basin within the boundaries of Kenya and the major districts where the basin is located 106

Figure 4-2. Spatial distribution of soil types for the basin. Source of data: 1980 Unesco Soil Map modified by Franz (2007) 107

Figure 4-3. Land classification map of watershed. Source of information: AVHRR data modified by Franz (2007). 108 Figure 4-4. The study sub-catchment (in green) was selected because the density of the rainfall stations (dots in dark blue) .......................................... 109 Figure 4-5. The conceptual scheme of the TETIS model used as the hydrological sub-model in this research. 112

Figure 4-6. The matrix F. Each row is one map, and each column is a time series of observations for a given location 115

Figure 4-7. Matrix used in the EOF analysis. $t$ is the time (equal to the number of maps) and $\mathrm{N}$ is the number of pixels.

120

Figure 4-8. Location of the center of the cells where the manual calibration was carried out. The value of the Pearson correlation coefficient between the satellite NDVI and the simulated LAI appears together with the cells used to the manual calibration of the model 124

Figure 4-9. Variance explained by the first ten EOFs during the calibration period (year 2000). 126

Figure 4-10.Comparison between the loadings of the normalized NDVI provided by satellite (observed loadings) and the normalized LAIr simulated by the model (simulated loadings) during the calibration period (year 2000, upper panels) and during the validation (year 2001, 2002 and 2003; lower panels). The y-axes reflect the unitless loadings of each EOF. The x-axes reflect the number of the analyzed maps ( 45 and 65 maps were used for model's calibration and validation respectively).

Figure 4-11. Temporal Pearson correlation coefficient between the NDVI provided by MODIS and the $\mathrm{LAI}_{\mathrm{r}}$ simulated by the model during the calibration period (year 2000). The two areas with negative values correspond to the Mount Kenya and Aberdare Mountains. 128 
Figure 4-12 Spatial Pearson correlation coefficient during the calibration (year 2000) distinguishing between the main land uses: tree, shrubs and grass. The whiskers were calculated according to the $98 \%$ percentile and the outliers were plotted as $x$. The median is the line inside boxplot and the mean is the quadrangle. 130

Figure 4-13 Comparison between the maps where each pixel contains the difference between the temporal mean calculated in this particular pixel and the general mean calculated using the all dataset of the simulated $\mathrm{LAl}_{\mathrm{r}}$ (left) and observed NDVI (right) for the calibration period (year 2000). This difference is a measure of spatial gradient of both variables (LAI $r$ and NDVI).

Figure 4-14. Variance explained by the first ten EOFs during the validation period (year 2001, 2002 and 2003).

Figure 4-15. Temporal Pearson correlation coefficient between the NDVI provided by MODIS and the $\mathrm{LAl}_{\mathrm{r}}$ simulated by the model during the validation period (years 2001, 2002 and 2003). The two areas with negative values correspond to the Mount Kenya and Aberdare Mountains. 132

Figure 4-16 Spatial Pearson correlation coefficient during the validation distinguishing between the main land uses: tree, shrubs and grass. The whiskers were calculated according to the $98 \%$ percentile and the outliers were plotted as $x$. The median is the line inside boxplot and the mean is the quadrangle 133 Figure 4-17. Comparison between the maps where each pixel contains the difference between the temporal mean calculated in this particular pixel and the general mean calculated using the all dataset of the simulated LAI $\mathrm{r}_{\mathrm{r}}$ (left) and observed NDVI (right) in validation (years 2001, 2002 and 2003). This difference is a measure of spatial gradient of both variables ( $L A I_{r}$ and NDVI). 133

Figure 4-18. Time series of rainfall and observed and simulated daily discharge $\left(\mathrm{m}^{3} / \mathrm{s}\right)$ during the validation period $(2000,2001$ and 2002$)$..... 134 
On the use of satellite data to calibrate a parsimonious ecohydrological model in ungauged basins Doctoral Thesis 


\section{LIST OF TABLES}

Table 2-1. Vegetation indices compiled by Silleos et al. (2006) ........................ 58

Table 2-2. General specifications of the MODIS sensors (extracted from http://modis.gsfc.nasa.gov/about/specifications.php) ................................... 60

Table 2-3. MODIS products and their corresponding sources......................... 60 Table 2-4. List of publications in which satellite data was used to calibrate different models extracted from the Web of Knowledge database using the search topics specified in the introduction section .......................................... 64

Table 3-1. Vegetation units in La Hunde y La Palomera forest (Table extracted from Molina, 2010) 72

Table 3-2. Means of the forest structure characteristics in the experimental plot. Table extracted from Del Campo et al. (2014) and adapted from Molina and Del Campo (2012) 72

Table 3-3. Values proposed by Calpp and Hornberger (1978) for the parameters: $\Psi$ ae, $\mathrm{n}$ and $\mathrm{b}$ 82

Table 3-4. Inputs, state variables and parameters of the LUE-Model's hydrological sub-model 82

Table 3-5. Inputs, state variables and parameters of the LUE-Model's dynamic vegetation sub-model 85

Table 3-6. Range of parameters values, initial values and final results obtained during the calibration process 90

Table 3-7. Results of the validation using field data for the LUE-Model and Biome-BGC models (observational period from 27/03/2008 to 31/05/2011) ...... 92 Table 3-8. Results of each model in terms of Blue (exceedance) and Green (evapotranspiration) water 93

Table 4-1. Summary of the initial values, the search range and the final value of the parameters or correction factors of both sub-models (hydrological and dynamic vegetation) as well as the units and the reviewed references 125 
On the use of satellite data to calibrate a parsimonious ecohydrological model in ungauged basins Doctoral Thesis 
On the use of satellite data to calibrate a parsimonious ecohydrological model in ungauged basins Doctoral Thesis 
Water is the foundation for all biological life on Earth and one of the basic links between the biosphere and atmosphere. It is equally fundamental for humans and nature (Tolba, 1982). In an environment of growing scarcity and competition for water, increasing the understanding of all fluxes of the water cycle lies at the heart of the scientific community's goals. Traditionally, water and vegetation have been considered as different systems. However, it is necessary to take a holistic approach which considers the question of the water cycle in an integrated manner by taking into account both: blue water and green water (Birot et al., 2011). Around this idea, the new discipline Ecohydrology emerged in the early $20^{\text {th }}$ century and, from then; it has grown steadily as shown by the increasing number of research lines and scientific papers related to this new field.

The necessity of this new discipline is even more evident in arid and semiarid regions where the hydrological cycle and the vegetation dynamics are tightly interconnected. That's why a coupled modeling of these two systems is needed to fully reproduce the ecosystems' behavior over time and to predict possible future responses to climate change.

However, most of the current hydrological models includes the vegetation as static parameter and not as state variable. In fact, most of them are able to represent fairly well the observed discharge at the catchment outlet, but usually including the vegetation as a static parameter (Quevedo and Francés, 2008). There are some exceptions taking explicitly the vegetation as state variable but in those cases, the models' complexity and parametrical requirements increase substantially. Hence, a lot of information is required to implement them and that information is not always available. In fact, in practice, we have to deal against the 'data scarcity - high parametrical requirements' issue really often.

To reduce that issue, two strategies can be applied: (1) simplification of the models' conceptual scheme and (2) increase of data availability by incorporating new sources of information. In this thesis, we explored the use of a distributed parsimonious ecohydrological modelling (with low parametrical requirements) calibrated and validated exclusively with remote sensing data.

First, we used the parsimonious ecohydrological model proposed by Pasquato et al. (2015) in an experimental plot located in a semi-arid Mediterranean forest. Due to its simplicity, some processes are neglected in its conceptualization because only the main processes are included. That's why it was important to test their accuracy and reliability. To address this issue, we decided to compare 
the results provided by this parsimonious model against the corresponding ones provided by a complex physically-based ecohydrological model. The results in this previous stage suggested that the model was able to adequately reproduce the dynamics of vegetation as well as the soil moisture variations. In other words, it has been shown that a parsimonious model with simple equations can achieve good results in general terms. But, as long as we applied the model at plot scale, the challenging task to reproduce the spatial variation of the vegetation and water cycle remained.

To explore the spatio-temporal variation of the vegetation and the water cycle, the distributed version of the parsimonious ecohydrological model used previously was applied in a basin located in Kenya, concretely in the Upper Ewaso Ngiro River basin. In order to explore the potential applicability of the satellite data, we calibrated the model using exclusively the NDVI provided by NASA. First of all, we had to deal with the fact that we were not calibrating the model with only one temporal series such as historical streamflow as usual. In fact, satellite data is composed by one temporal series per pixel. We had to identify how to use spatio-temporal (and not only temporal) data during models' calibration and validation. In that sense, unfortunately, there is still a deep lack in literature.

A methodology based on the use of Empirical Orthogonal Function analysis was proposed and successfully applied. This experience provided amazing and promising results. The obtained results demonstrated that: (1) satellite data of vegetation dynamics contains an extraordinary amount of information that can be used to implement ecohydrological models in scarce data regions; (2) the proposed semi-automatic calibration methodology works satisfactorily and it allows to incorporate spatio-temporal data in the model parameterization and (3) the model calibrated only using satellite data is able to reproduce both the spatiotemporal vegetation dynamics and the observed discharge at the outlet point. It is important to highlight the positive consequences of this last result particularly in ungauged basins where the use of satellite data could be an alternative in order to obtain a proxy of the streamflow at outlet point. 
On the use of satellite data to calibrate a parsimonious ecohydrological model in ungauged basins Doctoral Thesis 
El agua es la base de toda vida biológica en la Tierra y uno de los enlaces básicos entre la biosfera y la atmósfera. Es igualmente fundamental para los seres humanos y la naturaleza (Tolba, 1982). En un entorno de creciente escasez de agua y de mayor competencia por conseguirla, una mayor comprensión y conocimiento de todos los flujos del ciclo del agua se encuentran entre los objetivos claves de la comunidad científica. Tradicionalmente, el agua y la vegetación se han considerado como sistemas diferentes pero es claramente necesario tomar un enfoque holístico que considere la cuestión del ciclo del agua de una manera integrada, teniendo en cuenta tanto el agua azul como el agua verde (Birot et al., 2011). Alrededor de esta idea surgió la nueva disciplina llamada Ecohidrología a principios del siglo XX y desde entonces, no ha dejado de crecer tal y como demuestran el creciente aumento de líneas de investigación y publicaciones científicas relacionadas con este nuevo campo.

Esta nueva disciplina es todavía más necesaria en regiones áridas y semiáridas, donde el ciclo hidrológico y la dinámica de la vegetación están estrechamente interconectados. Es por eso que es necesaria una modelización acoplada de estos dos sistemas para reproducir totalmente el comportamiento de los ecosistemas a través del tiempo y predecir posibles futuras respuestas al cambio climático.

Sin embargo, la mayoría de los modelos hidrológicos actuales incluye la vegetación como un parámetro estático y no como una variable de estado. De hecho, la mayoría de ellos son capaces de representar bastante bien el caudal observado en el punto de desagüe de la cuenca, pero por lo general incluyendo la vegetación como un parámetro estático (Quevedo y Francés, 2008). Hay algunas excepciones que toman explícitamente la vegetación como variable de estado, pero en esos casos, la complejidad y el número de parámetros a determinar de los modelos aumentan sustancialmente. Por lo tanto, se requiere una gran cantidad de información para utilizar dichos modelos y esa información no siempre está disponible. De hecho, en la práctica, tenemos que hacer frente a la temible combinación de "escasez de datos - alto número de parámetros a determinar" con mucha frecuencia.

Para reducir este problema, se pueden aplicar dos estrategias: (1) simplificar la complejidad conceptual de los modelos y así reducir el número de parámetros a calibrar, y/o (2) aumentar la disponibilidad de datos mediante la incorporación de nuevas fuentes de información. En esta tesis, hemos explorado el uso de un modelo ecohidrológico distribuido y parsimonioso (con pocos parámetros a 
determinar) que ha sido completamente calibrado y validado exclusivamente con datos de teledetección.

En primer lugar, se utilizó el modelo ecohidrológico parsimonioso propuesto por Pasquato et al. (2015) en una parcela experimental situada en un bosque mediterráneo semiárido. Debido a su simplicidad, algunos procesos se asumen despreciables y no se incluyen en su conceptualización. De hecho, sólo los procesos principales se incluyen. Es por eso que resultaba de vital importancia comprobar su fiabilidad e idoneidad. Para abordar esta cuestión, decidimos comparar los resultados proporcionados por este modelo parsimonioso contra los correspondientes resultados generados por un modelo ecohidrológico basado físicamente y con una conceptualización muy compleja. Los resultados obtenidos en esta primera etapa de la tesis sugirieron que el modelo era capaz de reproducir adecuadamente la dinámica de la vegetación, así como las variaciones de humedad del suelo. En otras palabras, se pudo demostrar que un modelo parsimonioso con ecuaciones simples puede lograr buenos resultados en términos generales. Pero, como el modelo había sido aplicado a escala de parcela, todavía quedaba como tarea pendiente reproducir la variación espacial de la vegetación y del ciclo hidrológico.

Para explorar la variación espacio-temporal de la vegetación y del ciclo del agua, se aplicó la versión distribuida del modelo ecohidrológico y parsimonioso utilizado previamente en una cuenca situada en Kenia, concretamente en la cuenca alta del río Ewaso Ngiro. Al mismo tiempo, con el fin de explorar la posible aplicabilidad de los datos de satélite, calibramos el modelo utilizando exclusivamente el NDVI proporcionada por la NASA. En primer lugar, tuvimos que lidiar con el hecho de que no estábamos calibrando el modelo con una sola serie temporal como se hace habitualmente usando el los datos históricos de caudal observado. De hecho, los datos de satélite están compuestos por una serie temporal por píxel. Así que fue completamente necesario proponer e identificar una metodología que diera respuesta a cómo usar los datos espaciotemporales (y no sólo temporales) durante la calibración y validación de modelos. En ese sentido, existe todavía una profunda falta de trabajos y líneas de investigación en literatura.

Se propuso y se aplicó con éxito una metodología basada en el uso de la identificación de las funciones ortogonales empíricas (EOF por sus siglas en inglés). Esta última prueba proporcionó resultados sorprendentes y prometedores. De hecho, los resultados obtenidos demostraron que: (1) los 
datos de satélite contienen una cantidad extraordinaria de información que puede ser usado para implementar modelos ecohidrológicos en regiones donde no se dispone de tal cantidad de información; (2) la metodología de calibración propuesta funciona satisfactoriamente y permite incorporar datos espaciotemporales en el proceso de parametrización del modelo, y (3) el modelo calibrado sólo con datos de satélite es capaz de reproducir tanto la dinámica espacio-temporal de la vegetación así como el caudal observado en el punto de desagüe de la cuenca. Es importante destacar las consecuencias positivas de este último resultado sobre todo en cuencas no aforadas, donde el uso de datos de satélite podría ser una alternativa para obtener una aproximación del recurso en el punto de desagüe. 
On the use of satellite data to calibrate a parsimonious ecohydrological model in ungauged basins Doctoral Thesis 
On the use of satellite data to calibrate a parsimonious ecohydrological model in ungauged basins Doctoral Thesis 
L'aigua és la base de tota vida biològica a la Terra i un dels enllaços bàsics entre la biosfera i l'atmosfera. És igualment fonamental per als éssers humans i la naturalesa (Tolba, 1982). En un entorn de creixent escassetat d'aigua i de major competència per aconseguir-la, una major comprensió i coneixement de tots els fluxos del cicle de l'aigua es troben entre els objectius claus de la comunitat científica. Tradicionalment, l'aigua i la vegetació s'han considerat com a sistemes diferents però és clarament necessari prendre un enfocament holístic que considere la qüestió del cicle de l'aigua d'una manera integrada, tenint en compte tant l'aigua blava com l'aigua verda (Birot et al., 2011). Al voltant d'aquesta idea va sorgir la nova disciplina anomenada Ecohidrología a principis del segle XX i des de llavors, no ha deixat de créixer tal com demostren el creixent augment de línies de recerca i publicacions científiques relacionades amb aquest nou camp.

Aquesta nova disciplina és encara més necessària en regions àrides i semiàrides, on el cicle hidrològic i la dinàmica de la vegetació estan estretament interconnectats. És per això que és necessària una modelització acoblada d'aquests dos sistemes per reproduir totalment el comportament dels ecosistemes a través del temps i predir possibles futures respostes al canvi climàtic.

No obstant això, la majoria dels models hidrològics actuals inclou la vegetació com un paràmetre estàtic i no com una variable d'estat. De fet, la majoria d'ells són capaces de representar suficientment be el cabal observat en el punt de desguàs de la conca, però en general incloent la vegetació com un paràmetre estàtic (Quevedo i Francès, 2008). Hi ha algunes excepcions que prenen explícitament la vegetació com a variable d'estat, però en aquests casos, la complexitat i el nombre de paràmetres a determinar dels models augmenten substancialment. Per tant, es requereix una gran quantitat d'informació per utilitzar aquests models i aquesta informació no sempre està disponible. De fet, en la pràctica, hem de fer front a la temible combinació de "escassetat de dades - alt nombre de paràmetres a determinar" amb molta freqüència.

Per reduir aquest problema, es poden aplicar dues estratègies: (1) simplificar la complexitat conceptual dels models i així reduir el nombre de paràmetres a calibrar, i/o (2) augmentar la disponibilitat de dades mitjançant la incorporació de noves fonts d'informació. En aquesta tesi, hem explorat l'ús d'un model ecohidrològic distribuït i parsimoniòs (amb pocs paràmetres a determinar) que ha estat completament calibrat i validat exclusivament amb dades de teledetecció. 
En primer lloc, es va utilitzar el model ecohidrològic i parsimoniòs proposat per Pasquato et al. (2015) en una parcel-la experimental situada en un bosc mediterrani semi-àrid. A causa de la seva simplicitat, alguns processos s'assumeixen menyspreables i no s'inclouen en la seva conceptualització. De fet, només els processos principals s'inclouen. És per això que resultava de vital importància comprovar la seva fiabilitat i idoneïtat. Per abordar aquesta qüestió, decidim comparar els resultats proporcionats per aquest model parsimoniòs contra els corresponents resultats generats per un model ecohidrològic basat físicament i amb una conceptualització molt complexa. Els resultats obtinguts en aquesta primera etapa de la tesi van suggerir que el model era capaç de reproduir adequadament la dinàmica de la vegetació, així com les variacions d'humitat del sòl. En altres paraules, es va poder demostrar que un model parsimoniòs amb equacions simples pot aconseguir bons resultats en termes generals. Però, com el model havia estat aplicat a escala de parcel-la, encara quedava com a tasca pendent reproduir la variació espacial de la vegetació i del cicle hidrològic.

Per explorar la variació espai-temporal de la vegetació i del cicle de l'aigua, es va aplicar la versió distribuïda del model ecohidrològic i parsimoniòs utilitzat prèviament en una conca situada a Kenya, concretament en la conca alta del riu Ewaso Ngiro. Al mateix temps, amb la finalitat d'explorar la possible aplicabilitat de les dades de satèl-lit, calibrem el model utilitzant exclusivament el NDVI proporcionat per la NASA. En primer lloc, vam haver de bregar amb el fet que no estàvem calibrant el model amb una sola sèrie temporal com es fa habitualment usant les dades històriques de cabal observat. De fet, les dades de satèl-lit estan compostes per una sèrie temporal per píxel. Així que va ser completament necessari proposar i identificar una metodologia que donase resposta a com usar les dades espai-temporals (i no només temporals) durant el calibratge i validació de models. En aquest sentit, existeix encara una profunda falta de treballs i línies de recerca en literatura.

Es va proposar i es va aplicar amb èxit una metodologia basada en l'ús de la identificació de les funcions ortogonals empíriques (EOF per les seues sigles en anglès). Aquesta última prova va proporcionar resultats sorprenents i prometedors. De fet, els resultats obtinguts van demostrar que: (1) les dades de satèl-lit contenen una quantitat extraordinària d'informació que pot ser usada per implementar models ecohidrològics en regions on no es disposa de tal quantitat d'informació; (2) la metodologia de calibratge proposat funciona satisfactòriament 
i permet incorporar dades espai-temporals en el procés de parametrització del model, i (3) el model calibrat només amb dades de satèl-lit és capaç de reproduir tant la dinàmica espai-temporal de la vegetació així com el cabal observat en el punt de desguàs de la conca. És important destacar les conseqüències positives d'aquest últim resultat sobretot en conques no aforades, on l'ús de dades de satèl-lit podria ser una alternativa per obtenir una aproximació del recurs en el punt de desguàs. 
On the use of satellite data to calibrate a parsimonious ecohydrological model in ungauged basins Doctoral Thesis 


\section{CHAPTER 1. INTRODUCTION}


On the use of satellite data to calibrate a parsimonious ecohydrological model in ungauged basins Doctoral Thesis 


\subsection{General introduction}

A better understanding of the components of catchments' water balance has traditionally been one of the main objectives of the hydrological community (Gerten et al., 2004). To this end, it is certainly well-known that the vegetation plays a key role in a catchment's water balance particularly in semi-arid regions (Laio et al.,2001). In these water-controlled ecosystems, the vegetation key role on controlling the hydrological cycle is such that the actual evapotranspiration may account for more than $90 \%$ of the precipitation (Pilgrim et al., 1988; Huxman et al., 2005; Andersen, 2008).

In spite of this, traditionally, very few hydrological models have incorporated vegetation dynamics as a state variable, neglecting in this way most of the interactions of water with vegetation and vegetation dynamics themselves (Snyder et al., 2000; Aydin et al., 2005 and others). In fact, most of them are able to represent fairly well the observed discharge at the catchment outlet, but usually including the vegetation as a static parameter (Quevedo and Francés, 2008).

However, in the last decades, considerable efforts have been made to understand and reproduce adequately the interactions between the vegetation and the water cycle and the number of hydrological models which explicitly take into account the vegetation development as a state variable has increased substantially: RHESSyS (Tague and Band, 2004), SWIM (Krysanova et al., 2005), GEOTOP (Rigon et al., 2006), LG-TM (Wolf, 2011), etc. A fairly discussion about the evolution of the ecohydrological models as well as a classification according to their conceptualization is given in the next chapter.

In practice, most of the time, these models are difficult to operate because of the high number of parameters that are required to be estimated (Quevedo and Francés, 2008). This represents a particularly challenging task, especially considering that in operational applications the available information is frequently quite limited, in particular for arid and semi-arid regions which often could be categorized as ungauged basins (Andersen, 2008). In those cases, two different strategies could be applied in order to, at least, reduce the problem caused by the combination of complex models together with data scarcity: (1) simplifying models' complexity and (2) increasing data availability by incorporating new sources of information (e.g. remote sensing). In fact, according to Arnold et al. 
(2011), the critical challenge is to build minimalistic still realistic models and, we add, whose requirements and complexity match data availability.

Previous works in this issue have focused on strategies for simplifying ecohydrological models in semiarid regions. Again, a deep discussion and a compilation of papers focused on this strategy are given in the next chapter. Particularly in this study, we have focused on the use of the parsimonious and dynamic vegetation LUE-Model proposed by Pasquato et al. (2015). Briefly, the parsimonious LUE-model simulates gross primary production (GPP) as a function of absorbed photosynthetically active radiation (APAR) and the vegetation light use efficiency (LUE). Net primary production (NPP) is then calculated taking into account maintenance respiration. This model is focused particularly on simulating foliar biomass, which is obtained from NPP through an allocation equation based on the maximum LAI sustainable by the system (Pasquato et al., 2015). The Light Use Efficiency models have been posited as attractive candidates for coupling with conceptual hydrological models due to their nature and low number of parameters (Arora, 2002).

However, since the LUE-Model is a parsimonious and conceptual model, some vegetation processes are neglected. That's why it is important to check that the most relevant processes are being captured by the model. For this reason, the present study compared the capability of this parsimonious model against a physically-based model reproducing the interaction between vegetation and water. The selected physically-based model was the well-known Biome-BGC (Thorton et al., 2002). Both models were applied in a semi-arid forest experimental plot (East of Spain) and their performances were analyzed against field data (daily soil water content and transpiration).

At the same time, we wanted to know if the use of remote sensing data with this parsimonious model could be an option comparable to that of using the physically-based model together with field observations. For this reason, the parsimonious LUE-Model was calibrated using exclusively remote sensing data and validated using field observations, while the BIOME-BGC model was implemented using field measurements as usual. The question of using satellite data alone clearly is crucial in those cases in which there are not field measurements.

The results in this first application suggested that the parsimonious model was able to adequately reproduce the dynamics of vegetation and it also was able to 
reproduce properly the soil moisture variations. All this work is described more accurately in Chapter 3 and it was published in the journal Ecological Modelling (Ruiz-Pérez et al., 2016b). Although it showed great results in relation to the use of satellite information, all this research was done at plot scale so the challenge to include the spatial information provided by the satellite data remained.

In that sense, understanding and predicting vegetation patterns and their response to climate and other environmental stressors is a critical research challenge (Aber et al., 2001). It is recognized that many outstanding issues in Plant Ecology and Ecohydrology are directly related to an incomplete understanding of the spatial and persistence of spatial patterns (Caylor et al., 2005). Precisely, one of the great advantages of using satellite data is that it provides not only temporal variation but also spatial distribution of the observations. That's why we wanted to apply the proposed ecohydrological model at catchment scale using its distributed version and, at the same time, to develop a methodology in order to include spatio-temporal data such as satellite data in model's calibration and validation.

The model was used in a basin located in Kenya, concretely in the Upper Ewaso Ngiro River basin. This experience provided amazing and promising results. The model was capable to produce daily LAI (Leaf Area Index) maps (spatio-temporal series of LAl) and, also, discharge at the outlet point with a good accuracy in both cases. Therefore, the results highlighted the enormous utility of satellite data. It was possible to completely implement the hydrological and the vegetation components of TETIS-VEG daily model only using NDVI data and the model validation can be considered satisfactory. This fact is a promising conclusion particularly in ungauged basins such as most of the basins located in developing countries. It means that satellite data could be used in order to obtain, at least, a proxy of the observed discharge. At the same time, this result also showed the key role played by vegetation in water-controlled areas such as the upper Ewaso Ngiro River basin in Kenya.

On the other hand, the use of remote sensing data together with a distributed model at catchment scale has the great advantage of including not only temporal information but also spatial information. One useful way to investigate the spatiotemporal relations between the spatio-temporal patterns of fluxes and states in the soil-vegetation-atmosphere continuum is applying the method of empirical orthogonal functions (EOF, Fang et al., 2015). To our knowledge, the EOF analysis has not been applied in an automatic calibration yet. In this thesis, 
we did use the EOF analysis during the automatic calibration process. All this work is described deeply in Chapter 4 and it was submitted for publication in the Journal of Hydrology (still under revision).

\subsection{Main objectives}

As mentioned in the general introduction and deeply discussed in the next Chapter 2, there exists a lack in terms of hydrological models which explicitly incorporate the vegetation dynamics as state variable although it is well-known the importance of the vegetation in the water cycle. That's why the research group in which this thesis was developed (Research Group of Hydrological and Environmental Modelling) showed interest in understanding how vegetation and water are interconnected and how this link can be modelled specially in arid and semi-arid environments.

This research line started with the contribution of Quevedo (2010) and, later, followed by Pasquato (2013). Both these were focused on the development of a parsimonious ecohydrological model to be used in water-controlled areas (nutrients cycle was not included). But, in both these, the different proposed parsimonious ecohydrological models were applied at plot scale. That's why the first task of the current thesis was to adapt this model in order to be used at basin scale and, at the same time, to explore if a distributed parsimonious model can provide good results or more complexity is required when it is used at catchment scale.

Additionally, Pasquato (2013) took the first steps to analyze the potential utility of remote sensing data in ecohydrological modelling. She focused on the analysis of some vegetation indexes provided by satellite and their relation with vegetation dynamics. A revision of practical experiences using remote sensing data in ecohydrological modelling was not conducted because she was more focused on the identification of the advantages and disadvantages of each analyzed vegetation index. In this thesis, this revision was carried out due to the increasing quantity and quality of the available remote sensing data.

All this work was motivated by the fact that the use of this kind of data is promising especially in such areas where there is not information. In that sense, most of catchments in developing countries can be categorized as ungauged and, precisely in developing countries, it seems that the worrying state of 
resources availability could become even worse due to the Global Change impact (IPCC, 2007).

Although there exist some researches using satellite data in model's calibration and validation (more information and references in Chapter 2), the proper use of this kind of data still remains as a challenging task. In fact, in all reviewed papers, authors used the temporal information provided by the remote sensing data but, in most cases, they did not use properly the spatial information contained in this kind of data. At this point, the research questions are: could satellite products be used to implement a distributed ecohydrological model or are field measurements totally necessary? If so, how do this spatio-temporal data have to be used? And, keeping in mind that an automatic calibration is essential in modelling when a conceptual model is used, which mathematical methodology can be used in order to calibrate automatically the proposed ecohydrological model using spatiotemporal data?

Hence, the main question of this project is how to properly use existing remotely sensed information for calibration and validation of distributed ecohydrological models. To address this question, a parsimonious distributed ecohydrological model was tested in different places (experimental plot located in Spain and a poorly gauged basin in Kenya) and at different working scales (plot and basin scale) and a methodology to tackle the spatio-temporal data provided by satellite was developed and applied. 
On the use of satellite data to calibrate a parsimonious ecohydrological model in ungauged basins Doctoral Thesis 


\section{CHAPTER 2. RESEARCH FRAMEWORK}


On the use of satellite data to calibrate a parsimonious ecohydrological model in ungauged basins Doctoral Thesis 


\subsection{Ecohydrology: a brief history}

In the early $20^{\text {th }}$ century, the first scientific investigations focused on understanding the linkages between vegetation-water relationships and the hydrological response of the basins were conducted (e.g. Engler, 1919; Hursh and Brater, 1941). The reason was that scientific community started to realize that sustainable development of freshwater resources should move beyond conceptual theories to practice in an age where the need for effective water resource management had reached a critical threshold (Zalewski et al., 1997). According to this movement, the new discipline Ecohydrology, should involve the understanding of hydrologic, social and biotic mechanisms of the catchment (Zalewski et al. 1997). In the last $20^{\text {th }}$ century, multiple agencies and the scientific community in general already recognized the necessity and the potential benefits accruing from environmental research that crossed traditional disciplines (Newman et al., 2006). Specifically, Ecohydrology was largely originated from improved understanding of the interactions between water and terrestrial ecosystems facilitated by the United Nations Educational, Scientific and Cultural Organization (UNESCO) Man and the Biosphere Programme (MAB) Programme "Role of land/inland water ecotones in water management and restoration"' (e.g., Zalewski 1992; Naiman et al. 1995). Further development of the concept was made by the UNESCO International Hydrological Programme (IHP) where large scale and long term hydrological processes were integrated with biota dynamics and social aspects in a catchment (Zalewski et al. 1997).

Thanks to this great effort in the past, this discipline seeks (1) how hydrological processes influence the distribution, structure, function and dynamics of biological communities and (2) how feedbacks from biological communities affect the water cycle (in-depth discussions of the Ecohydrology definition are given by Baird and Wilby (1999), Rodriguez-Iturbe (2000), Nuttle (2002), Porporato and Rodirguez-Iturbe (2002), etc.). The common aspect between all of the cited publications is that the merger of Ecology and Hydrology into a science of Ecohydrology was aimed at understanding environmental systems in a more integrated or comprehensive way (Newman et al., 2006).

Once the Ecohydrology discipline was defined, it has grown steadily as a scientific discipline in the twenty years since its inception in 1996 (IHP) and formulation in 1997 (Zalewski et al. 1997). Research at the hydrology-ecology interface has a long tradition, beginning with seminal work on vegetation and hydrology (e.g. Hack and Goodlett, 1960; Eagleson, 1978). But, the ecohydrology 
field increased substantially when some authors (e.g. Baird and Wilby, 1999; Bond, 2003; Rodriguez-Iturbe, 2000) embraced the 'new' ecohydrological paradigm. This increase can be proved by the increasing number of research papers as well as the increasing number of seminars and courses about Ecohydrology as discussed in the next section.

\subsection{Ecohydrology: bibliographic search data}

The more or less recently established journal Ecohydrology, together with several foundational textbooks (e.g. Eagleson, 2002; Porporato and Rodriguez-Iturbe, 2002), have undoubtedly propelled the discipline forward through interdisciplinary collaboration and the formation of several echohydrology-centered graduate research and degree programs worldwide. Furthermore, a bibliographic survey of the ISI Web of Knowledge Science Citation Index database was undertaken using the following words in the topic search: ecohydrology. This search looked for each term in the title, abstract and keyword lists of millions of publications (i.e. articles, letters and book reviews) in ISI-rated journals and conference proceedings since 1981. Unfortunately, this bibliographic approach is likely to provide an underestimate of the true extent of ecohydrological research because some publications with ecohydrology as the main topic do not use this term. Notwithstanding the limitation of the bibliographic analyses, it is obvious that the use of such term has increased strongly since the early 1990s until now. For example, there was only one publication during 1991 while, in 2015, there were a total of 106 publications (Figure 2-1).

Hannah et al. (2004) analyzed the content of the papers about ecohydrology and classified them based upon the dominant subject matter: (1) ecology-flora, (2) ecology-fauna, (3) ecology-flora and fauna, (4) hydrology-water resource management, (5) hydrology-ecosystem response, (6) hydrology- water resources management and ecosystem response and, (7) discussion papers. The majority of papers focused on plant-soil-water interactions (ecology-flora) while hydrologywater resources management was the next most common subject area. More recently, Westbrook et al. (2013) analyzed two independent data sets. The first set was articles indexed in Science Direct, published between January 2000 and December 2011, that contained the terms 'ecohydrology' or 'eco-hydrology' in their key words, titles or abstracts. The second data set was papers published in Ecohydrology (the journal) from its first issue to December 2011. They categorized all papers into four different groups: (1) fauna, reports of hydrological 
impacts on fauna and fauna (excluding humans) impacts on hydrological processes and patterns; (2) biogeochemistry, articles reporting how soil properties are affected by climate; (3) human impact, studies that examined ecohydrology of crops or changes in land use; and (4) flora, studies exploring natural plant-water relationship. Of the 339 articles reviewed by them, they found that $72 \%$ of these articles was focused on flora, $17 \%$ on fauna, $10 \%$ on biogeochemical and $9 \%$ of the articles on human impact. The sum is more than $100 \%$ because some articles belonged to different groups simultaneously.

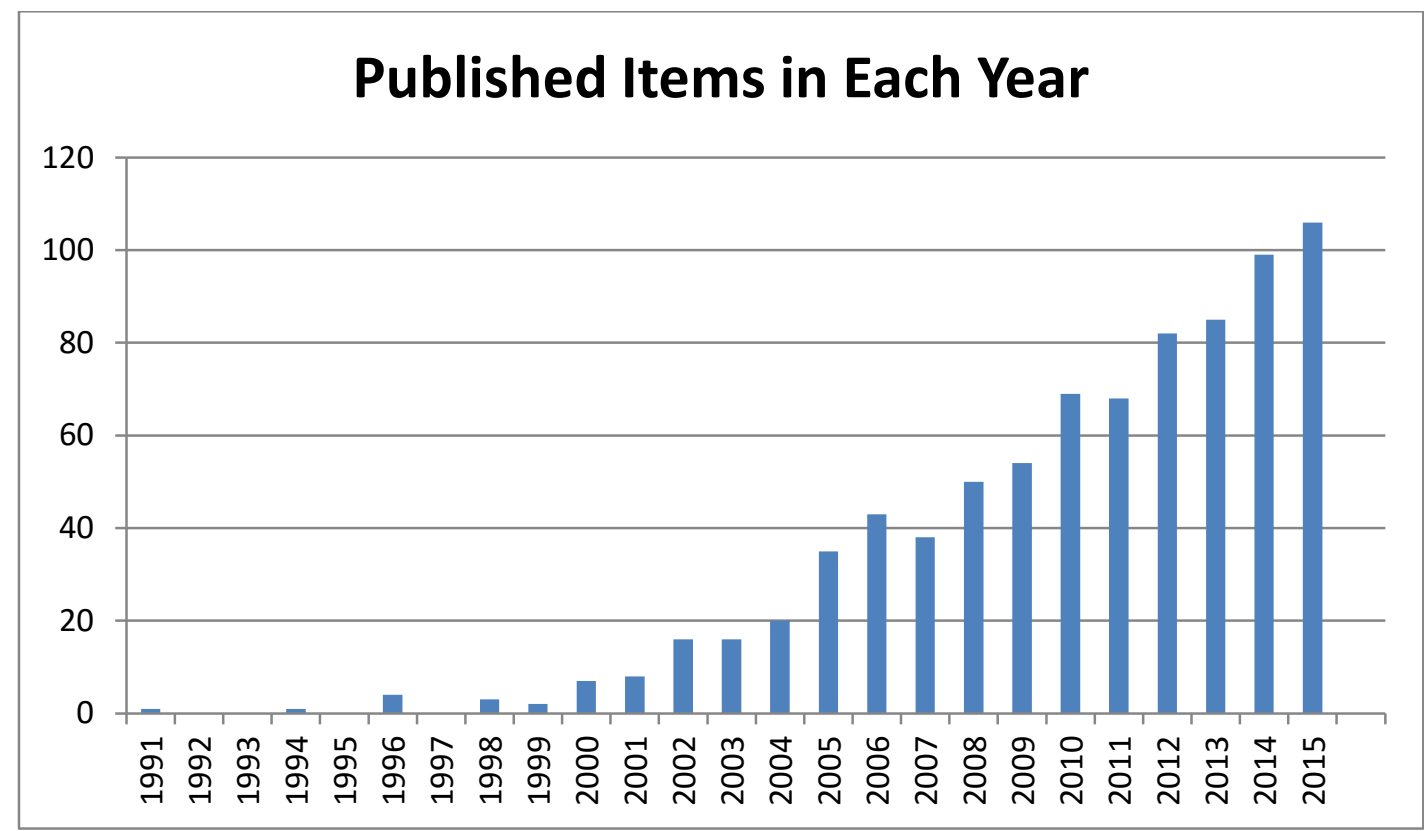

Figure 2-1. Published items with the term ecohydrology in the title, abstract and keyword lists from 1991 to 2016

The two most cited publications were written by Rodriguez-Iturbe et al. (2001) and Laio et al. (2001) respectively. Both authors belonged to the same research team and both papers were included in a serial of publications about watercontrolled ecosystems. In fact, they were really useful during the elaboration of this doctoral thesis because we focused on water-controlled ecosystem as they did. As shown in the next section, the integral vision of Ecology and Hydrology is really important particularly in water-controlled areas due to the key role played by vegetation in the water cycle. 


\subsection{Plants and water-controlled ecosystems}

The role of plant-water relations is of central interest to the field of ecohydrology because plants occupy a key component of the hydrologic cycle. On one hand, we know that plants need water to survive, and thus, the distribution, composition and structure of plant communities are directly influenced by spatiotemporal patterns in water availability. On the other hand, plants are a primary conduit for returning terrestrial water to the atmosphere (Chapin et al., 2000) mediating albedo and roughness (Pielke et al., 1998), thereby exerting a strong effect on hydrologic fluxes of the terrestrial-atmospheric system. The pivotal role plants play in modulating many hydrologic processes, which will be deeply explained below, has long been recognized by both ecologists and hydrologists, leading to efforts to refine and deepen understanding of water fluxes, flows and transport within these respective disciplines.

This plant's key role is even more important in water-controlled ecosystems. Water-controlled environments include arid, semiarid, and subhumid regions (sometimes collectively called drylands), and occupy approximately $50 \%$ of the global land area (Parsons and Abrahams, 1994). These environments are considered water limited because annual precipitation $(P)$ is typically less than annual reference evapotranspiration $\left(E T_{0}\right)$, such that the ratio of $P$ to $E T_{0}$ ranges from about 0.03 to 0.75 , and because extreme temporal variability results in extended periods with little to no precipitation (Parsons and Abrahams, 1994; Guswa et al., 2004). Although variable with respect to physiography, geology, soils and vegetation, these environments are often sensitive and prone to change because of limitations in water, which dictate fluxes and transport in the critical zone.

Therefore, water-controlled ecosystems are complex, evolving structures whose characteristics and dynamic properties depend on many interrelated links between climate, soil and vegetation. In these particular regions, the connections between the role of plants in the water balance and their water-stress response is a fascinating topic which has been explored during the last years and it is still being explored nowadays. In the next paragraphs, the following concepts will be described: (1) how water availability affects plants survival strategies and, (2) how the distribution of the plants affects water fluxes and vice versa.

On one hand, plants adapted to water limited environments have evolved different strategies to cope with water restrictions. According to Lubczynski 
(2009) the plant adaptation mechanisms are manifested by the following properties in order to increase the efficiency of water use: (1) small leaves with efficient internal structure minimizing loss of water due to evaporation, (2) small above-ground biomass compared to below-ground biomass (some trees that are only a few meters tall, often have roots expanding several tens of meters down below the surface), (3) specific root patterns allowing to search for water, (4) seasonal, water dependent flowering, and (5) the ability to capture soil moisture from the air, from the shallow subsurface and from the deep subsurface including groundwater and to redistribute water using roots. Nonetheless, the main and common strategy developed by plants is related to the stomata closure. In a brief summary, transpiration is a consequence of stomata opening which is needed to acquire $\mathrm{CO}_{2}$ from the atmosphere. Plants can regulate stomata opening, depending on ambient light, $\mathrm{CO}_{2}$ intercellular partial pressure and cellular turgor. Particularly, partial or total stomatal closure is a fundamental protection mechanism of plants against desiccation when soil water is scarce (Laio et al., 2001). In consequence, water limitation reduces the ability of leaves to take up $\mathrm{CO}_{2}$, even under conditions of sufficient light, due to a restriction in stomatal conductance and limited root water (van der Molen et al., 2011).

On the other hand, plants have an important effect over the water cycle and the distribution of the fluxes (Breshears and Barnes, 1999). Jasechko et al. (2013) used distinct isotope effects of transpiration and evaporation to show that transpiration is by far the largest water flux from Earth's continents, representing 80 to $90 \%$ of terrestrial evapotranspiration. On the basis of their analysis of a global data set of large lakes and rivers, they concluded that transpiration recycles $62,000 \pm 8,000 \mathrm{~km}^{3}$ of water per year to the atmosphere, using half of all solar energy absorbed by land surfaces in the process.

But the effect of plants is not only in terms of amount of water transpired by them; species composition and structure also affect the water availability (Asbjornsen et al., 2011). In fact, the amount of a particular event's available water is ultimately defined by the ability of 'water users' to initiate and maintain higher/lower metabolic rates (Schwinning and Sala, 2004). Therefore, the soil moisture remains more or less time depending on the different users. For example, surface dwelling organisms only consume the water of the immediate soil surface, while for higher plants the water provided by an event remains available until soil water potentials throughout the rooted portion of the infiltration depth drop below some plant-extractable level. 
Yet in the late 1990s, some authors showed that the position of a site along the grassland/forest continuum characteristic of most of water-controlled environments, and the associated relative proportions of the two types of cover, affect many ecosystem properties - including near-ground energy input (Breshears et al., 1997, 1998), water balance (Aguiar et al., 1996; Schulze et al., 1996), erosion rates (Ludwig and Tongway, 1995; Reynolds et al., 1997; Davenport et al., 1998), and nutrient cycling (Padien and Lajtha, 1992). Trompvan Meerveld and McDonnell (2006) demonstrated that vegetation has a larger influence on soil moisture patterns than local surface or subsurface topography. Vegetation can exert effect on the vertical and horizontal distribution of water in the soil water column (Caylor et al., 2006). Plant water uptake patterns from different soil depths, which often vary spatially and temporally between different plant functional types, can also directly influence soil water dynamics during the growing season (Asbjornsen et al., 2008; Dalsgaard et al., 2011; Lu et al., 2011; Schwinning 2010). Furthermore, plants can directly influence soil water dynamics through the active redistribution of water by plant roots. This hydraulic redistribution has been shown to occur in a wide range of ecosystems (Bleby et al., 2010; Domec et al., 2010; Oliveira et al., 2005).

Hence, their results did show that the heterogeneity of soil moisture (vertical and horizontally) depends on the distribution of plant types. At the same time, particularly in semiarid and arid regions, heterogeneity in soil moisture is the key factor that determines the distribution of plant types (Breshear and Barnes, 1999). In fact, more recently, Piedallu et al. (2013) demonstrated how soil water content spatial distribution improves the performance of the models by refining the prediction of the spatial distributions of species compared with the predictions made using simple climatic water proxies. Definitely, the spatial structure of soil moisture and its evolution in time is both cause and consequence of vegetation (Rodriguez-Iturbe, 2000).

Precisely, soil moisture, plants and their coupling are at the heart of ecohydrology and the soil water balance (Tromp-van Meerveld and McDonnell, 2006). Taking into account that scientists use models as hypotheses in order to understand the behavior of the real world's functioning (Savenije, 2009), integral ecohydrological models should now be used and developed. This last question will be discussed in the following section. 


\subsection{Ecohydrological modelling}

In spite of this deeply demonstrated important plants' role, traditionally, very few hydrological models have incorporated vegetation dynamics as a state variable, neglecting in this way most of the interactions of water with vegetation and vegetation dynamics themselves (Snyder et al., 2000 and Aydin et al., 2005 and others) as mentioned in the General Introduction in Chapter 1.

However, in the last decades, considerable efforts have been made to understand and reproduce adequately the interactions between the vegetation and the water cycle and the number of hydrological models which explicitly take into account the vegetation development as a state variable has increased substantially: RHESSyS (Tague and Band, 2004), SWIM (Krysanova et al., 2005), GEOTOP (Rigon et al., 2006), LG-TM (Wolf, 2011), etc.

Regarding ecological models, in the past, most of them incorporated the hydrological components just by including the ratio between actual and reference evapotranspiration, such as the Sim-CYCLE model (Ito and Oikawa, 2000) and Frankfurt Biosphere Model (Lüdeke et al., 1994). Others also incorporated the soil moisture just as an empirical function, such as the Carbon Exchange Between Vegetation, Soil and Atmosphere model (CEVSA, Cao and Woodward, 1998). Nowadays, most of them have a more accurate description of the hydrological components, such as the BIOME-BGC model (Thorton et al., 2002), which is used in the present work and is explained below, the Gotilwa+ model (Gracia et al., 1999) which calculates the soil moisture by mass balance or, Tethys-Clorhis (Fatichi et al., 2012) which is a physically-based model that incorporates even the snow dynamics and their effects on the vegetation.

Other current option is the use of a hydrological model coupled to an ecological model (or viceversa). Some examples are: FOREST-BGC plus TOPMODEL (Band et al., 1993) or, more recently, LPJ-GUESS plus TOPMODEL (Wolf, 2011).

In this point, it would be interesting to present a classification of ecohydrological models. But, in Ecohydrology, there is considerable ambiguity in the used terminology (Arnold et al., 2011) due to ecohydrological modelling has multidisciplinary origins with the modelling techniques used by researchers biased to either ecological or hydrological approaches depending on the researchers' background (King and Caylor, 2011). Figure 2-2 showed the different terms used 
in Ecology and Hydrology compiled by Arnold et al. (2011). Hereafter, we used the terminology used predominantly in Hydrology due to our own background and distinguished between three different types of models: empirical models or black boxes, conceptual and physically-based models.

\section{Synonyms}

Empirical model ${ }^{2}$

Descriptive model ${ }^{1}$

Statistical model $^{1}$

Minimal model for ideas ${ }^{1}$
Conceptual model ${ }^{2}$

Teleonomic model ${ }^{1}$

Minimal model for a system ${ }^{1}$
Physically-based model ${ }^{2}$ Mechanistic model ${ }^{1}$

Process model ${ }^{e}$

Synthetic model for a system ${ }^{1}$

Complexity of process implementation

Understanding relationship between variables

Underlying physical processes

Predictive power at system scale

Explaining system sub-components

Empirical system description

Mechanistic system description

Purpose: understanding system function

\section{Black box}

$$
\text { Grey box }
$$

White box

\section{L \\ Top-down approach \\ Downward approach}

Holism

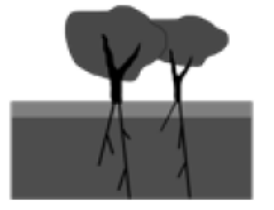

Bottom-up

Upward approach

Reductionism

Figure 2-2. Continuum of model terminology according to the level of process detail and understanding within the model. The terminology originated from (1) ecological and (2) hydrological science. Figure extracted from

Arnold et al. (2011)

Chen et al. (2015) reviewed the most used models nowadays and they classified them into these three categories (empirical, conceptual and physically-based). Analyzing their conceptualizations, the main differences between them are related to how the actual evapotranspiration is calculated and/or how the biomass is modelled. According to the calculation of the actual evapotranspiration, two strategies can be found. First, some models use the concept of reference 
evapotranspiration in order to calculate the actual evapotranspiration following the recommendations provided by the document FAO-56. Some examples are: SWAT (Arnold et al., 2005), SWIM (Krysanova et al., 2005), and EcoHAT (Yang et al., 2009). On the other hand, there are models using the Penman-Monteith equation in order to calculate the actual transpiration and evaporation (or the combined evapotranspiration). In this case, the reference evapotranspiration is not required. Some examples are: TOPOG (Vertessy et al., 1996); Model Macaque (Band et al., 1993); VIP (Mo et al., 2007) among others.

Regarding to the biomass simulation, there are models from the simplest to the most complex conceptualizations. The simplest models calculate the dynamic growth of vegetation by a simple empirical relationship, mostly by calculating potential growth and then calculating the actual production based on a sort of stress factor which takes into account the temperature, the water and/or nutrient availability. For example, the SWAT model, developed and used by the U.S Department of Agriculture, uses a vegetation module which calculates the dynamic potential growth of vegetation according to the solar utilization and then the actual growth is simulated according to the ecological stress. At the other extreme, some models such as Biome-BGC (explained in detail and used Chapter 3) simulate all physiological, biochemical and hydrological processes. Hence, the dynamic growth of vegetation is reproduced with a high level of detail.

The advantages and disadvantages of each kind of model have been deeply discussed in general (e.g. Beven, 2001; Khakbaz, 2012; Ruiz-Pérez et al., 2016a) and in particular for ecohydrological models (Arnold et al., 2015; Chen et al., 2015). The common conclusion is that the selection of a model depends on: (1) the purpose of the model and the working scale, (2) existing system understanding and, (3) practical constraints such as available data and computational power. In fact, the physically-based models have a complex computation involving large amount of parameters, most of which are difficult to obtain (Chen et al., 2015).

That's why ecohydrological studies often face the problem that many models have extensive parametrical requirements, while available data are scarce. Inapplicability of the wide range of possible ecohydrological models due to scarce data motivates the need for a modelling approach that can be well constrained to available data and still model the dominant processes (Pande et al., 2012). Having done a bibliographic review, we observed two different strategies in order to deal with this 'scarce data - parametrical requirement' issue: strategies for simplifying the complexity of the models and, the use of new and innovative 
source of observed data (remote sensing data, new sensors, experimental catchments/plots, etc.).

Regarding to the simplification of the models, a few papers have focused on strategies for simplifying ecohydrological models. Most notably, Montaldo et al. (2005) experimented with five different levels of vegetation model complexity, each one with one less vegetation state variable, in an attempt to identify a parsimonious and robust ecohydrological model for semiarid climates. Motivated by this research, Istanbulluoglu et al. (2012) repeated the same procedure using five different model variants but in this case across a climate gradient. More recently, Arnold et al. (2015) tested five alternative structures of an echohydrological model of flood-groundwater-vegetation in order to identify the minimal required complexity in their particular study area which is a dryland located in Namibia, Africa. With different purposes, Wi et al. (2015) studied the effect of an increase of the model complexity on streamflow projections under climate change. The conclusions provided by these works were ambivalent. For example, Arnold et al. (2015) found the most complex version of their model provided the most reliable results, while Istanbulluoglu et al. (2012) obtained that the simplest model's results were accurate enough. For their part, Wi et al. (2015) found that a complexity increase did not increase uncertainty in streamflow projections, even though parameter equifinality did emerge.

In our opinion, the key does not consist on the identification of the proper complexity level required by the system to be modelled regardless the available data and observations of this particular system. In fact, a lot of authors, such as Pokhrel and Gupta (2010), Khakbaz et al. (2012) and Wi et al. (2015) (only citing the most actual), have found better results when the parametric complexity of the distributed model is aligned with the data available for calibration. According to Arnold et al. (2011), the critical challenge is to build a minimalistic still realistic model, and we add, whose complexity and requirements match data availability. Although there is not an unique opinion about the controversial topic of parsimony, it seems demonstrated that mathematically programming only dominant processes is a promising option for modelling in data scarce areas (Pande et al., 2012). In this thesis, we chose a parsimonious and simple ecohydrological model to be used in water-controlled and scarce data environments.

Regarding to the second strategy, among the new and innovative source of information, there is a number of exciting developments in monitoring tools useful 
for ecohydrological research over the last decades (Wang et al., 2012). For example, isotope tracers and analyses (Wang et al., 2012), cosmic-ray and electromagnetic imaging for the soil moisture monitoring (Zreda et al., 2008), new low-cost systems for taking environmental observations and communicating them over a cell phone system such as PulsePod developed by Caylor et al. (2015), remote sensing measurements and so on.

With the advantages of covering large areas and being fast and convenient, remote sensing is widely used in model implementation, which is a revolutionary change compared with the traditional measurements (Zhao, 2003). Environmental remote sensing essentially makes use of radiant energy to extract information on ground features along large swath areas within a short period of time (Zhang and Kovacs, 2012). Common remote sensing platforms include satellites, airplanes, balloons and helicopters, and a variety of sensors such as optical and near infrared sensors and RADAR are installed in them. For example, the use of small unmanned aerial systems (UAS) has flourished during the last decade to monitor environmental change (Zhang and Kovacs, 2012). There are currently a plethora of these instruments available at various costs. But, in practical applications, they still have some issues to solve. The main ones are related to the image processing and the no availability of historical records large enough. In the case of satellite data, many years of worldwide data are available: Landsat program, for example, has been active since the 70's. This makes possible long term and retrospective analysis of the phenomena or areas of interest (Vicente-Serrano et al., 2010). That's why we focused on the use of satellite data in order to control the vegetation dynamics as can be read in the next two sections.

\subsection{Satellite data}

The sixth proclaim of the declaration of the United Nations Conference on the Human Environment at Stockholm in 1972 said: '[...] Through ignorance or indifference we can do massive and irreversible harm to the earthly environment on which our life and wellbeing depend. Conversely, through fuller knowledge and wiser action, we can achieve for ourselves and our posterity a better life in an environment more in keeping with human needs and hopes. There are broad vistas for the enhancement of environmental quality and the creation of a good life. What is needed is an enthusiastic but calm state of mind and intense but orderly work. For the purpose of attaining freedom in the world of nature, man 
must use knowledge to build, in collaboration with nature, a better environment. $[\ldots]$

After Stockholm convention, the interest of a fuller knowing of the interactions between atmosphere, hydrosphere and land surface increased substantially and research projects about Earth observation started. It could be said that the Stockholm convention was the starting point of the satellite data acquisition development (Mas et al., 2011). Here we presented three important points in order to answer the following questions: (1) why and how is the vegetation related to satellite data?, (2) which kind of data can we use in vegetation monitoring and how can we acquire such information? and, (3) how have satellite data been used in the past and how can this data be used nowadays and in the future?

\subsubsection{Vegetation and satellite data}

In her doctoral thesis, Pasquato (2014) highlighted that the use of satellite data requires the knowledge of the structure and functions of vegetation and its reflectance properties. Thanks to this knowledge, it is possible to link the vegetative states and structures of a certain ecological system of interest to their reflectance behavior. In this document, a brief summary about the link between plants and satellite is presented.

Briefly, once reflected by the Earth's surface, the radiation spectrum encompasses the range of $400 \mathrm{~nm}$ to $2500 \mathrm{~nm}$. This reflected optical spectrum can be divided into three different wavelength categories: visible (VIS), from 400 $\mathrm{nm}$ to $700 \mathrm{~nm}$; near infra-red (NIR), from $700 \mathrm{~nm}$ to $1300 \mathrm{~nm}$; and shortwave infra-red (SWIR), from $1300 \mathrm{~nm}$ to $2500 \mathrm{~nm}$. The total range of $400 \mathrm{~nm}$ to 2500 $\mathrm{nm}$ can be measured by a wide variety of remote sensors from multispectral (Landsat, MODIS) to hyperspectral (AVIRIS).

Using these different spectrum bands, the called vegetation indices (VIs) can be calculated. The VIs are designed to highlight specific characteristics of vegetation, combining surface reflectance at two or more wavelengths in the solar-reflected optical spectrum, and using the reflectance characteristics of leaf components and canopy structure. Basically, healthy canopies of green vegetation have a very distinct interaction with certain portions of the electromagnetic spectrum. In the visible regions, chlorophyll causes strong absorption of energy, primarily for use in photosynthesis. This absorption peaks 
in the red and blue areas of the visible spectrum, while the green area is reflected by clorophyll. At the same time, the NIR region of the spectrum is strongly reflected through the internal structure of the leaves. Taking into account this phenomenon, the majority of VIs compares red and NIR reflectances, taking advantage of the highly different response of green vegetation in these two spectral regions.

Nowadays, there is a massive amount of different Vls prioritizing different aspects of the plant-light relationship. Silleos et al. (2006) did a great effort in order to compile the most used VIs in vegetation monitoring in the last 30 years (Table 2-1). More recently, Viña et al. (2011) compared the suitability of a total of eight VIs for the remote assessment of the green leaf area index. Pasquato (2014) described the most common VIs (all of them showed in Table 2.1) and, later, compared the suitability of two well-known VIs: the Normalized Difference Vegetation Index (NDVI) and the Enhanced Vegetation Index (EVI).

But the Normalized Difference Vegetation Index (NDVI) is by far the widest-used $\mathrm{VI}$ and this is the VI used in this research work. The NDVI is calculated according to the equation in Table 2-1. This index varies between -1 and 1 . Bare soils are generally characterized by very low, positive NDVI values; vegetated areas tend to show positive values, with increasing index as vegetation canopy becomes denser. Free standing water results in very low positive or even slightly negative NDVI values, while clouds and snow fields are characterized by negative values of this index.

It is deep-demonstrated that the NDVI is sensitive to green leaf biomass, so that it can be primarily employed to monitor the photosynthetically active biomass of plant canopies (Tucker, 1979). In fact, during the late 90s, some authors (e.g. Carlson and Ripley, 1997) demonstrated that although the NDVI is not an intrinsic physical quantity, it is indeed correlated with certain physical properties of the vegetation canopy, particularly, with the leaf area index (LAI) and biomass productivity. The LAI is a dimensionless quantity defined as the total one-sided area of photosynthetic tissue per unit ground surface area (e.g. Gobron, 2008). Hence, it represents the amount of leaf biomass in an ecosystem. Previous studies have demonstrated the relationship between satellite-derived NDVI and LAl or ground biomass productivity (Tucker et al., 1985, Hobbs, 1995, Wang et al., 2004, Wang et al., 2005, Gitelson et al., 2006, Funk and Budde, 2009 and Becker-Reshef et al., 2010). However, it is also well documented that the relationship between NDVI and LAI is far from perfect (e.g. Tucker et al., 1985; 
Prince, 1991; Prince et al., 1995; Pettorelli et al., 2005). The main limitation of using NDVI to estimate LAI is that NDVI can reach saturation in dense vegetation canopies; i.e., NDVI becomes insensitive at high values of leaf area index (Asrar et al., 1984, Hatfield et al., 1985, Sellers, 1985, Hobbs, 1995, Asner et al., 2003 and Chen et al., 2006), which may lead to an underestimation of LAl increases in high (dense) biomass regions. According to Turner et al. (1999), the relationship between LAI and NDVI can be considered as linear for low values, but beyond a certain value of LAI, the change in NDVI with LAI becomes insignificant. This threshold tends to be reached when LAI attains a value between 2.5 and 3.0 (Price, 1992; Liu and Huete, 1995; Jasisnki, 1996). In this research project, the observed/expected LAI are around 2.0. Hence, we did not have to worry about this issue.

Table 2-1. Vegetation indices compiled by Silleos et al. (2006)

\begin{tabular}{cl}
\hline Vegetation indices & Author \\
\hline$N D V I=(N I R-R) /(N I R+R)$ & Birth and McVey (1968) \\
$S A V I=\frac{N I R-R}{N I R+R} *(1+L)$ & Rouse et al. (1974) \\
$T V I=\sqrt{(N I R-R) /(N I R+R)}+0.5$ & Huete (1988) \\
$C T V I=\frac{N D V I+0.5}{|N D V I+0.5|} * \sqrt{|N D V I+0.5|}$ & Deering et al. (1975) \\
$T I V I=\sqrt{|N D V I+0.5|}$ & Perry and Lautenschlager (1984) \\
$R V I=R / N I R$ & Thiam (1997) \\
$N R V I=\frac{R V I-1}{R V I+1}$ & Richardson and Wiegand (1977) \\
$\qquad V I=G *(1+L) * \frac{N I R-R}{N I R+C_{1} * R-C_{2} * B+L}$ & Baret and Guyot (1991) \\
$P V I=\sqrt{(R g g 5-R p 5)^{2}+(R g g 7-R p 7)^{3}}$ & Huete et al.(1999) \\
$P V I 1=(b * N I R-R+a) / \sqrt{\left(b^{2}+1\right)}$ & Pichardson and Wiegand (1977) \\
$D V I=g * M S S 7+M S S 5$ & Perry and Lautenschlager (1984) \\
$A V I=2 * M S S 7-M S S 5$ & Richardson and Wiegand (1977) \\
$T S A V I 1=\frac{a *(N I R-a) *(R-b)}{R+a * N I R-a * b}$ & Ashburn (1978) \\
\hline
\end{tabular}

Symbology (in order of appearance):

$\mathrm{NIR}=$ near infrared, $\mathrm{R}=$ red, $\mathrm{B}=\mathrm{blue}, \mathrm{L}=$ soil, $\mathrm{C} 1$ = adjustment factor, $\mathrm{C} 2=$ adjustment factor, $\mathrm{G}=$ gain factor, $\mathrm{Rp}=$ reflectance at a vegetation spot for Landsat bands MSS5 and MSS7, Rgg= reflectance of soil background, a= intercept of the soil line, $b=$ slope of the soil line, $g=$ slope of the soil line, MSS7= reflectance in the near infrared 2 band, MSS5= reflectance in the visible red band 


\subsubsection{Satellite data and Vegetation Indexes acquisition: MODIS products}

As mentioned before, after the Stockholm Convention in 1972, the scientific community focused on the interactions between atmosphere, hydrosphere and land surface. In fact, during the late 1980s, some projects about the global land coverage were carried out, such as the International Geosphere and Biosphere Program (IGBP). This project mapped the terrestrial coverage using the Advanced Very High Resolution Radiometer (AVHRR) installed in NOAA satellites. It provided global databases during more than two decades. However, the AVHRR data had some disadvantages to be used for ecological monitoring: (1) low spatial resolution, (2) low spectral resolution and (3) high predisposal to saturation (Ichoku et al., 2003). It is important to mention that the AVHRR was designed originally for climatic monitoring.

This fact motivated the creation of new sensors and new systems designed specifically for terrestrial land monitoring. In this sense, the Earth Observing System (EOS) of NASA appeared as the most ambitious project. The EOSDIS (Earth Observing System Data and Information System) is based on two principles: (1) no discrimination and (2) no exclusivity. No discrimination means that every single person in the world can acquire the global data as easier as possible and the data are completely free. No exclusivity means that all works using this data must be published and spread. Precisely for the two principles, we decided to use the EOS products.

Among the EOS products, the Moderate Resolution Imaging Spectroradiometer (MODIS) stands out. It is aboard the Terra and Aqua satellites launched in 2000 and 2002 respectively. The MODIS instrument provides high radiometric sensitivity (12 bit) in 36 spectral bands ranging in wavelength from $0.4 \mu \mathrm{m}$ to 14.4 $\mu \mathrm{m}$ (Table 2-2). Two bands are imaged at a nominal resolution of $250 \mathrm{~m}$ at nadir, with five bands at $500 \mathrm{~m}$, and the remaining 29 bands at $1 \mathrm{~km}$. A \pm 55 -degree scanning pattern at the EOS orbit of $705 \mathrm{~km}$ achieves a 2,330-km swath and provides global coverage every one to two days. The bands from 1 to 7 are used for terrestrial applications; the bands from 8 to 16 for oceanic monitoring and from 17 to 19 for atmospheric observation. The bands from 20 to 36 correspond to the thermal infrared. 
Table 2-2. General specifications of the MODIS sensors (extracted from http://modis.gsfc.nasa.gov/about/specifications.php)

\begin{tabular}{ll}
\hline Property & Information \\
\hline Orbit & $705 \mathrm{~km}, 10: 30$ a.m. descending node (Terra) or 1:30 p.m. ascending node (Aqua), \\
& sun-synchronous, near-polar, circular \\
& $20.3 \mathrm{rpm}$, cross track \\
Scan rate & $2330 \mathrm{~km}$ (cross track) and 10 km (along track at nadir) \\
Swath dimensions & $17.78 \mathrm{~cm}$ \\
Telescope & $1.0 \times 1.6 \times 1 \mathrm{~m}$ \\
Size & $228.7 \mathrm{~kg}$ \\
Weight & $162.5 \mathrm{~W}$ (single orbital average) \\
Power & $10.6 \mathrm{Mbps}$ (peak daytime); 6.1 Mbps (orbital average) \\
Data rate & 12 bits \\
Quantization & $250 \mathrm{~m}$ ( 1-2 bands) \\
Spatial resolution & $500 \mathrm{~m}$ (3-7 bands) \\
& $1000 \mathrm{~m}$ (8-36 bands) \\
Design life & 6 years \\
\hline
\end{tabular}

The MODIS products can be divided into five levels from 0 to 4 . Level 0 means raw data (without any data treatment), level 1 contains the bands geolocated and calibrated, level 2 contains geophysical variables, level 3 contains the geophysical variables contained in level 2 but aggregated in time and level 4 is data generated by models. Atmosphere products are available through the LAADS web. Land Products are available through the Land Processes DAAC at the U. S. Geological Survey EROS Data Center (EDC). Cryosphere data products (snow and sea ice cover) are available from the National Snow and Ice Data Center (NSIDC) in Boulder, Colorado. Ocean color products and sea surface temperature products along with information about these products are obtainable at the Ocean Color Data Processing System (OCDPS) at Goddard Space Flight Center (GSFC). More information about obtaining MODIS data can be found from the information sites listed in Table 2-3.

Table 2-3. MODIS products and their corresponding sources

\begin{tabular}{ll}
\hline Product & Source \\
\hline MODIS level 1 data, geolocation, cloud mask, and & http://ladsweb.nascom.nasa.gov/ \\
atmosphere products & \\
MODIS land products & https://lpdaac.usgs.gov/ \\
MODIS cryosphere products & http://nsidc.org/daac/modis/index.html \\
MODIS ocean color and sea surface temperature products & http://oceancolor.gsfc.nasa.gov/ \\
\hline
\end{tabular}




\subsubsection{Ecohydrological modelling and satellite data}

According to the previous subsection, satellite remote sensing has the ability to provide information on hydrological fluxes and state variables at (near-)global coverage and at (near-)real time, and at frequent temporal intervals. The given features provide unique opportunities for enhancing model simulations in remote areas (van Dijk and Renzullo, 2011). Now, the question is how to take advantage of this potential information for ecohydrological modelling.

Remote sensing data in ecohydrological modelling has been used, in general, in two different ways: as input in order to force the model or as target in order to calibrate and/or validate the model. There are a lot of examples of models forced by remote sensing data (Xiao et al., 2004; Yuan et al., 2010; and Stisen et al., 2011, Samaniego et al., 2011), but the applicability of remote sensing to calibrate and/or validate a model still remains as a challenging task.

Table 2-4 summarizes the reviewed publications related to this challenge, their calibration and validation strategies as well as some important comments. In order to make this compilation, a bibliographic survey of the ISI Web of Knowledge Science Citation Index database was undertaken using the following words combinations in the topic search: (1) satellite calibration, (2) satellite implementation, (3) satellite ecohydrological modelling, and (4) remote sensing ecohydrology. This search looked for each term in the title, abstract and keyword lists of millions of publications (i.e. articles, letters and book reviews) in ISI-rated journals and conference proceedings since 1981, although we only used the publications during the last decade. From the total of publications obtained by this search, only those that used the satellite data to calibrate and/or validate a model were selected. We know this compilation of publications was really sensitive to the used topic search and we apologize because of the no-cited papers due to this limitation but the Table 2-4 was complete enough for our purposes.

In following lines the most illustrative papers extracted from Table 2-4 will be discussed. Included as Ruiz-Pérez et al. (2016b), next chapter will discuss the applicability of satellite data during the calibration process comparing the results obtained by a parsimonious model calibrated only using satellite data (particularly, NDVI data) against the results obtained by a complex model calibrated using field measurements at pixel scale. At catchment scale, Immerzeel and Droogers (2008) used satellite-based evapotranspiration (ET) in 
combination with observed streamflow to calibrate the semi-distributed SWAT in a portion of the Krishna River basin in India. In Winsemius et al. (2008), satellitebased ET was used to constrain the parameter boundaries through bayesian techniques in order to calibrate a hydrological model in Luangwa River basin in Zambia. Zhang et al. (2009) concluded that multi-objective calibration of SymHyd model with streamflow and satellite-based ET produced better daily and monthly runoff compared to calibration with streamflow alone. More recently, Rientjes et al. (2013) calibrated a semi-distributed hydrological model using streamflow data and satellite-based ET in a catchment located in Iran. Regarding to other satellite products, GRACE (the US-German satellite mission) data have been used to calibrate both global and regional-scale surface hydrology models, in combination with stream discharge data (e.g. Lo et al., 2010). Zhang et al. (2011) calibrated the AWRA-L model with streamflow, NOAA-AVHRR LAI and TRMM-MI (Tropical Rainfall Measuring Mission- Microwave Imager) soil moisture using multiobjective criteria. The main conclusion of all of these references was the same: including remote sensing data into the model calibration/validation improves the results obtained by the models.

Closer to our objectives, a calibration scheme which relies solely on remote sensing data will be greatly beneficial in modelling at ungauged and scarce data catchments, especially if it can be demonstrated to result in improved estimation compared with uncalibrated model (Kunnath-Poovakka et al., 2016). But, only in few studies, the calibration is carried out exclusively with remote sensing. For instance, Gutmann et al. (2010) presented a method for identifying landscape hydraulic properties (LHPs) from MODIS surface temperatures. They calibrated LHPs in the Noah land surface model using only MODIS surface temperatures from 14 different sites and using observed flux data for model verification. Or, Velpuri et al. (2012) modelled Lake Turkana water level only using satellite information, even the forcing data was satellite-derived. In fact, they proposed a multi-source satellite data approach using satellite rainfall and ET from MODIS products while the model calibration and validation were carried out using the satellite altimetry information.

Considering all publications from Table 2-4, from a total of the reviewed publications, calibrations only using satellite data were performed in seven of them while a combination of satellite data and field measurements (specially, streamflow at the outlet) was used in the remaining 18. Similar results were obtained with regards to the validation: six publications only using field 
measurements (specially, historical streamflow), eight using a combination of field measurements and satellite data, two using only satellite data and one without any specification. But, more interesting is how the different calibrations were carried out.

In most of the cited examples, a sort of multi-objective calibration was used adopting only some cells/pixels to calibrate the entire catchment. According to Campo et al. (2006), the use of point measurements is not enough since they do not represent an integrated output of non-linear dynamics. In other cases, lumped models were used instead of distributed models using, in consequence, aggregated values of the satellite data and neglecting the spatial heterogeneity. If so, we are not taking the complete advantage provided by satellite imagery. Therefore, a method able to exploit the potential of the spatio-temporal information contained in remote sensed data is highly desirable. In Chapter 4, it can be seen our contribution in that sense by including both, temporal and spatial patterns of the satellite data, during both calibration and validation processes. 
Table 2-4. List of publications in which satellite data was used to calibrate different models extracted from the Web of Knowledge database using the search topics specified in the introduction section

\begin{tabular}{|c|c|c|c|c|}
\hline \multirow[t]{2}{*}{ Publication } & \multicolumn{2}{|c|}{ Calibration } & \multirow{2}{*}{$\begin{array}{c}\text { Validation } \\
\text { Data }\end{array}$} & \multirow[t]{2}{*}{ Comments } \\
\hline & Data & Method & & \\
\hline $\begin{array}{l}\text { Immerzed and } \\
\text { Droogers, } 2008\end{array}$ & $\begin{array}{l}\text { ET calculated by the } \\
\text { SEBAL model and MODIS } \\
\text { spectrum bands. } \\
\text { Historical streamflow }\end{array}$ & $\begin{array}{l}\text { Multi-objective } \\
\text { approach }\end{array}$ & Historical Streamflow & $\begin{array}{l}\text { Catchment scale. } \\
\text { Semi-distributed model. } \\
115 \text { sites (sub-catchments). }\end{array}$ \\
\hline $\begin{array}{l}\text { Parajka and Blöschl, } \\
2008\end{array}$ & $\begin{array}{l}\text { Snow cover data from } \\
\text { MODIS } \\
\text { Historical streamflow }\end{array}$ & $\begin{array}{l}\text { Multi-objective } \\
\text { approach }\end{array}$ & $\begin{array}{l}\text { Ground-based snow depth } \\
\text { observations } \\
\text { Historical streamflow }\end{array}$ & $\begin{array}{l}\text { Catchment scale } \\
\text { Semi-distributed model } \\
148 \text { sites (sub-catchments) }\end{array}$ \\
\hline $\begin{array}{l}\text { Arda Sorman et al., } \\
2009\end{array}$ & $\begin{array}{l}\text { Snow cover data from } \\
\text { MODIS } \\
\text { Historical streamflow }\end{array}$ & $\begin{array}{l}\text { Multi-objective } \\
\text { approach }\end{array}$ & $\begin{array}{l}\text { Snow cover data from MODIS } \\
\text { Historical streamflow }\end{array}$ & $\begin{array}{l}\text { Catchment scale } \\
\text { Lumped model } \\
\text { One site. }\end{array}$ \\
\hline Zhang et al., 2009 & $\begin{array}{l}\text { ET calculated through } \\
\text { Penman-Monteith using: } \\
\text { LAI, Albedo and Land } \\
\text { Cover from MODIS. } \\
\text { Historical streamflow }\end{array}$ & $\begin{array}{l}\text { Single-objective } \\
\text { approach }\end{array}$ & Historical Streamflow & $\begin{array}{l}\text { Catchment scale } \\
\text { Lumped model } \\
\text { One site. }\end{array}$ \\
\hline Lo et al., 2010 & $\begin{array}{l}\text { Total water storages } \\
\text { anomalies derived from } \\
\text { GRACE } \\
\text { Base flow estimates } \\
\text { from historical } \\
\text { streamflow }\end{array}$ & $\begin{array}{l}\text { Multi-objective } \\
\text { approach }\end{array}$ & $\begin{array}{l}\text { Total water storages anomalies } \\
\text { derived from GRACE } \\
\text { Base flow estimates from historical }\end{array}$ & $\begin{array}{l}\text { Catchment scale } \\
\text { Semi-distributed model } \\
\text { Three sites }\end{array}$ \\
\hline
\end{tabular}


On the use of satellite data to calibrate a parsimonious ecohydrological model in ungauged basins

Doctoral Thesis

\begin{tabular}{|c|c|c|c|c|}
\hline Sun et al., 2010 & $\begin{array}{l}\text { River widths from JERS-1 } \\
\text { SAR }\end{array}$ & $\begin{array}{l}\text { Single-objective } \\
\text { approach }\end{array}$ & Historical streamflow & $\begin{array}{l}\text { Catchment scale } \\
\text { Lumped model } \\
\text { One site }\end{array}$ \\
\hline $\begin{array}{l}\text { Werth and Güntner, } \\
\text { (2010) }\end{array}$ & $\begin{array}{l}\text { Total water storages } \\
\text { from GRACE } \\
\text { Historical streamflow }\end{array}$ & $\begin{array}{l}\text { Multi-objective } \\
\text { approach }\end{array}$ & No specified & $\begin{array}{l}\text { Catchment scale } \\
\text { Lumped model } \\
28 \text { sites }\end{array}$ \\
\hline Zhang et al., 2011 & $\begin{array}{l}\text { LAI from NOAA-AVHRR } \\
\text { SM from TRMM-TMI } \\
\text { Historical streamflow }\end{array}$ & $\begin{array}{l}\text { Multi-objective } \\
\text { approach }\end{array}$ & $\begin{array}{l}\text { LAI from NOAA-AVHRR } \\
\text { SM from TRMM-TMI } \\
\text { Historical streamflow }\end{array}$ & $\begin{array}{l}\text { Catchment scale } \\
\text { Distributed model } \\
579 \text { sites ( } 289 \text { to calibrate, } 290 \text { to } \\
\text { validate) }\end{array}$ \\
\hline Sun et al. 2012 & $\begin{array}{l}\text { GRACE-derived } \\
\text { groundwater storages } \\
\text { In situ water level } \\
\text { measurements }\end{array}$ & $\begin{array}{l}\text { Multi-objective } \\
\text { approach }\end{array}$ & $\begin{array}{l}\text { GRACE-derived groundwater } \\
\text { storages } \\
\text { In situ water level measurements }\end{array}$ & $\begin{array}{l}\text { Catchment scale. } \\
\text { Distributed model } \\
\text { One site }\end{array}$ \\
\hline Velpuri et al., 2012 & $\begin{array}{l}\text { Satellite altimetry from } \\
\text { TOPEX }\end{array}$ & $\begin{array}{l}\text { Single-objective } \\
\text { approach }\end{array}$ & Satellite altimetry from TOPEX & $\begin{array}{l}\text { Catchment scale. } \\
\text { Lumped model } \\
\text { One site }\end{array}$ \\
\hline $\begin{array}{l}\text { Franz and Karsten, } \\
2013\end{array}$ & $\begin{array}{l}\text { Three calibrations: } \\
\text { 1. Snow covered area } \\
\text { from MODIS } \\
\text { 2. Historical streamflow } \\
\text { 3. Combining both }\end{array}$ & $\begin{array}{l}\text { Multi-objective } \\
\text { approach }\end{array}$ & $\begin{array}{l}\text { Snow covered area from MODIS } \\
\text { Historical streamflow }\end{array}$ & $\begin{array}{l}\text { Catchment scale. } \\
\text { Lumped model } \\
\text { One site }\end{array}$ \\
\hline Riutjes et al., 2013 & $\begin{array}{l}\text { ET from MODIS } \\
\text { Historical Streamflow }\end{array}$ & $\begin{array}{l}\text { Multi-objective } \\
\text { approach }\end{array}$ & $\begin{array}{l}\text { ET from MODIS } \\
\text { Historical Streamflow }\end{array}$ & $\begin{array}{l}\text { Catchment scale. } \\
\text { Semi-distributed model. } \\
12 \text { sites. }\end{array}$ \\
\hline Corbari et al., 2015 & $\begin{array}{l}\text { LST from MODIS } \\
\text { LAI from MODIS }\end{array}$ & $\begin{array}{l}\text { Pixel-by-pixel } \\
\text { calibration. } \\
\text { Histograms } \\
\text { comparison }\end{array}$ & $\begin{array}{l}\text { LST from MODIS } \\
\text { Surface cumulated volume for one } \\
\text { year measured in field }\end{array}$ & $\begin{array}{l}\text { Catchment scale. } \\
\text { Distributed model. } \\
\text { One site }\end{array}$ \\
\hline
\end{tabular}


On the use of satellite data to calibrate a parsimonious ecohydrological model in ungauged basins

Doctoral Thesis

\begin{tabular}{|c|c|c|c|c|}
\hline Pasquato et al., 2015 & $\begin{array}{l}\text { LAI from MODIS } \\
\text { NDVI from MODIS } \\
\text { EVI from MODIS }\end{array}$ & $\begin{array}{l}\text { Single-objective } \\
\text { approach }\end{array}$ & $\begin{array}{l}\text { LAI from MODIS } \\
\text { NDVI from MODIS } \\
\text { EVI from MODIS }\end{array}$ & $\begin{array}{l}\text { Catchment scale } \\
\text { Lumped model } \\
\text { One site }\end{array}$ \\
\hline $\begin{array}{l}\text { Kunnath-Poovakka et } \\
\text { al., } 2016\end{array}$ & $\begin{array}{l}\text { ET from MODIS } \\
\text { SM from AMSR-E }\end{array}$ & $\begin{array}{l}\text { Multi-objective } \\
\text { approach }\end{array}$ & Historical streamflow & $\begin{array}{l}\text { Catchment scale } \\
\text { Distributed model } \\
\text { Two sites }\end{array}$ \\
\hline $\begin{array}{l}\text { Ruiz-Pérez et al., } \\
2016 b\end{array}$ & NDVI from MODIS & $\begin{array}{l}\text { Single-objective } \\
\text { approach }\end{array}$ & $\begin{array}{l}\text { NDVI from MODIS } \\
\text { Field measurements of transpiration } \\
\text { and SM }\end{array}$ & $\begin{array}{l}\text { Plot scale } \\
\text { Lumped model } \\
\text { One site }\end{array}$ \\
\hline
\end{tabular}




\section{CHAPTER 3. AT PLOT SCALE: TESTING THE MODEL}


On the use of satellite data to calibrate a parsimonious ecohydrological model in ungauged basins Doctoral Thesis 


\subsection{Introduction}

In both previous chapters, we highlighted the importance of the vegetation in the water cycle especially in water-controlled areas. The key role played by the vegetation has been demonstrated in a lot of research projects and publications (e.g. Laio et al., 2001; Huxman et al., 2005). That's why it seems unbelievable that most of the current hydrological models does not consider the vegetation as state variable but a static parameter neglecting in this way the active role of the vegetation dynamics. This fact is particularly serious in arid and semi-arid regions, where this thesis is focused on, because in these regions the ET may account more than $90 \%$ of the mean annual precipitation (Pilgrim et al., 1988; Huxman et al., 2005; Andersen, 2008).

On the other hand, according to Andersen (2008), arid and semi-arid regions can be considered as ungauged areas. Hence, in most of practical applications in these areas, there are not a lot of information and measurements in order to implement complex models. In Chapter 2, we called this combination as the 'complex models - data scarcity' issue and we mentioned two strategies to be applied: (1) simplification of the models and (2) search of new sources of information. In this context, we decided to use a parsimonious ecohydrological model in which the vegetation is a state variable and, at the same time, to explore the useful of satellite data as new source of information.

In particular, in this chapter, we used the parsimonious ecohydrological model proposed by Pasquato et al. (2015) in an experimental plot located in a semi-arid Mediterranean forest. Although the model is described in depth in following pages, it is important to mention that the model is composed by two sub-models: (1) a hydrological sub-model and (2) a dynamic vegetation sub-model. The hydrological sub-model is tank-based in which each tank represents different storages in the soil water column. On the other hand, the dynamic vegetation sub-model is based on the use of the Light Use Efficiency (LUE) index to simulate the green biomass. Anyway, the most important aspect is that both submodels are parsimonious. The relationships between different storages in the soil water column and the used equations are as simple as possible. The number of parameters is also as low as possible.

Precisely due to their simplicity, some processes are neglected. In fact, only the main processes are included in order to simplify their conceptualization. That's why it was important to test their accuracy and reliability. To address this issue, 
we decided to compare the results provided by this parsimonious model against the corresponding ones provided by a complex physically-based ecohydrological model described in section 3.4.2.

At the same time and as mentioned, we also wanted to explore the potential applicability of satellite data in ecohydrological modelling. To do that, we calibrated the parsimonious model with exclusively satellite data while the complex model used as reference was calibrated with field measurements as usual.

All this work was done in order to address this two main research questions: (1) is the proposed parsimonious model capable to satisfactory simulate vegetation and hydrological dynamics or is a more complex model needed? and, (2) could satellite products be used to implement a dynamic vegetation model or are field measurements totally necessary?

\subsection{Study area}

The study site is an experimental plot located in the Public Forest Monte de La Hunde y La Palomera with coordinates $1^{\circ} 12^{\prime} 30^{\prime \prime}$ W, 3905'30" in Valencia, East part of Spain ( Figure 3-1). La Hunde y La Palomera is a public utility forest (property of Generalitat Valenciana, number V1007V154). This forest has a total extension of 4,500 ha.

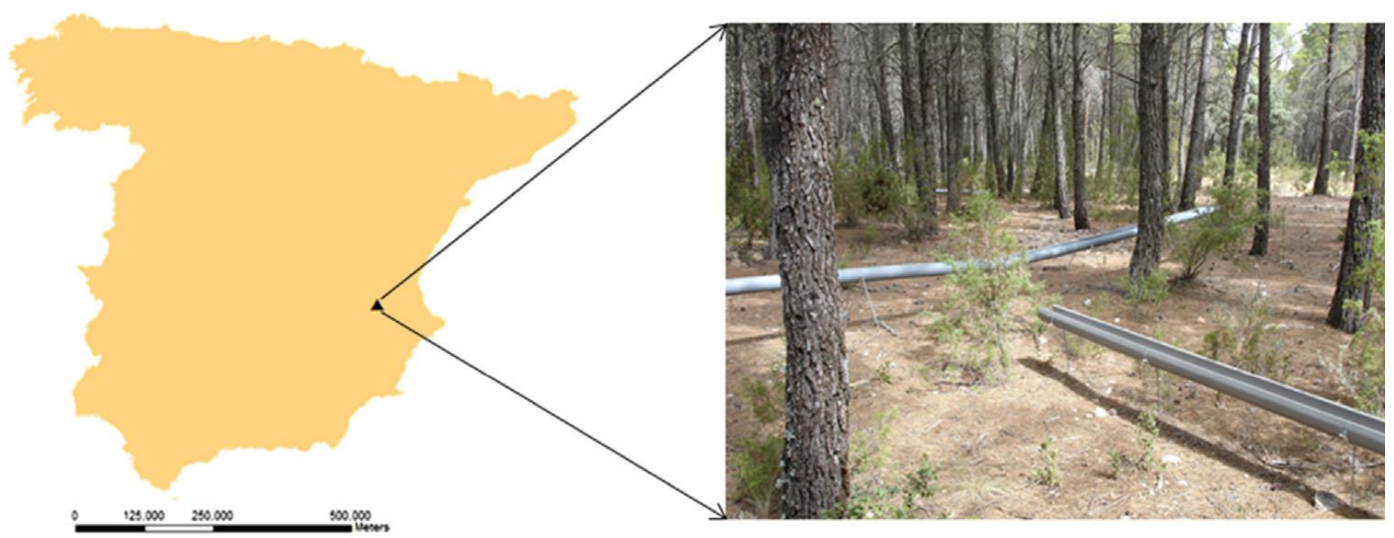

Figure 3-1. Location of the experimental plot study site. Detailed view of the 60 years old Aleppo pine plantation, control plot, used for this work 
The climate is Mediterranean with a mean annual rainfall of $466 \mathrm{~mm}$ and a mean annual temperature of $13.7{ }^{\circ} \mathrm{C}$ (1960-2007). The mean annual reference evapotranspiration is $749 \mathrm{~mm}$. Using the Köppen climate classification, the climate of this area is classified as semiarid (González-Sanchis et al., 2015). According to the statistical analysis done by Molina (2010), the rainfall is concentrated during the months of autumn while the driest months are during the summer. This distribution of the precipitation is characteristic of continental Mediterranean climate with three months of drought (FAO, 2005). According to Cervelló Royo (2008), the precipitation indexes of this mount are higher than the respective indexes of the surrounding mounts. Finally, this mount is located in a dry precipitation zone ${ }^{1}(350-600 \mathrm{~mm})$.

La Hunde y La Palomera forest is located on a calcareous fluvisol characterized by deep soils and variable textures (even in the same soil profile). The organic matter content is relatively low, approximately around $2 \%$. According to the samples extracted near to the study experimental plot, the sandy-silty loam soils predominate with high concentration of carbonate (16-38\%, pH 7.7-8.2) (Del Campo et al., 2008). Soil thickness ranges between 50 and $60 \mathrm{~cm}$.

The Forestry map of Spain (scale: 1:200,000, year: 1990) shows that there are eleven different vegetation species in the studied area. The description and the extension of each one can be found in Table 3-1. Particularly, the vegetation in the experimental plot is characterized by an homogeneous Aleppo pine (Pinus halepensis) plantation of high tree density with scant presence of other tree species either in forest gaps or as understory species (e.g., Quercus ilex sbsp. ballota, Pinus pinaster) ( Molina and Del Campo, 2012).

The Pinus halepensis plantations were established in the area during the late 1940s with high densities (approximately 1,500 trees/ha), and no forest management has been carried out due to the role of the forest in soil protection (Del Campo et al., 2014). In the described area, an experimental plot of $30 \times 30 \mathrm{~m}$ was stablished with different research objectives. In order to characterize the

\footnotetext{
${ }_{1}$ Precipitation zone is the translation of the Spanish term ombroclima. The ombroclima term is related to the amount of precipitation in a particular region (expressed generally in $\mathrm{mm}$ or in $1 / \mathrm{m}^{2}$ ). According to the annual mean of precipitation, there are six different classes in the Mediterranean region: arid $(<200 \mathrm{~mm})$, semi-arid (200-350mm), dry (350-600 mm), sub-humid (600-1,000 mm), humid (1,000-1,600 mm) and hyper-humid $(>1,600)$.
} 
vegetation mass of the experimental plot, Del Campo et al. (2014) measured the following variables: cover (\%), basal area $\left(\mathrm{m}^{2} / \mathrm{ha}\right)$, density (tree/ha), diameter at breast height $(\mathrm{DBH}, \mathrm{cm})$, LAl $\left(\mathrm{m}^{2} / \mathrm{m}^{2}\right)$, mean height $(\mathrm{m})$, heartwood area $\left(\mathrm{cm}^{2}\right)$, and sapwood area $\left(\mathrm{cm}^{2}\right)$. Table 3-2 shows the value of these variables measured on field.

Table 3-1. Vegetation units in La Hunde y La Palomera forest (Table extracted from Molina, 2010)

\section{Vegetation Unit}

Area $(\mathrm{Ha})$

1. Aleppo pine (Pinus Halepensis) plantation with shrubs of Rosmarinus officinalis and 719.07 mixed tomillar. Coverage of $95 \%$.

2. Aleppo pine (Pinus Halepensis) plantation with shrubs of Rosmarinus officinalis and $\quad 385.15$ Brachypodium retusum. Coverage of $70 \%$.

3. Degraded shrubs of pine with Rosmarinus officinalis and mixed tomillar

4. Mixed mass of Pinus pinaster, Quercus coccifera and shrubs of Rosmarinus officinalis

410.02 and mixed tomillar.

5. Mixed mass of Pinus Halepensis and Quercus ilex subsp. Ballota

6. Mixed mass of Pinus halepensis (30\%), Pinus halepensis plantation (20\%) and 1,043.34 Quercus ilex subsp. Ballota (10\%). Populus nigra in wet regions

7. Mosaic of Pinus halepensis, Quercus coccifera, Juniperus oxycedrus and Rosmarinus

$1,322.94$ officinalis.

8. Mixed tomillar

9. Dense shrubs

10. Tree mass of Pinus halepensis, Juniperus phoenicea and Quercus ilex subsp. ballota

11. Cropland

29.66

Table 3-2. Means of the forest structure characteristics in the experimental plot. Table extracted from Del Campo et al. (2014) and adapted from Molina and Del Campo (2012)

\begin{tabular}{lll}
\hline Characteristic & Units & Value \\
\hline Cover & $\%$ & 84 \\
Basal Area & $\mathrm{m}^{2} /$ ha & 40.1 \\
Density & Tree/ha & 1,489 \\
DBH & $\mathrm{cm}$ & 16.9 \\
LAl & $\mathrm{m}^{2} / \mathrm{m}^{2}$ & 2.6 \\
Mean Height & $\mathrm{m}$ & 11.5 \\
Heartwood area & $\mathrm{cm}^{2}$ & 0.58 \\
Sapwood area & $\mathrm{cm}^{2}$ & 230.9 \\
\hline
\end{tabular}

Finally, this place has been previously studied and modelled with different objectives (mostly sylviculture experiments). Information about the results of the 
previous studies can be found at González-Sanchis et al. (2015), Molina and Del Campo (2012) and, Del Campo et al. (2014).

\subsection{Data}

The data used in this chapter can be classified in two main groups: field measurements and satellite data. As field measurements, there are two groups: forcing data (precipitation and temperature) and data related to some variables of the model (transpiration and soil water content). In the following lines, a description about the collection of the mentioned field measurements and about the analysis of the used satellite products are given.

\subsubsection{Precipitation and Temperature time series}

Precipitation and temperature were measured in the experimental plot during the observational period from 27/03/2009 to 31/05/2011. The precipitation was measured using a standard pluviograph with a resolution of $0.2 \mathrm{~mm}$ (from Davis, USA). It was installed near to the experimental plot (around $50 \mathrm{~m}$ ) and without the influence of any object. It was measured every minute and the data was stored using an internal datalogger (Hobo, Onset application, USA). Anyway, we used the daily precipitation provided by the research group Re-Forest (our partner in two research projects).

On the other hand, temperature sensors (from Decagon Devices, USA) were installed in the middle of the experimental plot and at $1 \mathrm{~m}$ height. These sensors took a measure every 20 minutes. The data was stored in a datalogger EM50 with five connection channels. Once again, we only used daily maximum, minimum and mean temperature provided by the Re-Forest research group.

Furthermore, in order to increase the availability of forcing data, we also used the historical data of daily precipitation and maximum, minimum and mean temperature from a meteorological station located nearby the experimental plot. This station is located in Almansa (town near to the experimental plot), particularly, its UTM coordinates are $\mathrm{x}=664097$ and $\mathrm{y}=4307740$ and its altitude is equal to $698 \mathrm{~m}$. This station belongs to the Irrigation Integral Consultancy Service of Castilla-La Mancha Regional Government (known in Spanish as SIAR). 


\subsubsection{Transpiration and Soil Water Content time series}

Measurements of Soil Water Content (SWC) and transpiration were carried out in this experimental plot by Del Campo et al. (2014). Transpiration was measured in 4 trees by considering the diametrical distribution $(<20.5 \mathrm{~cm}$ low, $20.5-26.5 \mathrm{~cm}$ medium, $>26.5 \mathrm{~cm}$ high). Four trees were selected: one of the high, one of the low and two of the medium diameter class. This sample, although modestly sized, falls within the range considered in tree-water relation studies (Granier, 1987; Klein et al., 2013; Martínez-Vilalta et al., 2002).

The method to estimate the transpiration was based on the use of sap flow sensors, based on the Heat-Ratio Method (HRM, Burgess et al., 2001, Hernandez-Santana et al., 2011 and Williams et al., 2004) in all sample trees and programmed to average every hour. In each tree a HRM sap flow sensor (HRM sensor, ICT International, Australia) was placed at $1.3 \mathrm{~m}$ height and at the north side. In order to estimate daily values of sap flow in each tree, the sapwood areas were obtained by subtracting their heartwood area from the inner-bark area (Giuggiola et al., 2013) from the cores extracted for a growth analysis carried out by Del Campo et al. (2014). Finally, daily transpiration data was calculated as an average which takes into account the number of trees included in each diameter class (low, medium and high). In this way, plant transpiration was obtained in the experimental plot during the observational period from $27 / 03 / 2009$ to $31 / 05 / 2011$ (Figure 3-2).

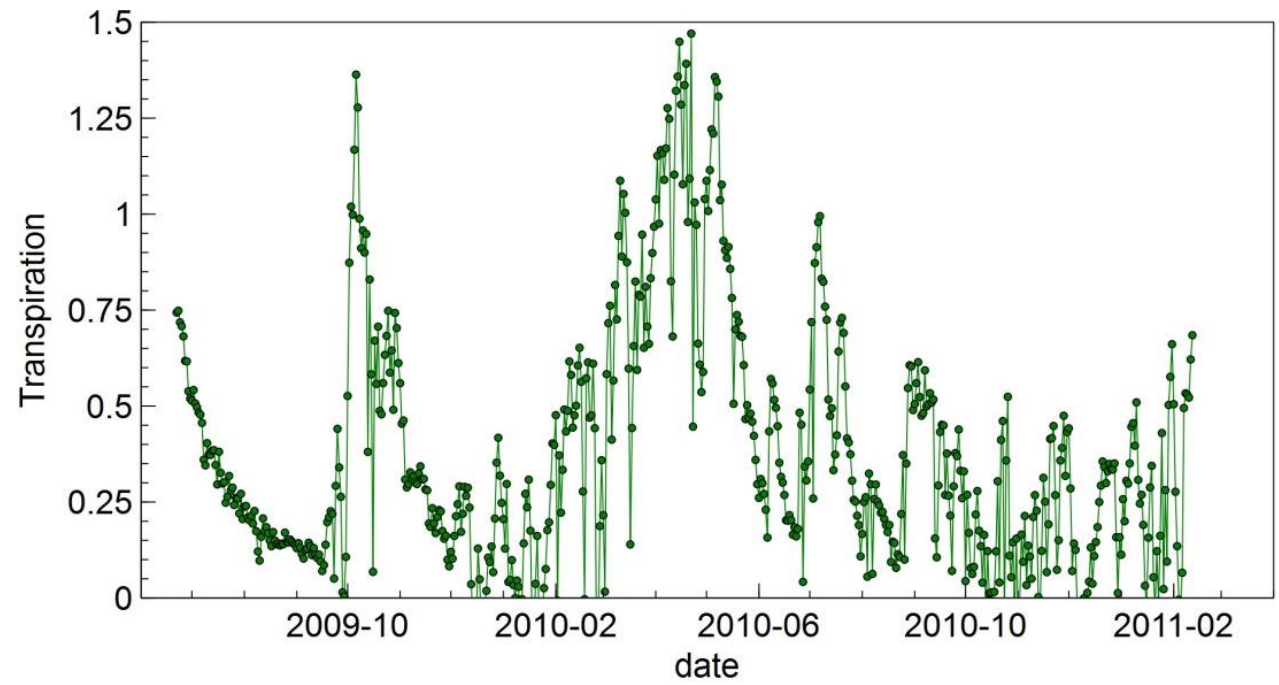

Figure 3-2. Transpiration measured in field during the observational period from $27 / 03 / 2009$ to $31 / 05 / 2011$ 
SWC was measured using 9 FDR sensors (EC-TM, Decagon Devices Inc., Pullman, WA), placed at $30 \mathrm{~cm}$ depth and considering either tree influence or not (i.e., under projected crown or not). SWC was continuously measured every 20 min. Field sensor calibrations were carried out by determining the gravimetric water content in four sampling dates (saturation, field capacity, between field capacity and wilting point and wilting point) to obtain the full range of SWC in the study site (Del Campo et al., 2014). Daily SWC data was calculated according to the vegetation cover, assuming that the sensors under tree influence (mean value) were representative of the area covered by vegetation and the sensors without tree influence (mean value) were representative of bare soil. In this way, soil moisture was obtained in the experimental plot during the observational period from 27/03/2009 to 31/05/2011 (Figure 3-3).

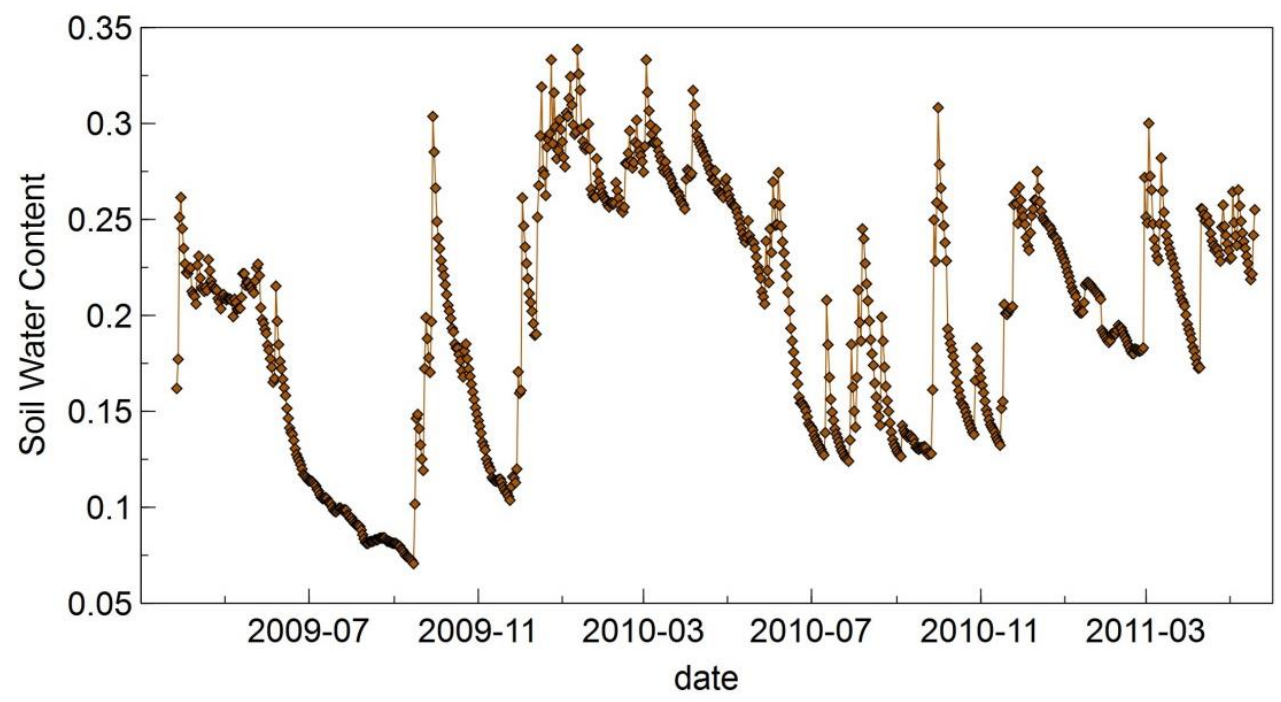

Figure 3-3. SWC measured in field during the observational period from $27 / 03 / 2009$ to $31 / 05 / 2011$

The Leaf Area Index (LAI) was estimated on field using a LAI-2000 sensor (LICOR, 1991) only once at the beginning of the work. Readings were taken under direct solar radiation (Molina and Del Campo, 2011) with a $270^{\circ}$ view cap and with the sensor always shaded to avoid light dispersions affecting sensor readings (LI-COR, 1991). The measured LAI has a value of 2.6 (Table 3-2). 


\subsubsection{Satellite data}

We analyzed the following satellite products provided by NASA (NASA Land Processes Distributed Active Archive Center (LP DAAC)): the Normalized Difference Vegetation Index (NDVI) included in the MOD13Q1 and MYD13Q1 products, the Leaf Area Index (LAI) included in the MOD15A2 and the MYD15A2 products and the actual evapotranspiration (ET) included in the product MOD16A2. For the coverage of the study site, the h17v05 tile is required, where $\mathrm{h}$ and $\mathrm{v}$ denote the horizontal and vertical tile number, respectively. The MODIS vegetation index datasets provided in Hierarchical Data Format (HDF) were imported to GeoTIFF format by MODIS Reprojection Tool (MRT) (software provided by NASA) and reprojected from the Integerized Sinusoidal (ISIN) projection to Universal Transform Mercator projection system.

The NDVI data is provided by NASA every 16 days and with a spatial resolution of $250 \times 250 \mathrm{~m}$. On the other hand, the LAI data is provided every 8 days and with a spatial resolution of $1 \times 1 \mathrm{~km}$. Both MODIS products were analyzed from $18 / 02 / 2000$ to $02 / 02 / 2013$. Finally, the ET datasets provided by NASA are evaluated using Mu et al.'s algorithm (2011) based on Penman Monteith equation (Monteith, 1965). This algorithm uses the following satellite information to be implemented: land cover classification, albedo, LAI and fPAR (Fraction of Photosynthetically Active Radiation). It is available from $01 / 01 / 2000$ to $26 / 12 / 2012$, provided every 8 days and with a spatial resolution of $1 \times 1 \mathrm{~km}$. As the study experimental plot is only of $30 \times 30 \mathrm{~m}$ and it is completely covered by one satellite pixel, we used directly the value of NDVI, LAI and ET from this pixel (Figure 3-4). In other words, interpolation techniques were not needed.

The used NDVI products (MOD13Q1 and MYD13Q1) are in level 3 that means they don't contain raw satellite data. Actually, the NDVI indices are retrieved from daily, atmosphere-corrected, bidirectional surface reflectance. Specifically, these products use a MODIS-specific compositing method based on product quality assurance metrics to remove low quality pixels. From the remaining good quality NDVI values, a constrained view angle approach then selects a pixel to represent the compositing period (from the two highest NDVI values it selects the pixel that is closest-to-nadir). On the other hand, LAI and ET products are in level 4 what means they are derived from a model as discussed in the following paragraph.

Despite the fact that all analyzed satellite products (NDVI, LAI and ET) showed a marked seasonal quasi-sinusoidal behavior as expected (Figure 3-4), the values 
of LAI were significantly lower than the one measured was 2.6. This field value is in agreement to values reported in literature (Sabaté et al., 2002; Sprintsin et al., 2007; Vicente-Serrano et al., 2010) for the same species and under similar climatic conditions. We know that this difference could be due to scale effects since we were comparing LAI measured in field against LAI provided by satellite. However, contrary to the NDVI which is calculated directly as difference between spectrum bands, the satellite LAI is simulated by a model. We were not able to be sure about the accuracy of this model in our particular pixel. Thus, the use of satellite LAI was finally dismissed. Likewise, as the Mu's algorithm employed to calculate ET uses the MODIS LAI, the use of satellite ET was also rejected. Hence, we used only the NDVI data from $18 / 02 / 2000$ to $02 / 02 / 2013$ to carry out the calibration of the LUE-Model.
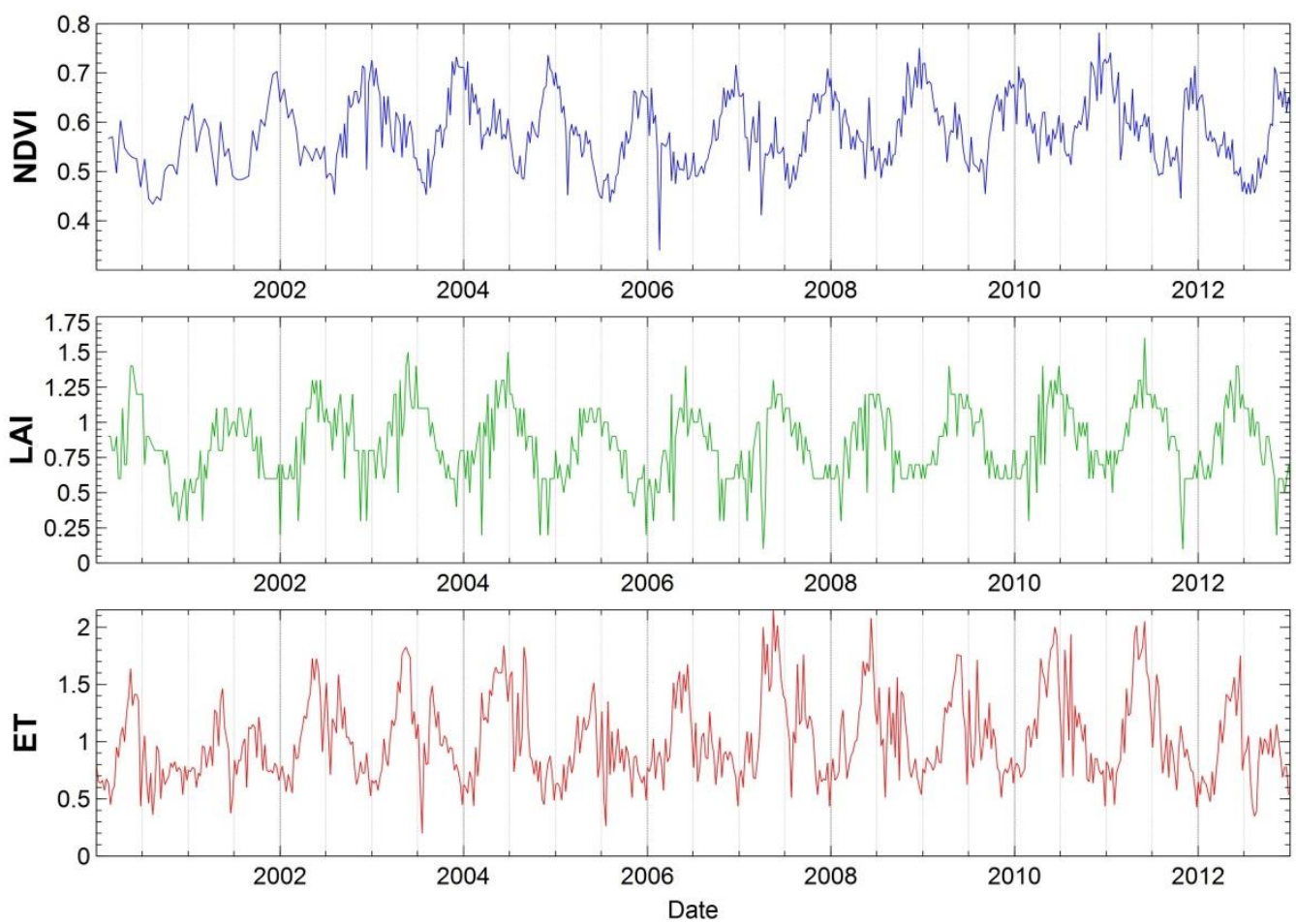

Figure 3-4. NDVI data included in MOD13Q1 and MYD13Q1 products, LAl included in MOD15A2 and MYD15A2, and ET included in MOD16A2 from MODIS (NASA) during the period from 01/01/2000 to 26/12/2012 


\subsection{Models}

Two models were used in this chapter: (1) the parsimonious LUE-Model proposed by Pasquato (2013) and slightly improved in this doctoral thesis and, (2) the physically-based BIOME-BGC model deeply used and tested around the world. Both models are described in the following lines.

\subsubsection{LUE-Model}

The tested dynamic vegetation model, the LUE-Model, was proposed by Pasquato et al. (2015). An important improvement on the maximum interception storage ( $I_{\max }$ was introduced. Pasquato et al. (2015) used a parameter called maximum interception storage which is stationary. In this version of the model, the $I_{\max }$ is calculated according to the product between the maximum leaf storage (a parameter) and the LAI simulated by the dynamic vegetation sub-model.

In their research, the model was used in an area with semi-arid climate obtaining satisfactory results. In this study, simulations are performed with a daily time step, on a per unit ground area basis and equations are solved with finite difference approximations. In order to provide a more detailed description, two different sub-models can be distinguished: (1) the hydrological sub-model and, (2) the dynamic vegetation sub-model.

\section{THE HYDROLOGICAL SUB-MODEL}

The dynamic vegetation model was coupled with a hydrological model based on a tank-based scheme (Figure 3-5). The first tank represents the amount of water retained by canopy. This water can only exit from this tank by direct evaporation. In this tank, the water balance is performed according to equations [ 1 ], [ 2 ] and [ 3 ].

$I_{t}^{*}=I_{t-1}+\min \left(P p t * \Delta t, I_{\max } * f_{c}-I_{t-1}\right)$

$E I_{t} * \Delta t=\min \left(E T_{0, t} * \Delta t, I_{t}\right)$

$I_{t}=I_{t}^{*}-E I_{t} * \Delta t$

where $\mathrm{t}$ is time, $\mathrm{I}$ is interception ( $\mathrm{I}^{*}$ is only an intermediate step), Ppt is precipitation, $I_{\max }$ is the maximum interception storage which is calculated 
according to the product between the maximum leaf storage and the LAI simulated by the dynamic vegetation sub-model, $\mathrm{f}_{\mathrm{c}}$ is the coverage factor, El is the evaporation from the interception storage and $E T_{0}$ is the reference evapotranspiration.

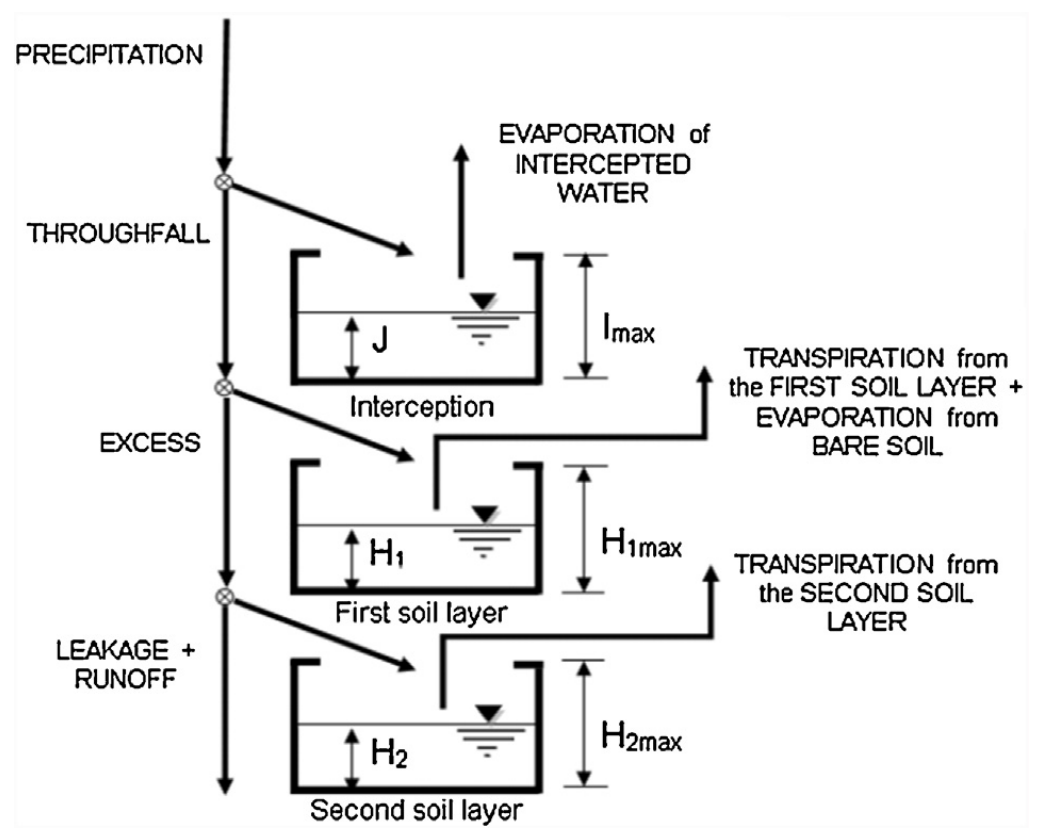

Figure 3-5. Scheme of the hydrological sub-model (extracted from Pasquato et al., 2015)

On the other hand, the effective root zone is divided into two superimposed layers, similar to Scanlon and Albertson (2003): a shallow layer that involves the processes of bare soil evaporation and superficial roots transpiration, and a second underlying layer that provides soil moisture to deeper roots (Figure 3-5). Transpiration (both from the shallow layer and from the deeper layer) is calculated according to FAO recommendations (Allen et al.,1998): the transpiration is obtained using the $\mathrm{ET}_{0}$ multiplied by a water stress factor $(\mathrm{f}(\mathrm{H}))$ and by a factor related to the current LAl simulated by the dynamic vegetation model, as shown in the following equations. Through this factor, the state of vegetation affects the hydrological fluxes and, consequently, the water storage in the different tanks. 


$$
\begin{aligned}
& H_{1, t}^{*}=H_{1, t-1}+\min \left(\mathrm{Thr} * \Delta t, H_{1, \max }-H_{1, t-1}\right) \\
& E_{b s, t} * \Delta t=\min \left(\left(E T_{0, t}-E I_{t}\right) * \Delta t *\left(1-f_{c}\right) * \beta\left(H_{1}\right)_{b s, t}, H_{1, t}^{*}\right) \\
& T_{1, t} * \Delta t=\min \left(\left(E T_{0, t}-E I_{t}\right) * \Delta t * f_{c} * \beta\left(H_{1}\right)_{t} * \min (1, L A I) * z_{1}, H_{1, t}^{*}\right) \\
& H_{1, t}=H_{1, t}^{*}-E_{b s, t} * \Delta t-T_{1, t} * \Delta t \\
& H_{2, t}^{*}=H_{2, t-1}+\min \left(E x c e s s * \Delta t, H_{2, \max }-H_{2, t-1}\right) \\
& T_{2, t} * \Delta t=\min \left(\left(E T_{0, t}-E I_{t}\right) * \Delta t * f_{c} * \beta\left(H_{2}\right)_{t} * \min (1, L A I) * z_{2}, H_{2, t}^{*}\right) \\
& H_{2, t}=H_{2, t}^{*}-T_{2, t} * \Delta t
\end{aligned}
$$

The subscripts 1 and 2 mean shallow and deep layer respectively. Thr is the throughfall, Excess is the vertical flux between the first and the second soil layer, $\mathrm{H}_{\mathrm{i}}$ is the water content of the $\mathrm{i}$ soil layer, $\mathrm{H}_{\mathrm{i}, \max }$ is the maximum static storage of the $i$ soil layer, Ebs is the bare soil evaporation and $z_{i}$ is the percentage of roots in the $i$ soil layer. The sum of $z_{1}$ and $z_{2}$ must be equal to one. The expression $\min (1, \mathrm{LAI})$ is the factor which replaces the crop factor recommended by the FAO 56. Finally, the water stress factor or soil water limitation $\beta\left(\mathrm{H}_{\mathrm{i}}\right)$ is calculated according to equation [11].

$$
\beta_{j}\left(H_{i}\right)=\left\{\begin{array}{cl}
1 & \text { for } H_{i} \geq H_{i, c r} \\
\left(\frac{H_{i}-H_{i, \text { lim }}}{H_{i, c r}-H_{i, l i m}}\right)^{q} & \text { for } H_{i, l i m}<H_{i}<H_{i, c r} \\
0 & \text { for } H_{i} \leq H_{i, \text { lim }}
\end{array}\right.
$$

where $\mathrm{H}_{\text {lim }}$ and $\mathrm{H}_{\mathrm{cr}}$ are the water storages $(\mathrm{mm})$ corresponding respectively to the wilting point and the critical point, below which transpiration is limited (Laio et al., 2001); $q$ is a measure of the nonlinearity of the effects of soil moisture deficit on plant condition (Porporato et al., 2001) and differs by species and might vary even among individuals (Rodriguez-lturbe et al., 1999). As an example, in drought tolerant species that adopt a water-saving strategy (e.g. Pinus halepensis Mill.), stomata opening is reduced before leaf water potential suffers any change (Baquedano and Castillo, 2006), generating a nonlinearity in the 
plant response to soil moisture shortage. For instance, Pasquato et al. (2015) recommends the use of an exponent equal to 3 for an Aleppo pine in a semi-arid region.

Regarding to the $\mathrm{H}_{\lim }$ and $\mathrm{H}_{\mathrm{cr}}$, both depend on the species and their strategy to survive during droughts as can be seen in the Figure 3-6 extracted from the wellknown and prestigious book Plant Ecology (Schulze et al., 2005)

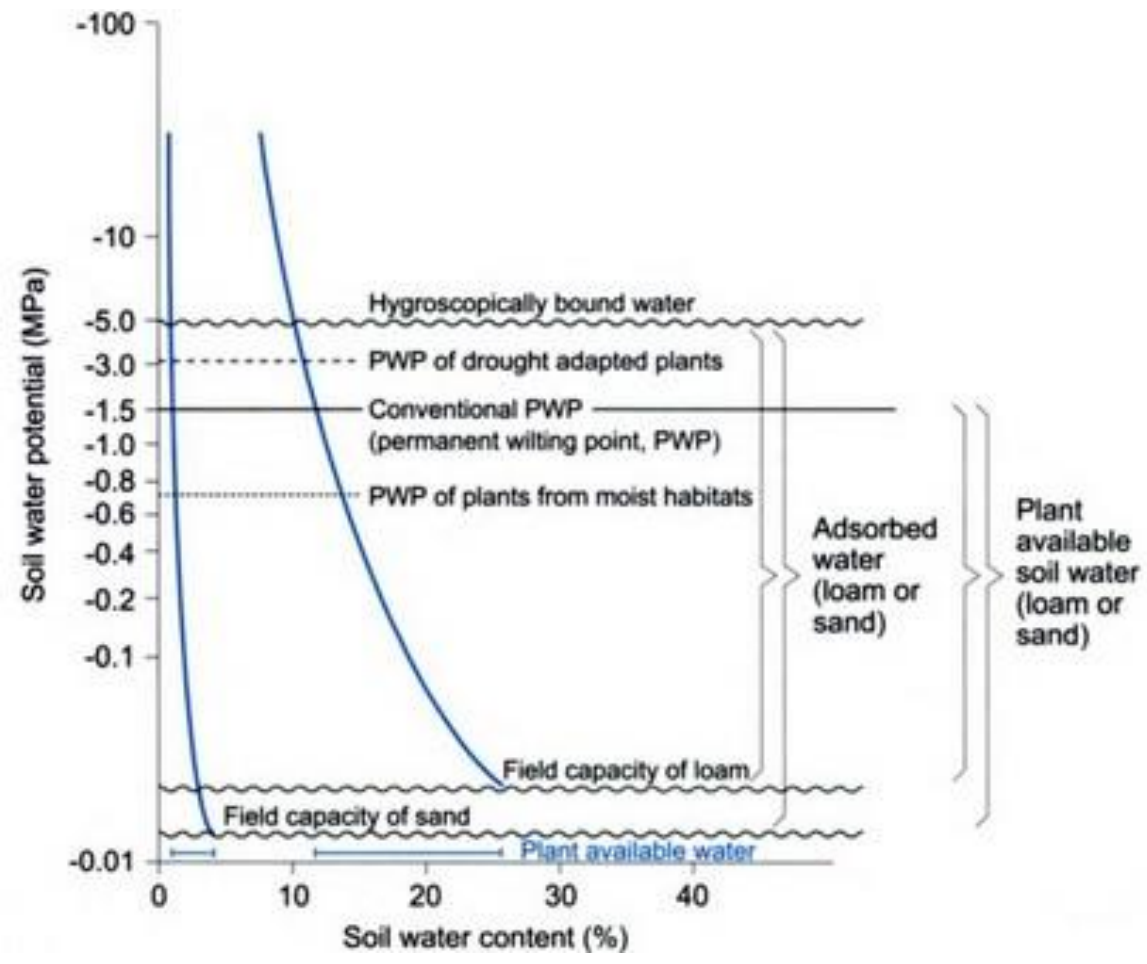

Figure 3-6. Soil water potential (MPa) at field capacity, permanent wilting point and hygroscopically bound water recommended in the book Plant Ecology (Schulze et al., 2005) for different types of soil and different plants according to their adaptation (drought or moist adapted)

The power function proposed by Clapp and Horberger (1978) was used in order to obtain the soil water content at wilting and critical points:

$\psi=\psi_{a e} *\left(\frac{n}{H}\right)^{b}$

where $\psi$ is the matric potential, $\psi_{\mathrm{ae}}$ is the matric potential of the air entry, $\mathrm{n}$ is the porosity, $\mathrm{b}$ is an index related to the distribution of the porosity and $\mathrm{H}$ is the water 
content. Clapp and Hornberger (1978) also proposed values for $\psi_{\mathrm{ae}}, \mathrm{n}$ and $\mathrm{b}$ according to the soil texture (Table 3-3).

To summarize and having showed all equations and relationships evolved in this hydrological sub-model, Table 3-4 contains a list of inputs, state variables and parameters together with the used symbols.

Table 3-3. Values proposed by Calpp and Hornberger (1978) for the parameters: $\Psi_{\mathrm{ae}}, \mathrm{n}$ and b

\begin{tabular}{lccc}
\hline Soil Texture & $\boldsymbol{\Psi}_{\text {ae }}[\mathrm{MPa}]$ & $\mathbf{n}$ & $\mathbf{b}$ \\
\hline Sand & $3.42 \mathrm{e}-04$ & 0.395 & 4.05 \\
Loamy sand & 1.74 e-04 & 0.410 & 4.38 \\
Sandy loam & $7.01 \mathrm{e}-04$ & 0.435 & 4.90 \\
Silt loam & $5.50 \mathrm{e}-03$ & 0.485 & 5.30 \\
Loam & $1.43 \mathrm{e}-03$ & 0.451 & 5.39 \\
Sandy clay loam & $8.43 \mathrm{e}-04$ & 0.420 & 7.12 \\
Silty clay loam & $1.43 \mathrm{e}-03$ & 0.477 & 7.75 \\
Clay loam & 3.53 e-03 & 0.476 & 8.52 \\
Sandy clay & $6.02 \mathrm{e}-04$ & 0.426 & 10.4 \\
Silty clay & $1.70 \mathrm{e}-03$ & 0.492 & 10.4 \\
Clay & $1.82 \mathrm{e}-03$ & 0.482 & 11.4 \\
\hline
\end{tabular}

Table 3-4. Inputs, state variables and parameters of the LUE-Model's hydrological sub-model

\begin{tabular}{|c|c|c|}
\hline & Definition & Symbol \\
\hline \multirow{4}{*}{ 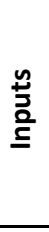 } & Precipitation & Ppt \\
\hline & Temperature & $\mathrm{T}$ \\
\hline & Solar Radiation & $\mathrm{R}$ \\
\hline & $\begin{array}{l}\text { Leaf Area Index (simulated by the } \\
\text { vegetation submodel) }\end{array}$ & LAl \\
\hline \multirow{10}{*}{ 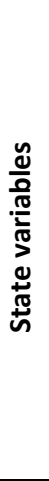 } & Interception & I \\
\hline & Static Storage in the first soil layer & $\mathrm{H}_{1}$ \\
\hline & Static Storage in the second soil layer & $\mathrm{H}_{2}$ \\
\hline & Throughfall & Thr \\
\hline & Excess & Ex \\
\hline & Leakage and runoff & L \\
\hline & Evaporation from the interception & $\mathrm{EI}$ \\
\hline & Evaporation from the bare soil & $E_{b s}$ \\
\hline & Transpiration from the first soil layer & $\mathrm{T}_{1}$ \\
\hline & Transpiration from the second soil layer & $\mathrm{T}_{2}$ \\
\hline
\end{tabular}




\begin{tabular}{llc}
\hline & Maximum leaf interception storage & $\mathrm{I}_{\max }$ \\
& Wilting point & $\theta_{\mathrm{wp}}$ \\
& Field capacity & $\theta_{\mathrm{fc}}$ \\
& Optimal point & $\theta^{*}$ \\
$\frac{\mathrm{d}}{\mathrm{d}}$ & Effective depth of the first soil layer & $\mathrm{d}_{1}$ \\
& Effective depth of the second soil layer & $\mathrm{d}_{2}$ \\
& Roots percentage & $\mathrm{Z}_{1}$ or $\mathrm{Z}_{2}$ \\
& Coverage factor & $\mathrm{fc}$ \\
\hline
\end{tabular}

\section{THE DYNAMIC VEGETATION SUB-MODEL}

The dynamics of vegetation biomass are modelled through a mass balance; where uptake is based on photosynthesis, simulated through the Absorbed Photosynthetically Active Radiation (APAR) and LUE factor (Arora, 2002; Polley et al., 2011).

Many approaches for estimating plant biomass production (Field et al., 1995; Running et al., 2004; Montaldo et al., 2005; Pasquato et al., 2015) are based on the use of the light use efficiency concept. The LUE is the proportionality between plant biomass production by terrestrial vegetation and absorbed photosyntetically active radiation in optimal conditions. However, this efficiency can be affected by stress conditions. The key factors contributing to the variation of this efficiency are: soil moisture content, air temperature (Landsber and Waring, 1997; Sims et al.,2006), and nutrient levels (Gamon et al., 1997; Ollinger et al., 2008). Our LUEModel simulates the leaf biomass ( $\mathrm{Bl}, \mathrm{kg} / \mathrm{m}^{2}$ ground) as follows (Pasquato et al., 2015):

$\frac{d B_{l}}{d t}=(L U E * \varepsilon * P A R * f P A R-R e) * \varphi_{l}\left(B_{l}\right)-k_{l} * B_{l}$

where $\varepsilon$ takes into account the reduction in LUE due to stress sources. In this study, as it was applied in a water-controlled catchment, the stress factors considered were only the water stress and the temperature stress. The nutrient levels were not considered, because they are not the dominant stress source in this semi-arid area. The water stress factor connects the dynamic vegetation model with the hydrological model. Re is the respiration, $\phi_{1}\left(B_{1}\right)$ is the fractional leaf allocation and $k_{l}$ is the leaf natural decay factor to reproduce the senescence. The respiration and the fractional leaf allocation are simulated as specified by Pasquato (2013). The fractional leaf allocation is simply calculated taking into 
account the maximum LAI sustainable by the system and according to the equation [14].

$\varphi_{l}=1-\frac{L A I}{L A I_{\max }}$

On the other hand, inspired in Sitch et al. (2003), respiration calculation (equation [ 15 ]) is based on tissue specific C: $\mathrm{N}$ ratios, air temperature and phenology. The model uses a variant of the Arrhenius equation in order to include the influence of the temperature in respiration rates using a tissue C:N ratio equal to 29 (Sitch et al., 2003). To obtain biomass instead of carbon, the model employs the relation $1 \mathrm{gC}$ in $2.2 \mathrm{~g}$ of dry organic matter (relation used in Montaldo, 2005; Pasquato, 2013 and García-Arias, 2015).

$$
R e=\frac{r r * B_{l}}{2.2 * 29} * e^{308.56 *\left[\frac{1}{56.02}-\frac{1}{T+46.02}\right]}
$$

where $\mathrm{rr}$ is the respiration rate in $\mathrm{gC} / \mathrm{gN}$ day and $\mathrm{T}$ is the daily mean temperature in Celsius degrees.

Finally, PAR and fPAR are the photosyntetically active radiation and the fraction of PAR absorbed by the canopy, respectively. More information about these terms can be found in Pasquato (2013). The daily PAR was obtained from the incident global radiation provided by a nearby meteorological station (the same station where the precipitation and temperature are measured) using a constant ratio of $0.48 \mathrm{MJ}$ (PAR)/MJ (global radiation) (McCree, 1972). The fPAR was obtained using the Beer-Lambert law according to the next equation:

$$
f P A R=0.95 *\left(1-e^{-k * L A I}\right)
$$

where $\mathrm{k}$ is the light extinction coefficient and the LAI is simulated through the specific leaf area (SLA) and the vegetation fractional cover (fc) according to equation [17].

$$
L A I=B_{l} * S L A * f_{c}
$$


However, Dawson et al. (1998) showed that NDVI is influenced by leaf water content. For this reason, some authors (Williams and Albertson, 2005; Pasquato et al., 2015) recommend the use of a water stress factor to make comparable the LAI with the NDVI as shown in the following equation:

$L A I_{r}=L A I *\left(1-\overline{\xi_{10}}\right)$

where the $L A I_{r}$ is the LAl comparable with NDVI and $\overline{\xi_{10}}$ is the average plant water stress of the previous 10 days as proposed by Williams and Albertson (2005).

Finally, having showed all equations and relationships evolved in this dynamic vegetation sub-model, Table 3-5 contains a list of inputs, state variables and parameters together with the used symbols.

Table 3-5. Inputs, state variables and parameters of the LUE-Model's dynamic vegetation sub-model

\begin{tabular}{|c|c|c|}
\hline & Definition & Symbol \\
\hline \multirow{4}{*}{$\begin{array}{l}\stackrel{n}{ } \\
\text { 을 }\end{array}$} & $\begin{array}{l}\text { Static storage of the first soil layer (simulated by the } \\
\text { hydrological sub-model) }\end{array}$ & $\mathrm{H}_{1}$ \\
\hline & $\begin{array}{l}\text { Static storage of the second soil layer (simulated by } \\
\text { the hydrological sub-model) }\end{array}$ & $\mathrm{H}_{2}$ \\
\hline & Temperature & $\mathrm{T}$ \\
\hline & Solar Radiation & $\mathrm{R}$ \\
\hline \multirow{4}{*}{ 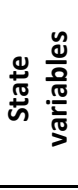 } & Leaf Biomass & $\mathrm{BI}$ \\
\hline & Fraction of the Photosynthetically Active Radiation & fPAR \\
\hline & Leaf Area Index & LAI \\
\hline & Leaf Area Index affected by water stress & $\mathrm{LAI}_{\mathrm{r}}$ \\
\hline \multirow{5}{*}{ 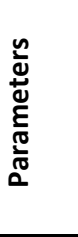 } & Light Use Efficiency index & LUE \\
\hline & Maximum LAI sustainable by the system & $\mathrm{LAI}_{\max }$ \\
\hline & Light extinction coefficient & $\mathrm{K}$ \\
\hline & Specific Leaf Area & SLA \\
\hline & Optimal Temperature & $\mathrm{T}_{\text {opt }}$ \\
\hline
\end{tabular}

\subsubsection{Biome-BGC model}

As representative of a complex model, this research used the Biome-BGC 4.2 model (Thorton et al., 2002) for two reasons. Firstly, the model is well 
documented, both technically and in scientific publications; second, the source code of the model is publicly available on the Internet (NTSG 2001). Furthermore, it is also widely used as a benchmark during Global Change analysis (e.g., Schimel et al., 1994). Complete descriptions of the model have been carried out in many studies (Pietsch et al., 2003; Tatarinov and Cienciala,2006; Chiesi et al., 2007; Maselli et al., 2009). The accuracy of the Biome-BGC model in this particular experimental plot was deeply demonstrated by González-Sanchis et al. (2015). These authors compared the obtained results using Biome-BGC with the results obtained using the same model around the world (Pietsch et al., 2003; Chiesi et al., 2002; etc.) and, also, with the obtained results using other approaches (Zhen-Ming et al.,2011; Keenan et al., 2009).

This model was not coded or modified by us. Hence, it is not relevant to give a detailed description of the model. Extracted directly from its User's manual, Biome-BGC could be described as follows: 'Biome-BGC is a mechanistic model that is used to estimate the state and fluxes of carbon $(\mathrm{C})$, nitrogen $(\mathrm{N})$, and water $\left(\mathrm{H}_{2} \mathrm{O}\right)$ into and out of an ecosystem. Biome-BGC is actively used in institutions around the globe and its most recent release is version 4.2. The three primary biogeochemical cycles represented in Biome-BGC are the $\mathrm{C}, \mathrm{N}$, and $\mathrm{H}_{2} \mathrm{O}$ cycles. In conjunction with these cycles, Biome-BGC models the physical processes of radiation and water disposition. Biome-BGC partitions incoming radiation and precipitation and treats the excess/unused portions as outflows. The primary physiological processes modeled by Biome-BGC are photosynthesis, evapotranspiration, respiration (autotrophic and heterotrophic), decomposition, the final allocation of photosynthetic assimilate, and mortality. To model these processes, Biome-BGC first models the phenology of the systems based on the input meteorological data.'

The model operates in a $1 \mathrm{~m}^{2}$ scale, with a daily time step and describes the dynamics of energy, water, carbon and nitrogen in a defined type of terrestrial ecosystem (deciduous broadleaf forest, coniferous forest or grassland). The model requires: daily climate data, information of the general environment (soil, vegetation and site conditions) and 34 parameters describing the ecophysiological characteristics of vegetation such as specific leaf area, water interception coefficient or light extinction coefficient. Biome-BGC is provided with default ecophysiological parameters sets for the major biome types, but these must be modified to adapt to Mediterranean ecosystems (Chiese et al., 2007). Water cycle calculation includes daily canopy interception, evaporation, 
transpiration, soil evaporation, soil water potential, soil water content and outflow (Figure 3-7).

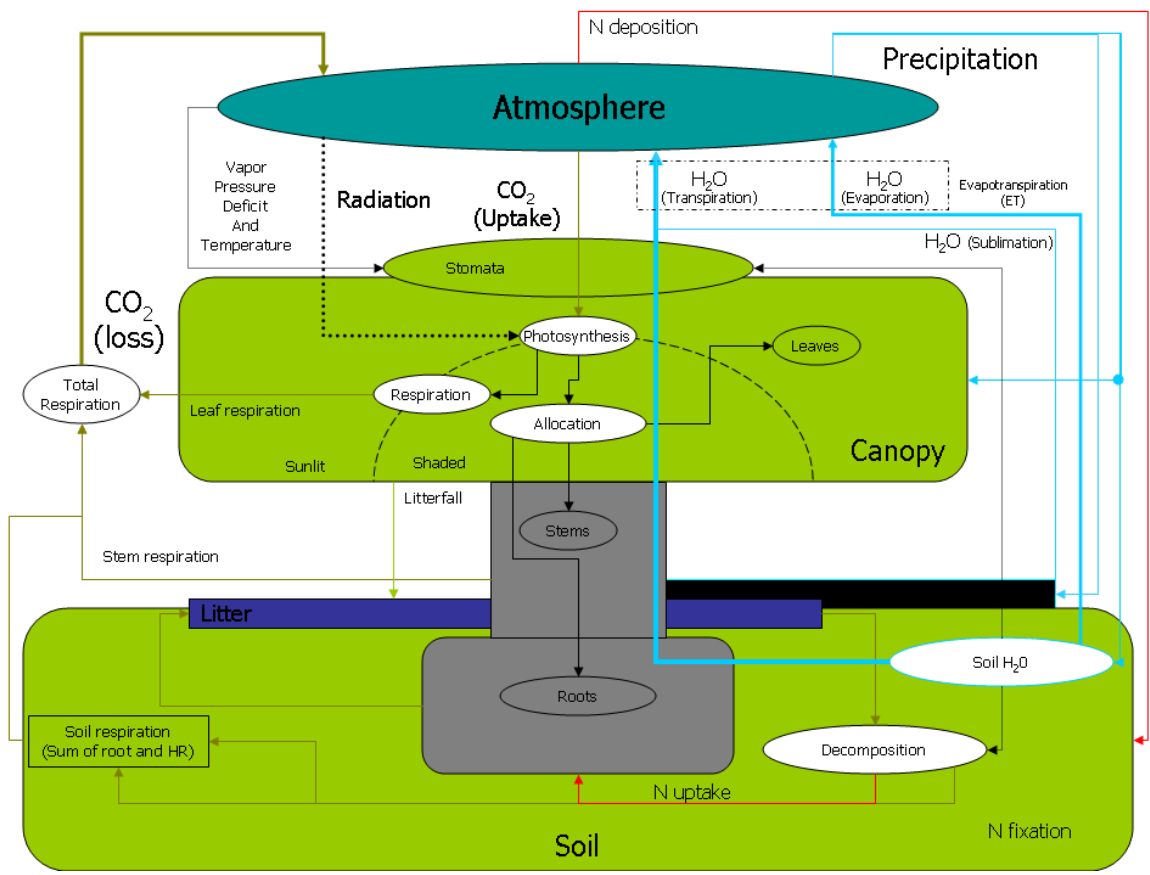

Figure 3-7. Biome-BGC detailed model flow chart (extracted from the Theoretically Framework of Biome-BGC, 2010)

Due to the objectives of this thesis, special attention deserves the simulation of the canopy transpiration. The canopy transpiration routine calculates the transpiration taking into account the leaf level and the stomatal conductances and using the Penman-Monteith equation. The Penman-Monteith equation is a general equation that relates the incoming radiation, vapor pressure deficit (VPD), the density of air, the specific heat of air, and the resistances to sensible heat flux and water vapor flux to the loss of latent heat by evaporation (Waring and Running 2007; Monteith and Unsworth 2008). For plant leaves, the PenmanMonteith equation considers the leaf level conductance to water vapor which is based on the stomatal conductance to water. To simulate the drivers of stomatal closure, Biome-BGC calculates a series of multipliers between 0 and 1 for: (1) photosynthetic photon flux density, (2) soil water potential, (3) minimum temperature, and (4) Vapor Pressure Deficit (VPD). The final multiplier is the product of these four multipliers. All this information is important to understand the discussion of the results. More details (not needed to be known for this 
thesis) can be found in the document: Theoretically Framework of Biome-BGC (2010).

\subsection{Methodology}

The LUE-Model was implemented following two steps: (1) calibration of the model only using the satellite NDVI and (2) validation using the available field measurements (transpiration and SWC. The performance of the model is then compared to that of the BIOME-BGC model by comparing the simulation results between them and with the field observations. The BIOME-BGC model was calibrated using the available field measurements as usual because we wanted to compare the results obtained by using a parsimonious model together with satellite data against the 'traditional' option of using a complex model together with field measurements.

The simulated period of both models included the period with available field data (27/03/2009 to $31 / 05 / 2011)$, as well as two different precipitation scenarios: dry (year 2005) and wet (year 2010). In particular, we computed the amount of 'blue water' (water in liquid form used for the human needs or which flows out the ecosystems) and the amount of 'green water' (water vapor form resulting from evaporation and transpiration processes) in order to obtain and compare the blue/green rate $(B / G)$ using both modelling alternatives.

As shown in the previous section, in the case of LUE-Model, the hydrological sub-model has eight parameters to be calibrated: (1) maximum interception storage, (2) the wilting point soil moisture, (3) field capacity soil moisture, (4) optimal point soil moisture, (5) effective depth of the first soil layer, (6) effective depth of the second soil layer, (7) distribution of roots and (8) coverage factor (

Table 3-4). With regards to the dynamic vegetation sub-model, there are five parameters to be calibrated: (1) LUE, (2) maximum LAI sustainable by the system, (3) light extinction coefficient, (4) SLA, Specific Leaf Area, and (5) optimal temperature (Table 3-5).

To calibrate both sub-models (thirteen parameters) we used the available NDVI data from $18 / 02 / 2000$ to $02 / 02 / 2013$. As NDVI is sensitive to green leaf biomass, it can be primarily employed to monitor the photosynthetically active biomass of plant canopies. As mentioned in Chapter 2, studies on various vegetation types (e.g., agroecosystems (Cohen et al.,2003), grasslands (Friedl et al., 1994), 
shrublands (Law and Waring,1994), conifer forests (Chen and Cihlar, 1996), and broadleaf forests (Fassnacht et al., 1997)) have led to the general conclusion that the spectral vegetation indices have considerable sensitivities to LAl. According to Turner et al. (1999), the relationship between LAI and NDVI can be considered as linear for low values. For this reason, the selected objective function was the Pearson's correlation coefficient between the simulated $\mathrm{LAl}_{r}$ and the satellite NDVI. Firstly, calibration was carried out using a manual adjustment of parameter's values and using values recommended in literature for each parameter (some sources were: Ceballos and Ruiz de la Torre, 1979; Calatayud et al., 2000 and others). Regarding to the wilting point, optimal point and field capacity, we used the values recommended by Caylor et al. (2005) for the same type of vegetation and in the same kind of environment. Specifically, we used $-0.015 \mathrm{MPa},-0.5 \mathrm{MPa}$ and $-3 \mathrm{MPa}$ for the field capacity, optimal point and wilting point, respectively (Figure 3-6). Using the relationships defined in Clapp and Hornberger (1978), these pressures were transformed into soil moisture. These values are not included in the calibration process.

Then, the model was calibrated automatically. This automatic calibration was carried out using a genetic algorithm called Evolver which looks for global maxima or minima. This algorithm needs initial values to start the calibration process and we used the values obtained during a previous manual calibration. The used initial values can be seen in Table 3-6 (next section) as well as the search range and the results of the calibration. Finally, the model was validated using daily field measurements of SWC and transpiration.

As explained previously, the Biome-BGC was calibrated and validated using daily transpiration and SWC. For calibration, the $70 \%$ of the field data was used, while the remaining $30 \%$ were used to validate the model. Data selection was carried out using a previous classification of the transpiration data into four classes, with class limits set at $(\mu-\rho), \rho$ and $(\mu+\rho)$ where $\mu$ is the average value and $\rho$ is the standard deviation. For each of the classes, the data was again separately classified according to the vapor pressure deficit range and season. In order to be sure that all four seasons were represented in both the calibration and the validation datasets, we used the $70 \%$ of each group to calibrate the model and the $30 \%$ to validate it. Finally, a t-test was applied to the both data sets and no significant statistical differences between sample means $(p \leq 0.05)$ was found. Since it is a model which works at $1 \mathrm{~m}^{2}$ scale (individual scale), it was applied in various trees and, later, we calculated an average of these 'individual' results. A 
more detailed description of this process can be found in González-Sanchis et al. (2015).

The performance of both models was analyzed comparing the simulation results to the field observations. The selected goodness-of-fit indexes were the Root Mean Square Error (RMSE), the Nash and Sutcliffe efficiency index (E) and the Pearson correlation coefficient (only for the LAI evaluation). As the main objective of this section is to know if a parsimonious model implemented only using satellite data can be used as alternative against a well-known physically-based model implemented using field measurements, we ran both models for a long period and, later, we compared the differences between them. The B/G water ratio was calculated using the results from each model. In our study case, on one hand, the Blue water is the excess water from the upper soil: i.e., surface runoff plus deep percolation. And, on the other hand, the Green water is calculated as the sum of the amount of water transpired by plants, the amount of water evaporated from the bare soil and the amount of water evaporated from the interception.

\subsection{Results}

In general, the calibration of the LUE-Model showed a strong positive relationship between the $\mathrm{LAl}_{\mathrm{r}}$ and the NDVI provided by satellite in the entire period (Figure $3-8$ ), with a Pearson correlation coefficient of 0.635 . The parameter values obtained during the calibration process are compiled in Table 3-6.

Table 3-6. Range of parameters values, initial values and final results obtained during the calibration process

\begin{tabular}{lllll}
\hline Parameter & Units & Initial value & Search range & Final value \\
\hline Maximum Interception storage & $\mathrm{mm}$ & 2.0 & {$[0.5-3.0]$} & 1.75 \\
Effective depth of the first layer & $\mathrm{mm}$ & 200.0 & {$[10,1000]$} & 100.00 \\
Effective depth of the second layer & $\mathrm{mm}$ & 800.0 & {$[100,5000]$} & 1100.00 \\
LUE & $\mathrm{Kg} / \mathrm{m}^{2} \mathrm{MJ}$ & 1.5 & {$[1.2,2.5]$} & 1.25 \\
Coverage factor & {$[-]$} & 0.8 & {$[0.1,1.0]$} & 0.90 \\
Distribution of roots & {$[-]$} & 0.3 & {$[0.0,1.0]$} & 0.10 \\
Maximum LAI & $\mathrm{m}^{2} / \mathrm{m}^{2}$ & 2.5 & {$[1.5,3.5]$} & 3.00 \\
Light extinction coefficient & {$[-]$} & 0.5 & {$[0.4,0.6]$} & 0.52 \\
SLA & $\mathrm{m}^{2} / \mathrm{kg}$ & 4.0 & {$[2.0,5.0]$} & 4.00 \\
Optimal temperature & $\circ \mathrm{C}$ & 18.0 & {$[10,30]$} & 15.00 \\
\hline
\end{tabular}


However, during the calibration, despite the fact that the simulated peak values of $\mathrm{LAl}_{\mathrm{r}}$ generally coincided with those of NDVI, a significant disagreement between both variables was obtained during two specific periods (shaded in Figure 3-8). During the first period, from July 2004 to December 2005, the LAl and the NDVI series were totally uncorrelated, especially during the beginning of this period. Likewise, in the second period, spring 2010, the simulated LAI maintained a high value while the NDVI decreased substantially.

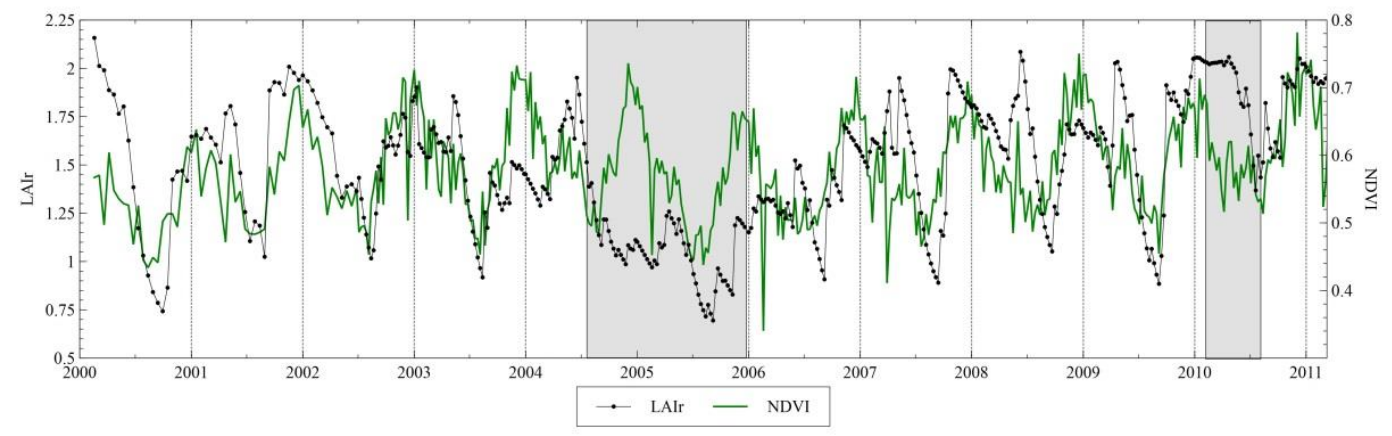

Figure 3-8. Comparison between $L A I_{r}$ simulated by the model and NDVI from satellite. The shaded areas correspond to the two specific periods with a significant disagreement between simulated $L A I_{r}$ and satellite NDVI

On the other hand, the validation of the LUE-Model with the field measurements showed a general agreement between the simulated and the measured SWC and transpiration (Figure 3-9), although the former appears to be more accurately reproduced (Table 3-7). The major disagreement in the prediction of transpiration values occurred during the spring of 2010 , which is the same period where the simulated $\mathrm{LAl}_{\mathrm{r}}$ and the NDVI were noticeably uncorrelated (Figure 3-8).

As mentioned before, the calibration and validation of the Biome-BGC was previously carried out in González-Sanchis et al. (2015) and the results are summarized in Table 3-7. The model predicted accurately SWC and transpiration, although like the LUE-Model, the Biome-BGC model also reproduced more accurately the dynamics of SWC (Figure 3-9). The E index is approximately 0.5 in the case of transpiration ( 0.532 in the calibration and 0.544 in the validation) while the same index in the case of SWC is higher than 0.7 ( 0.766 in the calibration and 0.715 in the validation). In any case, the obtained results were satisfactory in both, transpiration and SWC. 

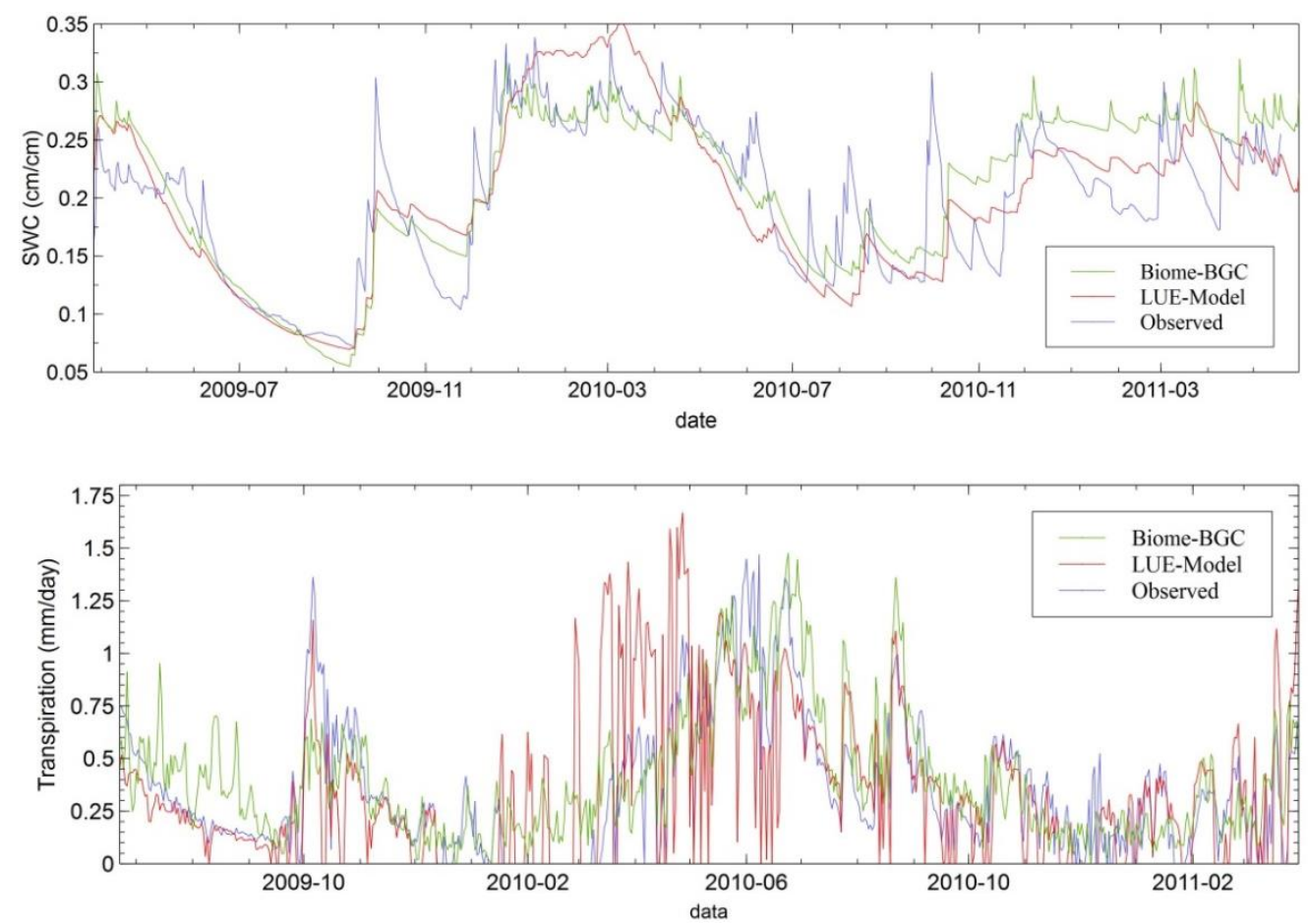

Figure 3-9. Transpiration (lower panel) and SWC (upper panel) measured in field and simulated by both models

Table 3-7. Results of the validation using field data for the LUE-Model and Biome-BGC models (observational period from $27 / 03 / 2008$ to $31 / 05 / 2011$ )

\begin{tabular}{lcccc} 
& \multicolumn{2}{c}{ Transpiration } & \multicolumn{2}{c}{ sWC } \\
\cline { 2 - 5 } & LUE-Model & Biome-BGC & LUE-Model & Biome-BGC \\
\hline E & 0.346 & 0.544 & 0.650 & 0.715 \\
RMSE & 0.274 & 0.209 & 0.051 & 0.070 \\
\hline
\end{tabular}

Therefore, both models reproduced with acceptable accuracy the water dynamics of the study site. In fact, the E indexes in terms of SWC were higher than 0.65 for both models (Table 3-7). However, as it was expected and it was shown by the selected goodness of fit indexes, the Biome-BGC appeared to be more accurate than the LUE-Model (Figure 3-9 and Table 3-7). Having compared the results of both models in a longer run (from 2004 to 2012 approximately), we can observe that there were not big differences between them (Figure 3-10). The agreement between SWC time series was very strong and it was better than the agreement between transpiration time series. But, in general, there were not big differences. 
In fact, the Pearson correlation coefficient values between them are 0.638 and 0.865 for the transpiration and SWC, respectively.

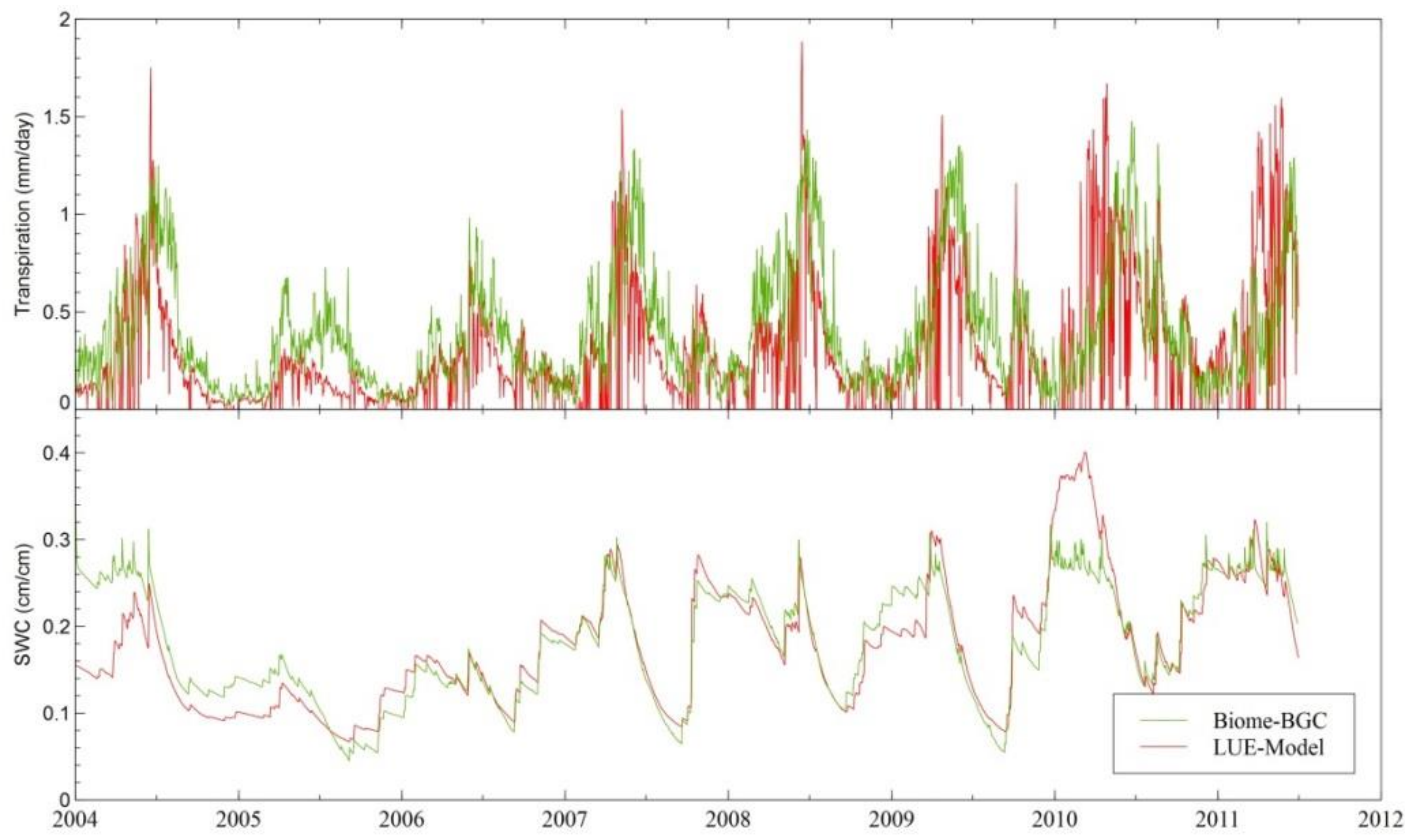

Figure 3-10. Transpiration (upper panel) and SWC (lower panel) time series simulated by both models (from 2004 to 2012 approximately)

Likewise, when estimating the general $B / G$ rate during the dry and the wet years, the models produce very similar results, with a rate around 0.1 in the dry year and around 0.8 in the wet year (Table 3-8).

Table 3-8. Results of each model in terms of Blue (exceedance) and Green (evapotranspiration) water

\begin{tabular}{|c|c|c|c|}
\hline & Flows & Dry year (2005) & Wet year (2010) \\
\hline \multirow[t]{4}{*}{ LUE-Model } & Precipitation (mm) & 188.00 & 739.00 \\
\hline & Evapotranspiration (mm) & 165.18 & 431.87 \\
\hline & Exceedance (mm) & 16.34 & 326.93 \\
\hline & $B / G$ & 0.098 & 0.757 \\
\hline \multirow[t]{4}{*}{ Biome-BGC } & Precipitation (mm) & 188.00 & 739.00 \\
\hline & Evapotranspiration (mm) & 156.30 & 408.80 \\
\hline & Exceedance $(\mathrm{mm})$ & 31.7 & 330.10 \\
\hline & $B / G$ & 0.104 & 0.807 \\
\hline
\end{tabular}




\subsection{Discussion}

In general, LUE and Biome-BGC models reproduced with acceptable accuracy SWC and transpiration values. Both models simulated more accurately SWC than transpiration dynamics, and a disagreement between simulated and observed daily transpiration can be found at certain periods for both models. The disagreement could be due to the fact that 2010 was an abnormally rainy period, and as an outlier, the models might not reproduce it properly. However, since the periods where the models performed with less accuracy were not the same, the high quantity of rain might not be the cause, or at least not the main one.

In order to identify the main reasons and understand why the models performances were different, a classification proposed by Del Campo et al. (2014) was used. Del Campo et al. (2014) grouped the simulated period in four spells according to the precipitation and the average daily temperature: Dry Cool (DC), Dry Warm (DW), Wet Cool (WC) and Wet Warm (WW). According to them, a dry spell was considered to begin when none of the previous 14 consecutive days registered a daily precipitation higher than $5 \mathrm{~mm}$. Obviously the other days were considered as wet spells. Hence, wet spell was set to a minimum to 14 days long, while dry spells was unlimited. On the other hand, a day was considered cool if its mean temperature was lower than $13.2^{\circ} \mathrm{C}$. Conversely, if the mean temperature of a day was higher than that temperature, it was considered a warm day.

Analyzing the performance of both models during each spell, it was possible to observe that both models behaved differently. The LUE-model did not reproduce accurately cool spells, either dry or wet, while the Biome-BGC was slightly less accurate when simulating dry spells, either cool or warm. Having analyzed the field data, it was possible to observe a significant linear relationship between transpiration and Vapor Pressure Deficit (VPD) during cool spells, which was stronger during WC spells (Figure 3-11). Contrarily, during warm spells, the transpiration was significantly correlated to the measured SWC (Figure 3-12). This behavior describes the general dynamics of the vegetation, where if soil water availability does not limit transpiration, it is expected that transpiration will be affected primarily by atmospheric evaporative demands (Monteith, 1965; Tanner and Fuchs, 1968). 

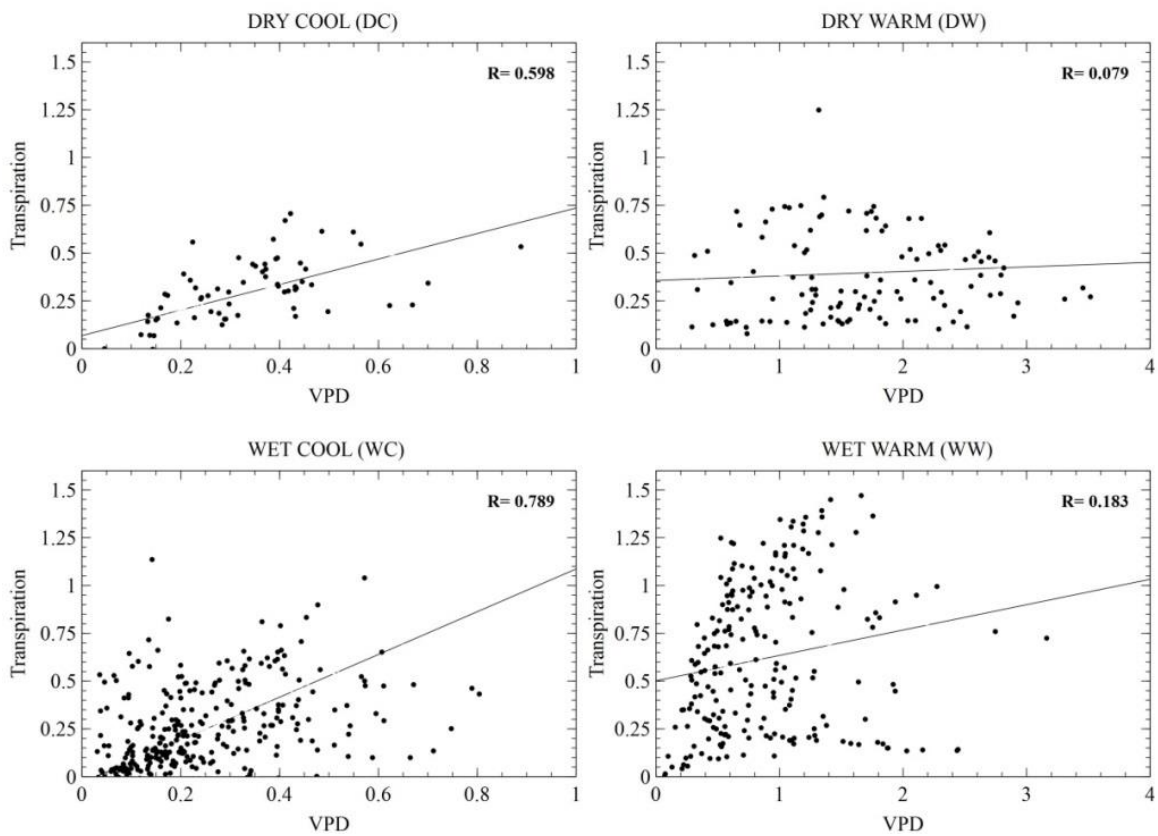

Figure 3-11. Linear correlation between transpiration and VPD during the different four groups stablished by Del Campo et al. (2014). $\mathrm{R}$ is the Pearson correlation coefficient
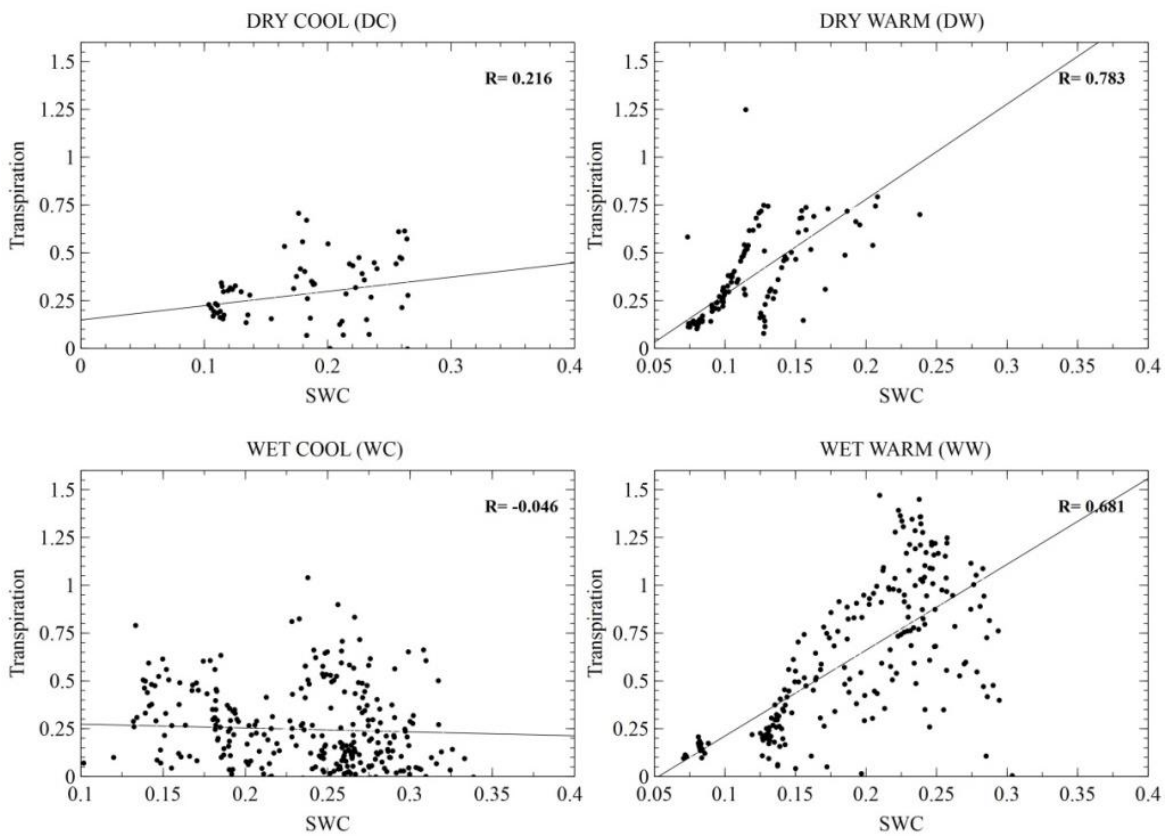

Figure 3-12. Linear correlation between transpiration and SWC during the different four groups stablished by Del Campo et al. (2014). $\mathrm{R}$ is the Pearson correlation coefficient 
Thus, the LUE-Model appeared not to include properly the atmospheric evaporative demands, and its performance during the periods when this demand prevailed over SWC was less accurate. But, the atmospheric evaporative demands should and could be included through a more accurate calculation of the $\mathrm{ET}_{0}$. Hence, these results did not highlight a limitation of the LUE-Model taking into account that the $\mathrm{ET}_{0}$ was calculated using the Hargreaves methodology which does not include the VPD in its definition.

With regards to the lower performance of the Biome-BGC model when simulating transpiration during dry spells, it was probably due to the fact that the model is not originally designed to reproduce arid or semi-arid environments. Hence, the performance of the model when simulating transpiration could decrease during drought periods because it does not take into account the different plants' strategies against droughts. Likewise, Jolly and Running (2004) used the BiomeBGC model to simulate drought-deciduous vegetation in the Kalahari and reported an underestimation of the transpiration. On the other hand, conversely to the LUE-Model, it had not problems when the limiting factor was the VPD. As explained in the description of the Biome-BGC model, it takes directly into account the VPD during the calculation of the canopy transpiration because it uses the Penman-Monteith equation and because the stomatal conductance is affected by a factor which is calculated according to the VPD.

As mentioned previously, when analyzing the performance of the LUE-model with satellite information, we observed that the main disagreement between $L A I_{r}$ and NDVI was produced during the period from July 2004 to December 2005, which was an extremely dry period. The precipitation during this period was $188 \mathrm{~mm}$, which is significantly lower than the annual mean precipitation registered in the study site $(466 \mathrm{~mm})$. Thus, according to the general dynamics of the vegetation, in this extremely dry period, the SWC would be expected to be the main driving factor of transpiration, and therefore, the performance of the LUE-Model was expected to be more accurate. Due to its conceptual structure, SWC and $\mathrm{LAI}_{\mathrm{r}}$ are highly correlated in the LUE-Model, and a significant decrease in SWC will also imply a significant decrease of $L A I_{r}$. However, the immediate response of $L A I_{r}$ to SWC variations during this particular dry period contrasted to that of NDVI, which appeared to be delayed a few months. NDVI values of arid or semiarid areas, as well as those of Mediterranean areas during the dry summer season, have been demonstrated to be strongly dependent on plant water availability in preceding days even months (Maselli, 2004). Given this fact, we did use LAI (and not 
directly LAI) as explained in sub-section 3.4.1. But, this strategy was not apparently enough in this extremely dry period. Thus, the disagreement between $\mathrm{LAl}_{\mathrm{r}}$ and NDVI found in this period is probably due to the late response of NDVI to a severe drought period. Indeed, after this drought period, NDVI decreased until August 2006, where the regression between LAI ${ }_{r}$ and NDVI, although significant (sig. <0.05) showed a low regression coefficient of 0.2. Contrarily, from August 2006 onwards, NDVI started to increase again probably as a response of the rain during the winter of 2006, and the regression coefficient increased to 0.69 .

The other disagreement between $\mathrm{LAI}_{\mathrm{r}}$ and NDVI was produced during the first half of 2010. Conversely to the previous period, 2010 was an abnormally rainy period. In this case, $L A I_{r}$ increased and remained with high values almost the first half of 2010. On the contrary, the increasing of NDVI was not observed until August, when the regression coefficient between $L A I_{r}$ and NDVI increased from 0.29 to 0.61 . In this case, the disagreement could be due to the $\mathrm{ET}_{0}$ did not take into account the limitation produced by the VPD as discussed above. However, with these exceptions, the LUE-Model captured well the dynamic of the vegetation provided by NDVI.

Likewise, the estimation of the general $B / G$ water balance using the LUE-Model and the Biome-BGC model produced very similar results when simulating both dry and wet years (Table 3-8). The similarity of the results enhanced the capability of the parsimonious LUE-Model to distribute water, which was very similar to that of the physically-based Biome-BGC model. But, the most important conclusion is that both models obtained a $B / G$ water ratio below 1 , i.e. more than half of the total annual rainfall would be consumed by the ecosystem and returned to the atmosphere, and a short quantity of water would be able to supply the catchment. A proper distribution of Blue and Green water is essential for a model as it raises the question of a loss of services that ecosystems provide to human and also the amount of available water to be used by vegetation. Particularly, in Mediterranean ecosystems, where the global climate change scenario predicts an increase in dry years over normal and wet periods (Giorgi and Lionello, 2008), an accurate distribution of the Blue and Green water is fundamental when designing water (and forest) management policies.

\subsection{Conclusions}

The results in this research suggest that the parsimonious model is able to adequately reproduce the dynamics of vegetation (the correlation coefficient with 
the satellite and field transpiration data are acceptable), and it also reproduces properly the soil moisture variations. In other words, it has been shown that a parsimonious model with simple equations can achieve good results in general terms, and it is possible to assimilate satellite information for the model implementation.

However, it also has been observed that the LUE-Model's accuracy is worse when the transpiration is limited by the atmospheric demands. It is important to mention that the LUE-Model used the $\mathrm{ET}_{0}$ during the calculation of the transpiration. As the LUE-Model implementation represented such situation in which there is not field information, the $\mathrm{ET}_{0}$ was calculated by Hargreaves and Samani method (this method only needs information of temperatures and radiation).

On the other hand, in this section, the satellite data played a key role in the implementation of the model. In fact, the measured transpiration data were available only for about two years as a field observation of the vegetation state and evolution. In this case, the satellite data was a very useful source of information, and its combination with the parsimonious LUE-Model demonstrated to be an accurate tool capable of predict the role of the vegetation in the water cycle with no field data.

Finally, we want to emphasize that it is known that the proposed model has limitations due to its simplicity. The accuracy of the results also depends on the quality of the observed data and, obviously, the satellite data has to be used with caution. Especially if we are focusing in just one pixel as it is the case in this previous stage of the thesis. It is clear that the advantages of using satellite data will likely increase when used at catchment scale. But, in our opinion, it was important to explore alternative sources of information, such as satellite data, and create models which can be implemented using this kind of information to be used where or when no field observations are available. There could be better models with better results but, this study wants to be a success example about how far a parsimonious model together with satellite data can arrive.

But, all this work was made at plot scale and the main objective of our research was the adaptation of a dynamic vegetation model which can be used at catchment scale. If the spatial scale is increased, the model has to take into account the dynamic growth of the vegetation but, also, its pattern. At the same time, at basin scale, we will use temporal maps of information. It means, we will 
not use the observed temporal series in only one pixel but spatial maps distributed in time. In the following chapter, we deal with the use of spatiotemporal data and we propose a methodology to handle this kind of information at catchment scale. 
On the use of satellite data to calibrate a parsimonious ecohydrological model in ungauged basins Doctoral Thesis 


\section{CHAPTER 4. AT CATHMENT SCALE: SPATIO-TEMPORAL MODELLING}


On the use of satellite data to calibrate a parsimonious ecohydrological model in ungauged basins Doctoral Thesis 


\subsection{Introduction}

This chapter addresses the original main purposes of this research: (1) the adaptation of a parsimonious ecohydrological model to be used distributed at basin scale and, (2) practical use of satellite data in order to calibrate and validate the proposed model.

In Chapter 2, we have discussed about the two possible strategies in order, at least, to reduce the 'scarce data - high parametrical requirements' issue. As mentioned, in this thesis we used a parsimonious ecohydrological model avoiding in this way a high parametrical requirement and we investigated the potential utility of satellite data.

The incorporation of new sources of information such as satellite data is even more interesting in places located in undeveloped countries where is hard to install and keep in operation the needed instrumentation. One example of these places is sub-Saharan Africa where the study area of this chapter is located. In this region, researchers often face the problem of extensive parametrical requirements and limited available data. Satellite remote sensing data may be able to fill this gap. But, these data require novel methodologies to exploit their spatio-temporal information that could potentially be incorporated in ecohydrological model calibration and validation.

In Chapter 3, we took the first steps regarding to the use of satellite data calibrating the LUE-Model exclusively with the NDVI included in the MODIS products and provided by NASA. In this first experience, we only took advantage of the temporal information provided by the satellite data, because the model was applied at plot scale. But, it is important to mention that the satellite data contain both, spatial and temporal information. In this context, the dual challenge of this fourth chapter is: (1) to adapt the model to be used at catchment scale and (2) to propose a methodology in order to calibrate the model using the spatio-temporal information provided by satellite data.

To address this dual challenge, the distributed version of the parsimonious ecohydrological model proposed in the previous chapter was applied in a basin located in Kenya, concretely in the Upper Ewaso Ngiro River basin. The study area was again located mostly in a water-controlled environment because our interest in these ecosystems and, because the used and slightly modified LUEModel (Pasquato, 2015) was originally designed to be used in this kind of 
environments (nutrients cycle is not simulated, i.e.: nutrients cannot be a limiting factor). As done at plot scale in the previous chapter, the model was calibrated only using NDVI data derived from MODIS.

Regarding the use of spatio-temporal data, a semi-automatic calibration procedure, based on Empirical Orthogonal Functions (EOF) techniques, was proposed and applied in the study area. This methodology is deeply explained in the next section 4.5.1 where the context, references, mathematical definition, meaning and procedure are detailed. Furthermore, as a novel contribution in this sense, we used this methodology to calibrate automatically the model which was a great challenge taking into account that, to our knowledge and in this field, this methodology had never been used in an automatic calibration.

It is important to say that this section of this doctoral thesis was thanks to an international collaboration between the Universitat Politècnica de València (Spain), Università degli Studi della Basilicata (Italy) and Princeton University (NJ, USA). The results originated a paper entitled 'Calibration of a parsimonious distributed ecohydrological daily model in a data scarce basin using exclusively the spatio-temporal variation of NDVI' which is still under revision.

\subsection{Study area: Upper Ewaso Ngiro River basin}

The Upper Ewaso Ngiro River basin is located in the Laikipia region of Kenya. The basin, with a drainage area of $15,200 \mathrm{~km}^{2}$ approximately, is surrounded by the Mount Kenya (South East) and the Aberdare Mountains (South West). As Kenya is located on the equator, the Intertropical Convergence Zone (ITCZ) affects the rainy regimes causing two distinct rainy and dry seasons. The first rainy season occurs from March to May (long rains), while the second rainy season occurs from October to December (short rains). It is important to mention that the general trend in the rainfall coefficient of variance correlates negatively when moving from dry to wetter regions, i.e. dry regions have the most variable rainfall creating very stressful growing conditions. A full and deep description of the rainfall pattern in this catchment was provided by Franz (2007).

Soil texture ranges from sandy clay to clay soils. Franz (2007) used qualitative descriptions for the basin collected from the 1980 Unesco Kenyan soil map and, from the fifty-five different soil types identified in the study area, eleven categories were obtained. Figure 4-2 illustrates the soil type map used in this thesis. 
Regarding to the land use, we used a land classification dataset constructed with the surface reflectivity measured by AVHRR satellite in previous projects (Franz et al., 2010). Briefly, elevations are dominated by forest and a large piece of land has been converted to cropland mainly the mid-latitudes of the basin. The remaining of the basin is classified as grassland, shrubland and wooded grassland (Figure 4-3).

In order to give a global vision of the current land uses, it is relevant to review the historical development of the farming system in Kenya and in the sub-Saharan Africa in general. In the early twentieth century large plantations were established throughout sub-Saharan Africa by individual settlers and, increasingly, large corporations such as Del Monte and Firestone (Smalley, 2013). In east and southern Africa, plantations were most extensive in the settler economies of Kenya, Zimbabwe and South Africa (Thompson, 1941; Jamal, 1993; Gibbon, 2011). But, the challenges facing those large plantations grew after nation states won independence from colonialism in the late 1950s and 1960s (1963 in the case of Kenya). First, the gradual arrival of worker legislation made labour more expensive for firms (Watts, 1994; Vermeulen and Cotula, 2010). Second, their land holdings became increasingly vulnerable to takeover by new African governments (Acland, 1971; Jamal, 1993; Sender and Jonhston, 2004). Third, they had begun to make more money in other areas such as shipping and marketing (Oya, 2012). These three developments explain the decline of large foreign plantations and their shift to small scale farming. This small scale farming is not supported by a proper irrigation system and local people depend on rainfall to water their land (Ngigi et al., 2008). Some researches point out that this small scale farming is going to cause greater stress on local water supplies due to the increasing population (mainly immigration) and illegal extractions from the river (e.g. Aarts, 2012).

Precisely, due to this land use change together with climate change and population increase, the Upper Ewaso Ngiro River basin is of particular interest. Furthermore, the majority of the basin $(\approx 80 \%)$ is in highly stressed conditions as shown by a simple water budget analysis carried out by Franz (2007). In this analysis, the irrigation was neglected because the small scale farming lacks an irrigation system. He calculated the annual runoff ratio, which is the ratio of annual precipitation to runoff, in order to characterize the potential stress of the basin. Basically, areas with runoff ratio greater than 0.4 are considered as water rich, whereas, areas with values lower than 0.4 are considered water stressed. The $80 \%$ of the basin has runoff ratios lower than 0.4 . 


\section{Upper Ewaso Ngiro river basin}

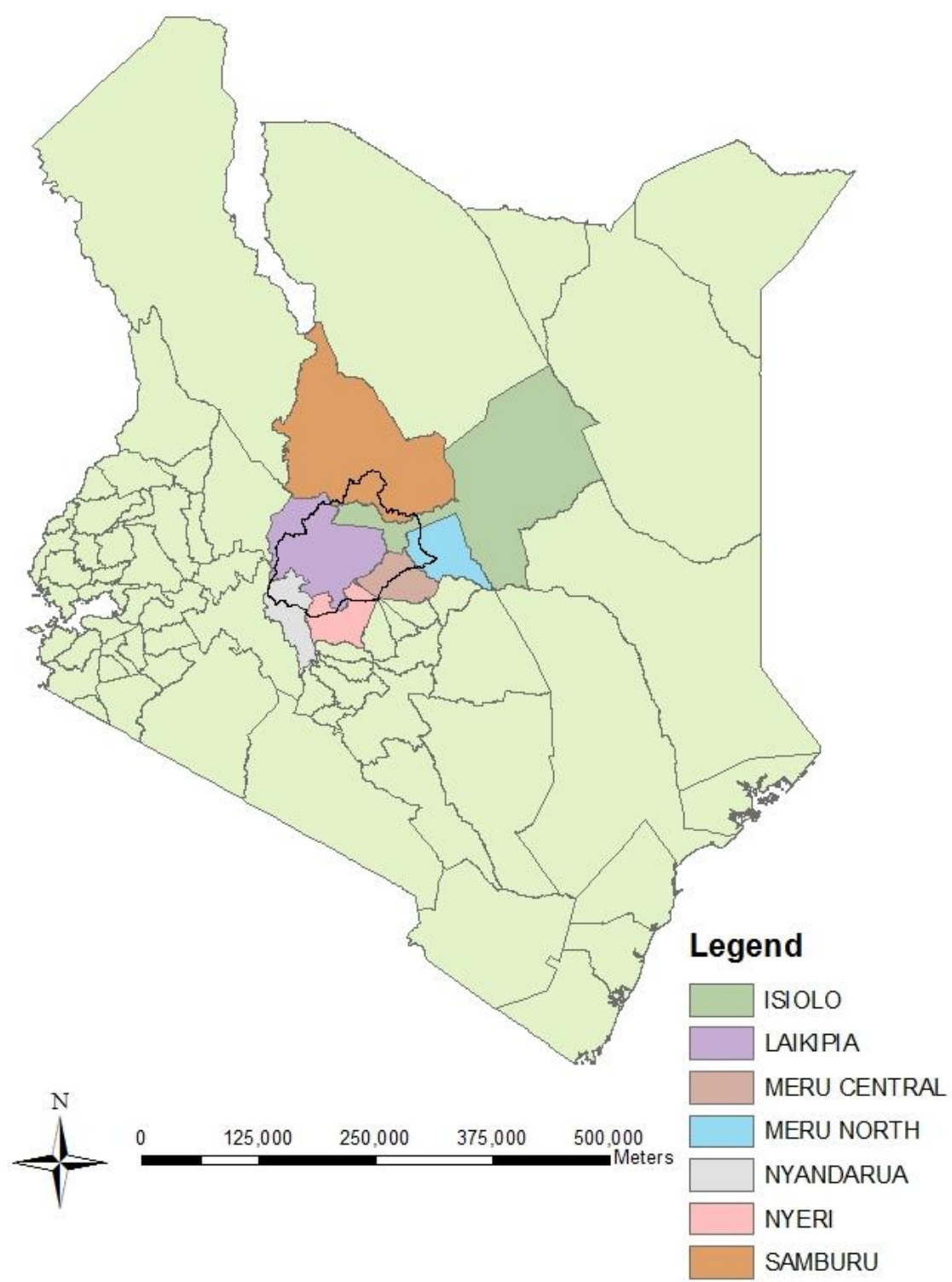

Figure 4-1 General map location of the upper Ewaso Ngiro River basin within the boundaries of Kenya and the major districts where the basin is located 


\section{Soil Type Cover}

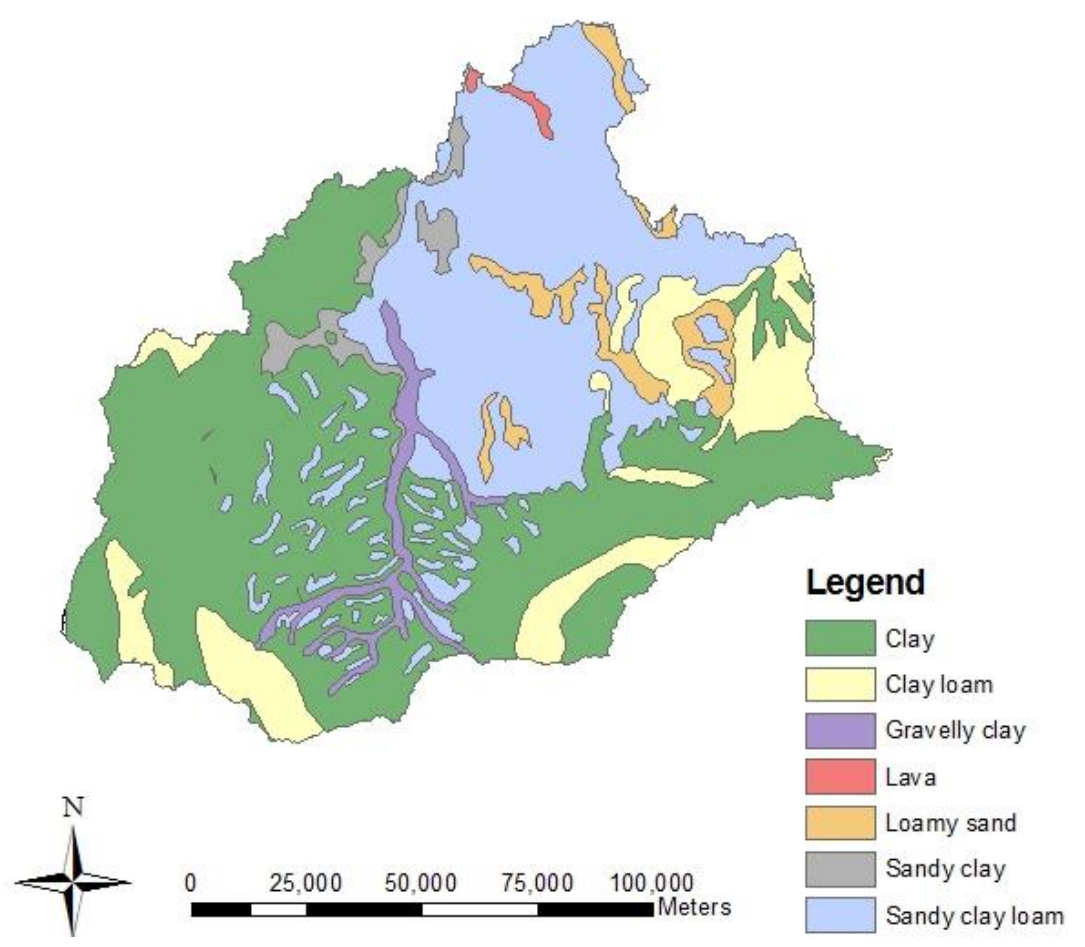

Figure 4-2. Spatial distribution of soil types for the basin. Source of data: 1980 Unesco Soil Map modified by Franz (2007) 


\section{AVHRR Land Cover Classification}

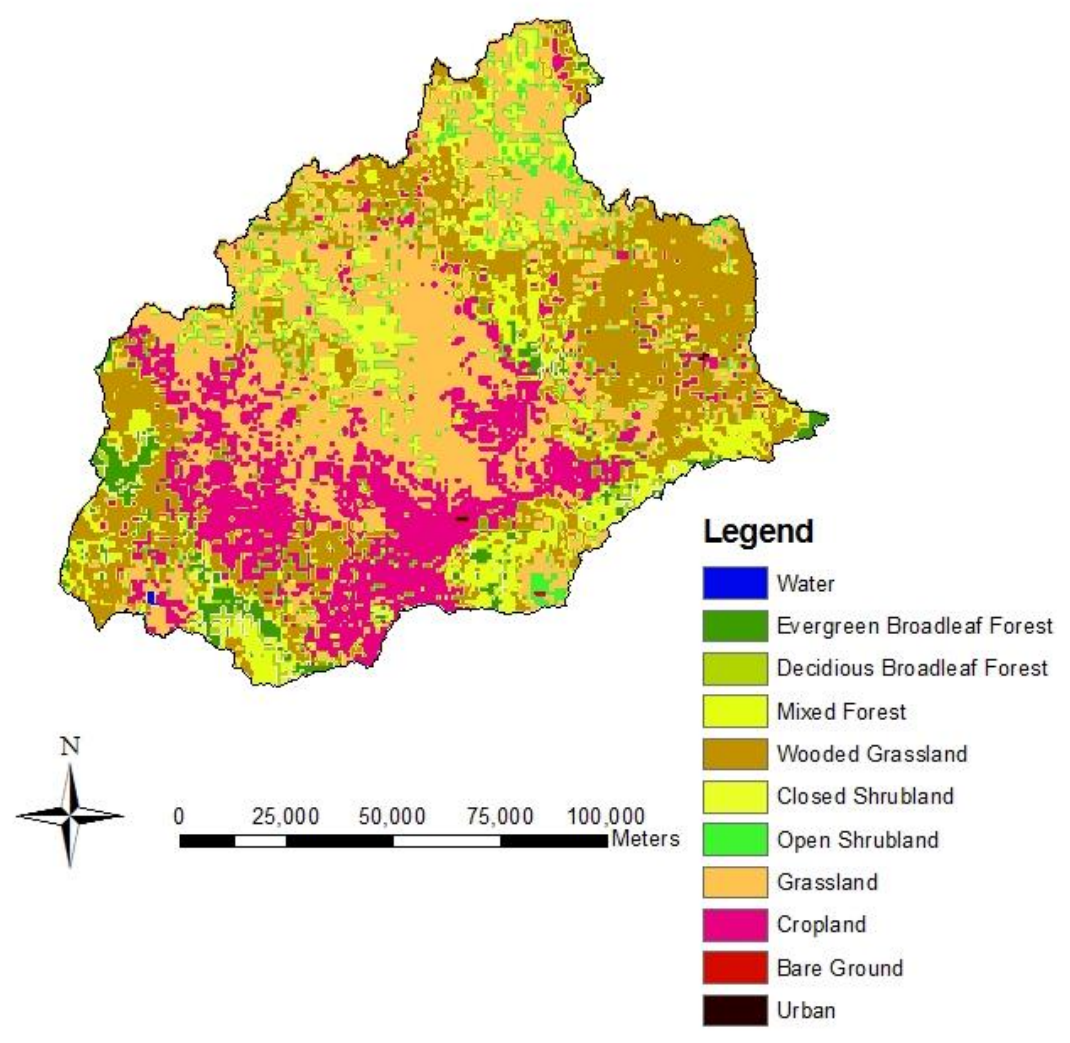

Figure 4-3. Land classification map of watershed. Source of information: AVHRR data modified by Franz (2007) 


\subsection{Data}

We used daily precipitation gauges with records from 1959 to 2003 provided by the Natural Resource Monitoring, Modeling and Management Project (NRM3) of Nanyuki, Kenya (illustrated by dots in Figure 4-4). Temperature and solar radiation records were obtained at the same stations. The reference evapotranspiration ( $E T_{0}$ ) was calculated using the Penman-Monteith equation, with the simplifications proposed by Allen et al. (2006). This approach is extremely useful to describe the spatial distribution of solar radiation and to derive the $\mathrm{ET}_{0}$ maps during any phase of the year (Manfreda et al., 2013). Due to the heterogeneity of precipitation gauge stations and since all different aspects of the basin were included, we decided to work with the sub-basin marked in Figure 4-4 (around 4,600 $\mathrm{Km}^{2}$ ). We also used the observed discharge of this sub-basin's outlet where data was available from 1980 to 2002 at daily scale.

\section{Upper Ewaso Ngiro river basin}

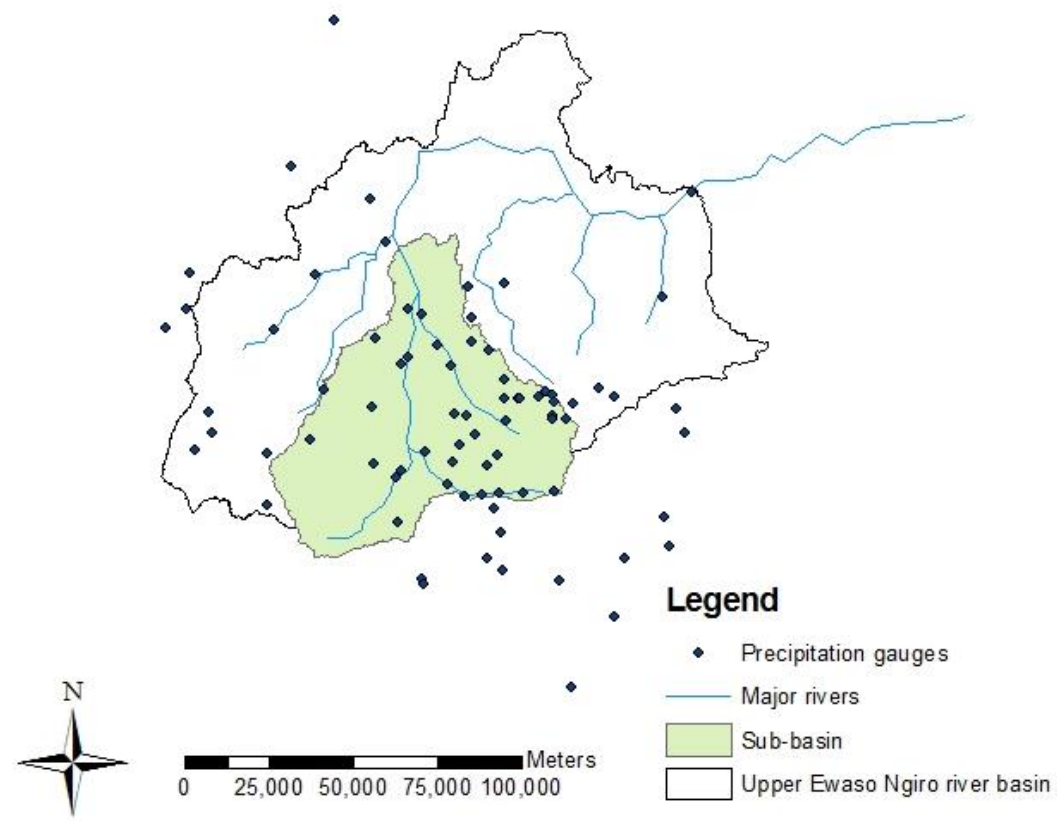

Figure 4-4. The study sub-catchment (in green) was selected because the density of the rainfall stations (dots in dark blue) 
Regarding to the satellite data, we employed the same satellite products as in the previous chapter: the NDVI included in the MOD13Q1 and MYD13Q1 products provided by NASA. As specified previously, these satellite products are provided every 16 days at 250-meter spatial resolution and they are available from 2000 to nowadays. Particularly in this case, due to the coverage of the study site, the h21v08 and h21v09 tile are required.

\subsection{Model description: TETIS-VEG}

The proposed model, the TETIS-VEG model, is a distributed hydrological model called TETIS (GIMHA, 2014) coupled with the LUE-Model (described in the previous chapter) as dynamic vegetation sub-model. Both models have simplicity in model structure in common. The used equations are as simple as possible in order to reduce the number of parameters. The sub-models (i.e.: hydrology and vegetation) are connected because the transpiration calculated in the hydrological sub-model depends on the LAl simulated by the dynamic vegetation model. At the same time, the simulated LAI depends on the water stress which is calculated using the hydrological sub-model. A more detailed description of this link can be found in Chapter 3. The hydrological sub-model can be used at different time scales (from minutal to daily) while the vegetation dynamic submodel has to be applied at daily scale. Hence, the TETIS-VEG model must be used at daily scale.

The TETIS model's conceptual scheme (Figure 4-5) consists on a series of connected reservoirs, each one representing different water storages in the soil column: interception (rainfall interception and water detention in puddles), first static soil layer (retained water by upper soil capillary forces, evaporation and transpiration can occur), second static soil layer (retained water by soil capillary forces, only transpiration can occur), surface, gravitational (upper soil water content above field capacity) and aquifer. Vertical connections between reservoirs describe the precipitation, evapotranspiration, infiltration and percolation processes. The horizontal flows describe the three different hydrological responses that give the discharge at the catchment outlet: overland runoff, interflow and baseflow. A more detailed description of the TETIS model can be found in GIMHA (2014).

The TETIS model uses a split-structure for the effective parameter value at each cell (Francés et al., 2007). The effective parameter is calculated using a 
correction factor (a scalar) multiplied by the estimated value of the parameter in each cell using all the available information (land use map, soil type map, DEM, deep of the soil layer, etc.) and expert's knowledge. In other words, this calibration strategy consists on an application of a scalar multiplier to each prior parameter field (specified from data describing watershed characteristics: soils, vegetation, topography, land use, etc.) and to estimate a "best" value for this multiplier via calibration (e.g., Francés and Benito, 1995; Bandaragoda et al., 2004; Canfield and Lopes, 2004; Eckhardt and Arnold, 2001; Francés et al., 2007; Pokhrel et al., 2008; Vieux et al., 2004; Yatheendradas et al., 2008). In this way, in a model with $\mathrm{Ng}$ grid cells and $\mathrm{Np}$ parameters per cell, the dimension of the calibration problem is thereby reduced from $\mathrm{Ng}^{*} \mathrm{~Np}$ to $1^{*} \mathrm{~Np}$. This so-called "multiplier" approach makes the assumption that the prior parameter field properly describes the spatial pattern of parameter variation (the pattern of relative magnitudes from cell to cell), but that the magnitudes of all the parameter values must be adjusted to achieve a better simulation of the model response.

Hence, we can distinguish between two parts: (1) a common correction factor for each type of parameter that takes into account the model, information and input errors and the temporal and spatial scale effects; and (2) the estimated parameter value at each cell. With the split-parameter structure, only nine correction factors were calibrated for the hydrological sub-model. Each one related to one of these estimated parameter maps: maximum static storage, evapotranspiration, infiltration capacity, slope velocity, percolation capacity, horizontal saturated conductivity for interflow, horizontal saturated conductivity for baseflow and channel movement.

The TETIS model becomes in TETIS-VEG when it is coupled with a dynamic vegetation sub-model. This dynamic vegetation sub-model was the LUE-Model described in the previous chapter. 


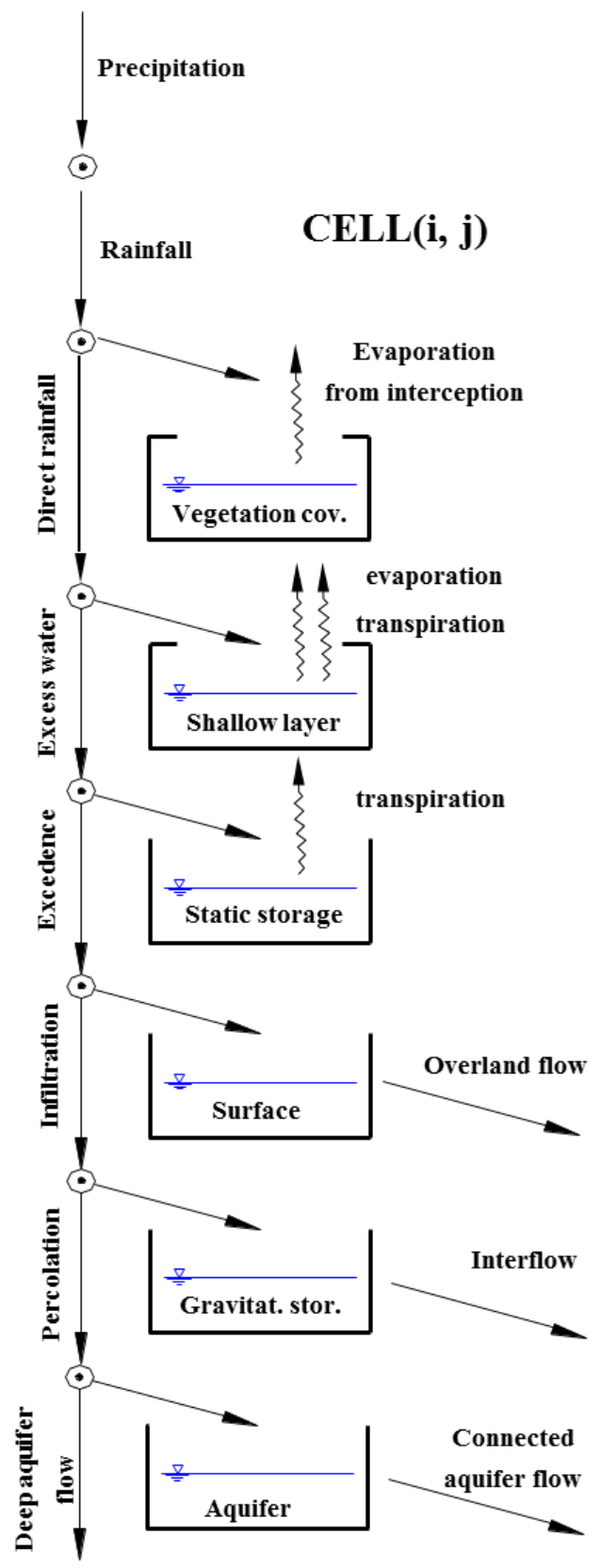

Figure 4-5. The conceptual scheme of the TETIS model used as the hydrological sub-model in this research 


\subsection{Methodology}

The work was carried out into three different steps: a manual calibration of the parameters, an automatic calibration of the parameters and a validation of the model. All of these steps are based on the idea that LAI and NDVI are intimately related. This link was discussed in Chapter 2.

One of the main objectives of this work was to explore the potential of the satellite for model calibration. Hence, we wanted to calibrate the TETIS-VEG model only using satellite data. Observed precipitation and temperature were available from 1960 to 2003 while the MODIS NDVI was available from 2000 to nowadays. We decided to use the year 2003 as the calibration period because it is the year in which there was satellite data but not observed streamflow. Very important: we wanted to calibrate the model only using satellite data. While the years 2000, 2001 and 2002 were used as the validation because, during these three years, satellite data and observed discharge were available. In order to avoid the effect of the initial conditions, we used one year as warming up period (the year 2002 and 1999 for model calibration and validation respectively).

In both cases, manual and automatic calibrations, we used the Empirical Orthogonal Function (EOF) analysis, as described in next section.

\subsubsection{EOF analysis}

The EOF analysis is a method for analyzing the spatial and temporal variability of geophysical fields. The description given here is far to be complete because we only want to introduce the topic and explain how we used this analysis for our purposes. Those who wish acquire further knowledge about this analysis should read some specific references. The book entitled 'Principal components analysis in meteorology and oceanography' written by Preisendorfer and Mobbley (1988) can be considered as the landmark book about EOF analysis. Another reference is the text book edited by Von Storch and Navarra (1995). In this case the main topic is the climatic variability, but it contains a review of methods for the analysis of patterns in geophysical fields together with some practical applications. Although these two references are the most complete and mathematically correct ones, they are at some point a little bit 'unfriendly'. In our opinion, for beginners with mathematical inclinations, the best option is the book entitled ' $A$ manual for EOF and SVD analyses of Climatic Data', written by Björnsson and Venegas (1997). 
The EOF method is used to analyze the spatio-temporal variability of a single variable but, comparison between different variables can also be performed using coupled EOF techniques (Björnssson and Venegas, 1997). The method identifies the most important patterns of spatial variability, their time variation, and presents a measure of the 'importance' of each spatial pattern. We refer to the spatial patterns as the EOFs (in literature, they are also called as principal components or even longer 'principal component loading pattern'), and to the time variation as loadings (in literature, there are several terms: expansion coefficient time series, expansion coefficients, EOF time series, principal components time series, etc.).

In practical application, it has been shown that EOF analysis is a useful methodology to investigate the spatio-temporal patterns of fluxes and states in the soil-vegetation-atmosphere continuum (Fang et al., 2015). In particular, Koch et al. (2015) carried out a validation of a distributed model using satellite based land surface temperature data by means of an EOF analysis. With other statistical purposes, the EOF analysis was used by Graf et al. (2014), Kim and Barros (2002) and Liu (2003). In a really different working scale (they analyzed the first centimeters of soil) Drewry and Albertson (2006) used the EOF analysis to associate spatial pattern in the errors of a canopy-atmosphere model with errors in the parameters. But, to our knowledge, the EOF analysis has not been applied in a model calibration yet. In this research, we used the EOF analysis during the model calibration and, moreover, we proposed a methodology which can be run automatically.

But first, it is necessary to explain how to use this methodology. The EOF method is essentially a linear algebra methodology based on matrix transformation. That's why the first step is the conversion of the spatio-temporal data to be analyzed into a matrix. Basically, we construct a matrix $(F)$ in which each column is the temporal variation of the data in a particular pixel/location while each row is the pixel/location values during a particular time step. Hence, if we had measurements of some variable at locations $x_{1}, x_{2}, \ldots x_{p}$ taken at times $t_{1}, t_{2}, \ldots . t_{n}$, we would obtain a matrix which size becomes $n$ by $p$ as shown in Figure 4-6. Then, usually, the second step is the obtaining of the anomalies of the analyzed data which was not needed in this study because we used normalized data (for reasons that will be explained later). 


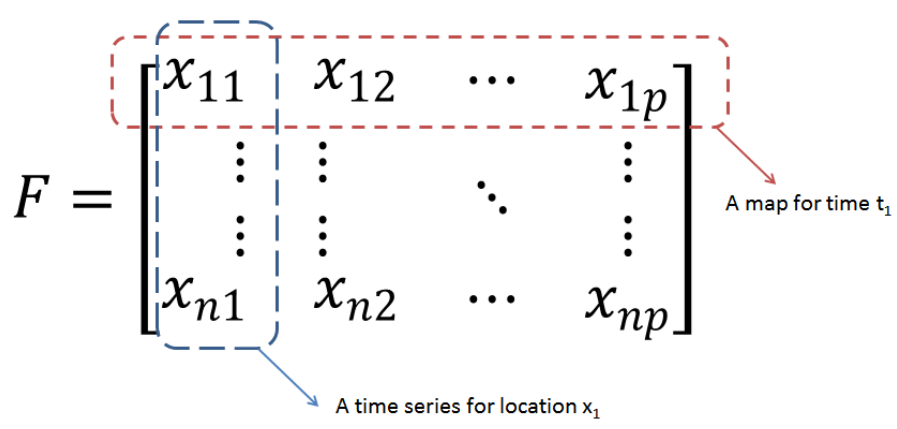

Figure 4-6. The matrix F. Each row is one map, and each column is a time series of observations for a given location

The next step of the applied EOF method consists on the calculation of the spatial F's covariance matrix $(R)$ according to equation [ 19 ]. Then, the eigenvalue problem is solved ${ }^{2}[20$ ].

$R=F^{T} * F$

$R * C=C * \Lambda$

$\Lambda$ is a diagonal matrix containing the eigenvalues $\lambda_{i}$ of $R$. The $c_{i}$ column vectors of $\mathrm{C}$ are the eigenvectors of $\mathrm{R}$ corresponding to the i-respective eigenvalues. Each of these eigenvectors can be regarded as a map. These eigenvectors are the EOFs. In what follows, we always assume that the eigenvectors are ordered according to the value of the eigenvalues. Thus, EOF 1 is the eigenvector associated with the biggest eigenvalue. The fraction of the total variance in $R$ explained by EOF $F_{i}$ is found by dividing the $\lambda_{i}$ by the sum of all the other eigenvalues. The time evolution of an $\operatorname{EOF}_{\mathrm{j}}\left(\overrightarrow{a_{j}}\right)$ is calculated according to equation [ 21 ]. The components of this time vectors are referred to as loadings in this document.

$\overrightarrow{a_{\jmath}}=F * E O F_{j}$

${ }^{2}$ Since $\mathrm{R}$ is a quadratic matric, $\mathrm{C}$ will have the property that $C^{-1}=C^{T}$ so equation 20 can just as well be written $R=C * \Lambda * C^{T}$. These two equations are used interchangeably. 
Using the spatial covariance calculated according to the equation [ 19 ], the EOF technique provides three different results: the main patterns or EOFs, their time evolution whose components are called loadings and the portion of spatial variance explained by each EOF which is calculated dividing each $\lambda$ by the trace of $\Lambda$.

Generally, the first EOF $F_{i}$ (with the higher $\lambda_{i}$ ) dominate the remaining of EOF. According to the idea of this analysis, this means that most of the behavior in our spatio-temporal data can be explained by just a few spatial patterns and their temporal variations. Precisely this is the main objective of this analysis because we use this method in order to reduce the data to a few different modes of variability. EOF analyses, and all its relatives (such as Empirical Normal Modes, Fourier decomposition, Wavelet-decomposition, etc) are methods that try to reduce the size of the analyzed data (Björnsson and Venegas, 1997).

Finally, some lines about the Singular Value Decomposition method (SVD) are given here due to its intimate connection with the EOF method. A non-expert reader could be quite confusing when it comes to discuss the connections between these two methods. Basically, the SVD method is a generalization to rectangular matrices of the diagonalization of a square symmetric matrix ${ }^{3}$ like in the EOF method (Björnsson and Venegas, 1997). The SVD method consists on the decomposition of any $\mathrm{n} \times \mathrm{m}$ rectangular matrix $\mathrm{F}$ according to equation [ 22 ].

$F=U * \mathrm{~T} * V^{T}$

where $\mathrm{U}$ is an $\mathrm{n} \times \mathrm{n}$ orthonormal matrix, $\mathrm{V}$ is an $\mathrm{m} \times \mathrm{m}$ orthonormal matrix and $\mathrm{T}$ is a diagonal $\mathrm{n} \times \mathrm{m}$ matrix with $\rho$ elements down the diagonal.

In order to identify the connection between the both methods, we form de covariance matrix $R$ calculated according to equation [ 19 ], and then do a SVD on $\mathrm{F}$ (the matrix constructed as shown in Figure 4-6). All this process is showed in equation [ 23$]^{4}$.

3 As explained above, the EOF method is applied to the covariance matrix and by definition the covariance matrix is a square symmetric matrix.

4 In order to understand the procedure, it is important to take into account that $U$ is an orthonormal matrix so $U^{T} * U=I$, being I the identity matrix. 


$$
\begin{gathered}
R=F^{T} * F=\left(U * \mathrm{~T} * V^{T}\right)^{T} *\left(U * \mathrm{~T} * V^{T}\right)=V * T^{T} * U^{T} * U * T * V^{T} \\
=V * T^{T} * T * V^{T}
\end{gathered}
$$

By comparing the equation in note 2 and the equation [ 23 ] it should be clear that $C=V$ and $\Lambda=T^{T} * T$. Hence, $\lambda_{i}=T_{i, i}{ }^{2}$. Following this demonstration, it can be said that the result obtained by application of the EOF method to the covariance matrix of $F(R)$ is equal to that one obtained by application of the SVD method to $F$ directly. That's why it has been said that at heart of the EOF method lies the technique of SVD (Björnsson and Venegas,1997). In fact, in this work, we used the SVD library available in Python, specifically called "scipy.linalg.svd".

\subsubsection{Manual calibration}

There is no dispute about the fact that due to observational and model conceptualization errors and time and space scale effects, any mathematical model must use effective parameters for a better reproduction of reality (Blösch and Sivapalan, 1996; Francés et al., 2007). The main reason of the calibration (manual or automatic) of a mathematical model is therefore to obtain the effective values of its parameters.

Particularly, this manual calibration was done with a dual purpose. First, we wanted to test the applicability of the proposed model in the study basin. Up to now, we only had tested the model at plot scale and we did not know its accuracy at catchment scale. Second, we wanted to obtain a first approximation for the parameters and, in this way, to constrain the automatic calibration. Basically, this manual calibration consisted on the usual ad hoc method (manual adjustment of parameter values) considering the Pearson correlation coefficient between the simulated $\mathrm{LAI}_{\mathrm{r}}$ and the observed NDVI in a total of 32 different cells within the basin.

These 32 cells were not selected randomly, but they were selected within homogeneous areas defined according to the main spatial patterns of the observed NDVI and the available spatial maps such as land-use map, soil map, DEM, slope map and soil depth map. Precisely, the main spatial patterns of the observed NDVI were identified using the EOF analysis: i.e., the EOF analysis was used to identify the main spatial patterns of the observed NDVI. The process consisted simply on the application of the methodology explained in the previous section about the EOF analysis. Then, we combined our own human perception 
and confusion matrices between the main spatial patterns of the observed NDVI and the spatial maps of model parameterization.

Traditionally, the confusion matrix is a standard tool for evaluation of statistical models and it is sometimes referred to as classification matrix. Although the confusion matrix is more common in machine learning and statistical models, it is also widely applied for map comparison in distributed modelling (Koch et al., 2015; Bennett et al., 2013; Van Vliet et al., 2013 among many others). Basically the confusion matrix compares actual to predicted values for each specific category defined previously. Generally, the rows in the matrix represent the values predicted by the model, whereas the columns represent the actual values. By its nature, the confusion matrix is an overall measure for similarity between two categorized maps. However, the comparison of numerical maps is feasible if they are categorized previously. In this research, we compared a categorized map (land use map, soil type maps, etc.) and a numerical map (the main patterns obtained by using the EOF methodology). That is why the main pattern of the observed NDVI (which is a continuous variable) was discretized according to the number of categories of the spatial maps (land use map, soil type map, etc.) and based on the similitude between the corresponding histograms.

There are a lot of metrics derived from the confusion matrices such as the accuracy index, the weighted accuracy index, the lift index, the Receiver Operator Characteristic (ROC) area, Mitre F-Score and many others. Caruana et al. (2006) showed a deep explanation about most of them. But, they are closely related to machine learning and our purpose was to measure the similarity between two categorized maps. More related to our purpose, Mouton et al. (2010) and García-Arias (2015) explained and used three different statistics: the Correctly Classified Instances (CCl), the Kappa statistics (k) and the weighted kappa $\left(k^{*}\right)$. Following the recommendations of Koch et al. (2015), we decided to use the last one calculated according to the equations [ 24 ], [25 ] and [ 26 ].

$$
\begin{aligned}
& k^{*}=\frac{f_{0}(w)-f_{e}(w)}{1-f_{e}(w)} \\
& f_{o}(w)=\frac{1}{N} \sum_{i=1}^{n} \sum_{j=1}^{n} w_{i j} * x_{i j}
\end{aligned}
$$


$f_{e}(w)=\frac{1}{N^{2}} \sum_{i=1}^{n} \sum_{j=1}^{n} w_{i j} * r_{i} * c_{j}$

where $x_{i j}$ are the elements contained in the confusion matrix and $w_{i j}$ are the elements contained in the matrix of weights. In that matrix, the elements in the diagonal are nulls and the remaining of cells is equal to the squared distance from them to the diagonal. $c_{j}$ corresponds to the number of cells simulated as category $\mathrm{j}$ (in practice, sum of the column $\mathrm{j}$ in the confusion matrix), while $r_{i}$ corresponds to the number of cells observed as category $i$ (in practice, sum of the row i).

This coefficient, whose maximum value is 1 representing a perfect agreement (Cohen, 1968), was employed in this analysis comparing cell by cell the categorized NDVI and the spatial maps of the model parameterization. Then, the maps related to the main patterns of the observed NDVI (land use and soil type maps as you can see below) were used in order to select the most appropriate cells for the manual calibration.

\subsubsection{Automatic calibration}

Automatic calibration procedures for hydrological models have been under development for decades and, still now, there are some advances with the degree of sophistication generally paralleling the increase in computational power. From the beginning, the goal has been to develop an objective strategy for parameter estimation that provides consistent performance by eliminating the kinds of subjective human judgements involved in the manual approach (Boyle et al., 2000) and taking into account the internal relationships between the different parameters to be calibrated. Knowing the importance of an automatic calibration in hydrological modelling, we wanted to propose an automatic calibration using spatio-temporal data.

The most innovative aspect of this particular automatic calibration was to incorporate the EOF analysis as an objective function. As proposed by Koch et al. (2015), we decided to build one integral matrix concatenating both the observed and predicted data. In this case, the matrix contains the normalized 
values of the NDVI provided by MODIS and the normalized values of the LAIr simulated by the model. In this way, the upper part of this matrix contains the temporal variation of the normalized observed NDVI in all cells as columns while the lower part contains the temporal variation of the normalized simulated $\mathrm{LAI}_{\mathrm{r}}$ in all cells as columns as shown in the Figure 4-7.

We decided to use the normalized values of the NDVI and $\mathrm{LAI}_{\mathrm{r}}$ because, although they are correlated, they differ in range and, therefore, they can't be compared directly. However, normalization implies that some spatial information is lost. In order to avoid these losses, we added two rows: the first contains the difference between the temporal mean of the observed NDVI at a particular pixel and the general mean using the complete NDVI dataset; and the second which contains the same but with the simulated LAI instead (Figure 4-7). In this way, we included the spatial gradient of the observed NDVI and the spatial gradient of the simulated $\mathrm{LAl}_{\mathrm{r}}$. These two rows can be plotted as two different maps and can be compared as measure of the model performance. If they are similar, it will mean that the spatial gradient remains.

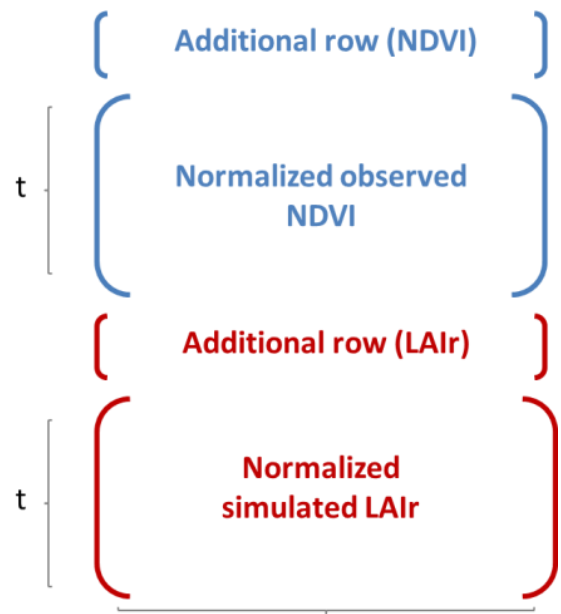

$\mathrm{N}$

Figure 4-7. Matrix used in the EOF analysis. $t$ is the time (equal to the number of maps) and $\mathrm{N}$ is the number of pixels.

Due to the area of the basin and the cell size, the number of pixels in the case study was $1,034,706$. For the calibration period (year 2003), there were 44 NDVI 
maps (one each 8 days more or less). Hence, the built integral matrix's size was 90 rows ( $44+44+2$ additional rows) times $1,034,706$ columns.

After the construction of this matrix, the EOF analysis was applied obtaining: the EOF maps for the matrix containing both NDVI and LAl, the portion of variance explained by each EOF map and the loadings of each EOF map. The combined EOF analysis yielded orthogonal EOF maps that explained the combined intervariability and intravariability of both data sets. It is important to understand that using only one matrix which contains both datasets (normalized NDVI and $L A I_{r}$ ), we were forcing to obtain the same EOF maps for both datasets. On the other hand, the loadings express for each time step how much, LAI $\mathrm{I}_{\mathrm{r}}$ and NDVI, contribute to the direction of the corresponding EOF. Hence, if the observed $\mathrm{NDVI}$ and the simulated $\mathrm{LAl}_{\mathrm{r}}$ were completely correlated, the temporal evolution of the EOF maps for both, NDVI and LAl r, would be essentially equal. The used objective function was based on that idea and it also took into account the portion of variance explained by each EOF in order to consider that the variance contribution decreases consecutively for the EOFs. Basically, the loading deviation was weighed to represent this accordingly as shown in equation [ 27 ].

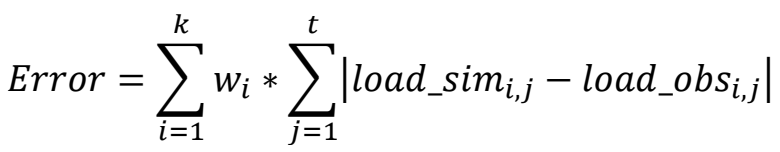

where Error is the objective function to minimize, $w_{i}$ is the portion of variance explained by the EOF $F_{i}$ load_simi,j is the loading of the EOF $F_{i}$ at time step $j$ for the simulated data (in this particular case, the normalized LAI ${ }_{r}$ ) and load_obs $s_{i, j}$ is the loading of the EOF $i$ at time step $j$ for the observed data (in this particular case, the observed normalized NDVI).

The calibration was performed using a genetic algorithm called Pyevolve (Perone, 2009). It searches for a global minimum of any given objective function. To start the automatic calibration, it needs a seed (initial values of the parameters) and a searching boundary of the variables to be calibrated. The results obtained after the manual calibration can be used as seeds and we should make sure that the searching boundaries are wide enough.

After the automatic calibration process, the temporal Pearson correlation coefficient between the NDVI provided by MODIS and the LAl simulated by the TETIS-VEG model in each cell can be calculated as a measure of the model's 
performance. Additionally, the spatial Pearson correlation between the LAIr and the NDVI maps can be calculated at each time step. For both correlation coefficients (spatial and temporal), we can use the original values of both datasets (NDVI and $\mathrm{LAI}_{\mathrm{r}}$ ), not the normalized values as used by the EOF analysis. It is important to mention that the Pearson correlation coefficient between two datasets $X$ and $Y$ is positive if $X$ and $Y$ tend to be simultaneously greater than, or simultaneously less than, their respective means. Hence, the mean should be representative. For this reason, in the case of the spatial correlation coefficient, we decided to distinguish between the main land uses: tree, shrubs and grass because each category had really different mean.

\subsubsection{Validation}

In this last step, we used the years 2000, 2001 and 2002 in order to validate the model. As during the calibration period (year 2003), there were data of precipitation, temperature and, also, NDVI provided by MODIS. Also, during the validation period, the observed discharge at the outlet point was available unlike during the calibration period.

To validate the model, we used the same methodology applied during the automatic calibration process. Keeping the parameter values obtained by the automatic calibration, we built the matrix concatenating the normalized value of the observed NDVI and the normalized value of the simulated $\mathrm{LAI}_{r}$ with two additional rows used to incorporate the spatial gradient of both datasets as explained above and shown in Figure 4-7. We also plotted these two maps and compared them as we did during the model calibration. Using the EOF techniques, we obtained the coupled EOF maps and their associated loadings and portion of variance explained by them. As during the calibration, we compared the deviation of the loadings for each EOF map and we calculated the Error function defined in equation [ 27 ].

Then, we calculated the temporal and the spatial Pearson correlation coefficient as we did during the calibration period. Finally, we calculated the Nash and Sutcliffe efficiency index and the error value between the observed discharge and the simulated discharge at the outlet point. 


\subsection{Results and discussion}

\subsubsection{Manual calibration}

It is important to remember that the main objective of this manual calibration was the identification of the most appropriate cells where the model could be tested. To do that, we identified the spatial main patterns of the observed NDVI and, then, we compared the EOFs with the available spatial maps (land use map, DEM, soil type map, etc).

Using our own human perception, we identified a certain relationship between the EOF $_{1}$ (which explained the $61.5 \%$ of the observed NDVI's spatial variance) and the land-use map. This potential relationship was supported by the Kappa coefficient described in the methodology section. It had a value of 0.34 which was not really high, but it showed the existence of a relationship between the analyzed maps. Hence, we could say that there was a connection between the $E \mathrm{~F}_{1}$ and the land-use map. Regarding to the EOF 2 (which explained the $10.5 \%$ of the observed NDVI's spatial variance) no connections with the spatial maps of physical characteristics were found. It might contain a mix of several drivers and, therefore, it can't be directly linked to a single one. Contrarily, the EOF 3 (which explained the 5.5\%) showed a good agreement with the soil maps (the Kappa coefficient was 0.32 )

Hence, the observed patterns of NDVI are strongly influenced by the land-use and the soil type spatial distribution. In the following, we combined both maps, extracted all possible combinations and selected randomly two cells of each combination obtaining a total of 32 cells covering the catchment area.

When the manual calibration was stopped, the Pearson correlation coefficient between the observed NDVI and the simulated $\mathrm{LAl}_{\mathrm{r}}$ was positive in 25 cells. There were only seven cases with negative correlation coefficient and they were located near to de Mount Kenya or Aberdare mountains (Figure 4-8). These bad results were discussed below in the automatic calibration section.

Finally, the Table 4-1 shows the obtained set of parameters after model's manual calibration. This set was used as seed during the automatic calibration. All parameters had values consistent with the reviewed literature (references embedded in the table). 


\section{Manual Calibration Results}
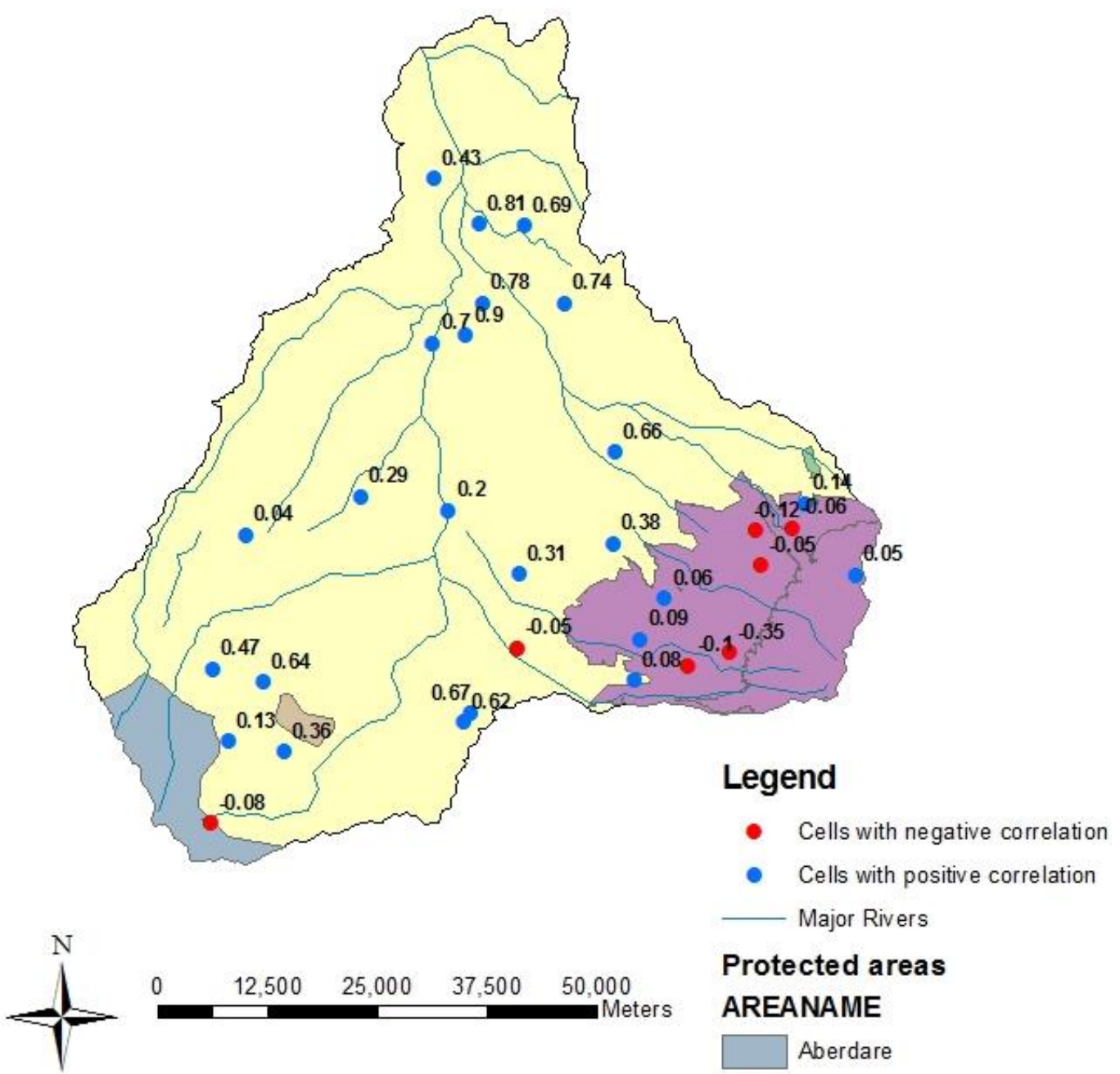

Protected areas AREANAME

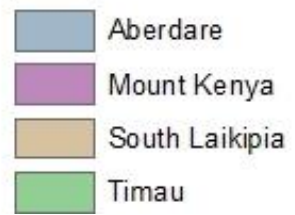

Figure 4-8. Location of the center of the cells where the manual calibration was carried out. The value of the Pearson correlation coefficient between the satellite NDVI and the simulated $\mathrm{LAI}_{\mathrm{r}}$ appears together with the cells used to the manual calibration of the model 
Table 4-1. Summary of the initial values, the search range and the final value of the parameters or correction factors of both sub-models (hydrological and dynamic vegetation) as well as the units and the reviewed references

\begin{tabular}{|c|c|c|c|c|c|c|c|}
\hline Model & $\begin{array}{c}\text { Correction factor or } \\
\text { parameter }^{*}\end{array}$ & Units & & $\begin{array}{l}\text { Initial } \\
\text { Value }\end{array}$ & Search Range & $\begin{array}{l}\text { Final } \\
\text { Value }\end{array}$ & References \\
\hline \multirow{9}{*}{ 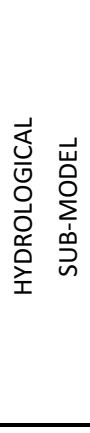 } & $\begin{array}{l}\text { FC1-Maximum Static } \\
\text { Storage }\end{array}$ & {$[-]$} & & 1.00 & {$[0.5,2.5]$} & 1.80 & [1] \\
\hline & FC2-Evapotranspiration & {$[-]$} & & 0.70 & {$[0.7,1.2]$} & 1.05 & [1] \\
\hline & FC3-Infiltration & {$[-]$} & & 0.20 & {$[0.01,2]$} & 0.12 & [1] \\
\hline & FC4-Slope velocity & {$[-]$} & & 1.00 & {$[0.1,1.2]$} & 1.00 & [1] \\
\hline & FC5-Percolation & {$[-]$} & & 0.08 & {$[0.001,2]$} & 0.05 & [1] \\
\hline & FC6-Interflow & {$[-]$} & & 140.00 & {$[0.001,100000]$} & 150.12 & [1] \\
\hline & FC7-Deep percolation & {$[-]$} & & 0.06 & {$[0.001,2]$} & 0.04 & [1] \\
\hline & FC8-Connected aquifer & {$[-]$} & & 20.00 & {$[0.001,100000]$} & 16.82 & [1] \\
\hline & FC9-Flow velocity & {$[-]$} & & 1.00 & {$[0.2,1.2]$} & 1.00 & [1] \\
\hline \multirow{18}{*}{ 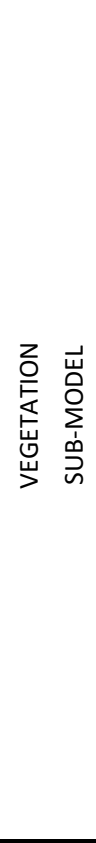 } & Specific Leaf Storages & $\mathrm{mm}$ & Tree & 0.50 & {$[0.5,3]$} & 0.43 & {$[2],[3],[4]$} \\
\hline & & & Srhub & 2.00 & {$[0.5,3]$} & 2.00 & \\
\hline & & & Grass & 2.00 & {$[0.5,3]$} & 2.00 & \\
\hline & LUE & $\begin{array}{c}\mathrm{kg} / \mathrm{m}^{2} \\
\mathrm{MJ}\end{array}$ & Tree & 1.50 & {$[1.2,2.5]$} & 1.14 & {$[5],[6]$} \\
\hline & & & Srhub & 1.50 & {$[1.2,2.5]$} & 1.14 & \\
\hline & & & Grass & 1.50 & {$[1.2,2.5]$} & 1.71 & \\
\hline & Coverage factor & {$[-]$} & $(* *)$ & 0.80 & {$[0.1,1.0]$} & 0.90 & {$[3],[4]$} \\
\hline & Distribution of roots & {$[-]$} & Tree & 0.30 & {$[0.0,1.0]$} & 0.10 & {$[3],[4],[7]$} \\
\hline & & & Srhub & 0.5 & {$[0.0,1.0]$} & 0.20 & \\
\hline & & & Grass & 0.7 & {$[0.0,1.0]$} & 0.34 & \\
\hline & Maximum LAI & $\mathrm{m}^{2} / \mathrm{m}^{2}$ & Tree & 2.50 & {$[0.5,3.5]$} & 3.10 & {$[5],[8],[9],[10]$} \\
\hline & & & Srhub & 2.00 & {$[0.5,3.5]$} & 2.00 & \\
\hline & & & Grass & 1.00 & {$[0.5,3.5]$} & 1.50 & \\
\hline & Light extinction coefficient & {$[-]$} & All & 0.50 & {$[0.4,0.6]$} & 0.52 & [11] \\
\hline & SLA & $\mathrm{m}^{2} / \mathrm{kg}$ & Tree & 4.00 & {$[2.0,5.0]$} & 4.00 & \\
\hline & & & Srhub & 6.00 & {$[4.0,20.0]$} & 10.00 & {$[5],[12]$} \\
\hline & & & Grass & 6.00 & {$[6.0,50.0]$} & 30.00 & \\
\hline & Optimal temperature & $\stackrel{\circ}{ } \mathrm{C}$ & All & 16 & {$[10,30]$} & 18 & [11] \\
\hline
\end{tabular}

$\left({ }^{*}\right)$ Regarding to the hydrological sub-model, the table shows the value of the correction factors while regarding to the vegetation sub-model, the table shows the parameter values

$\left.{ }^{* *}\right)$ The coverage factor depends on the location. The value in the table is the mean value.

[1] GIMHA Team, 2014

[2] Van Dijk et al., 2011

[3] Franz et al., 2007

[4] Caylor et al., 2006

[5] TRY Database (www.try-db.org)

[6] Yuan et al., 2007

[7] Le Roux et al., 1995

[8] Pasquato et al., 2015

[9] Ceballos and Ruiz de la Torre, 1979

[10] López-Serrano et al., 2000

[11] Ruiz-Pérez et al., 2016b 


\subsubsection{Automatic calibration}

The proposed automatic calibration is based on the assumption that the closer the loadings of the simulated values are to the loadings of the observed values, the higher the similarity is. The EOF 1 explained more than $60 \%$ of the dataset spatial variance while the $\mathrm{EOF}_{2}$ and the $\mathrm{EOF}_{3}$ explained around $10 \%$ each (Figure 4-9). The remaining EOFs explained less than 3\% each. Anyway, they were considered during the calibration process (weighted by the portion of variance explained by each one).

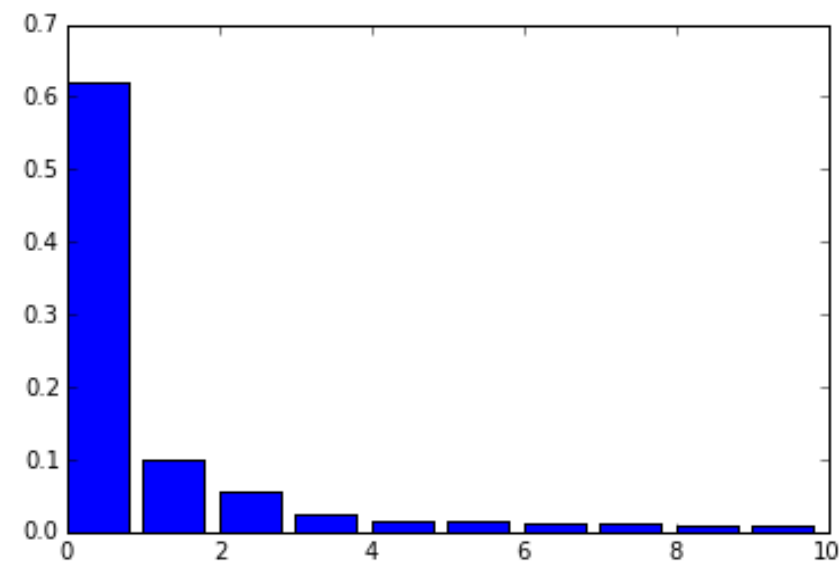

Figure 4-9. Variance explained by the first ten EOFs during the calibration period (year 2000).

There was a good agreement between the observed and simulated loadings of the EOF 1 (Figure 4-10, upper left panel). Thus EOF ${ }_{1}$ captured the predominant pattern that was found in both, the observed NDVI and the simulated $\mathrm{LAI}_{\mathrm{r}}$ data. Furthermore, the temporal variation of the EOF 1 's loadings seemed to be related to the two typical growing seasons in the catchment: the first one during MarchMay and the second one during October-December (Franz et al., 2010). On the other hand, the deviation between the observed and simulated loadings related to the $\mathrm{EOF}_{2}$ and the $\mathrm{EOF}_{3}$ were also small but slightly worse than EOF 1 . Testing the model manually, we could observe that the loadings of these both EOFs, $\mathrm{EOF}_{2}$ and $\mathrm{EOF}_{3}$, were sensitive to the initial conditions. Maybe, they reflected the immediate effect on the vegetation due to the soil moisture. Nevertheless, the accuracy between the observed and the simulated loadings could be considered satisfactory. The loadings of the remaining of EOFs were scattered which implies that mainly dissimilarities in both, measurement and model noise, are covered by these EOFs. 

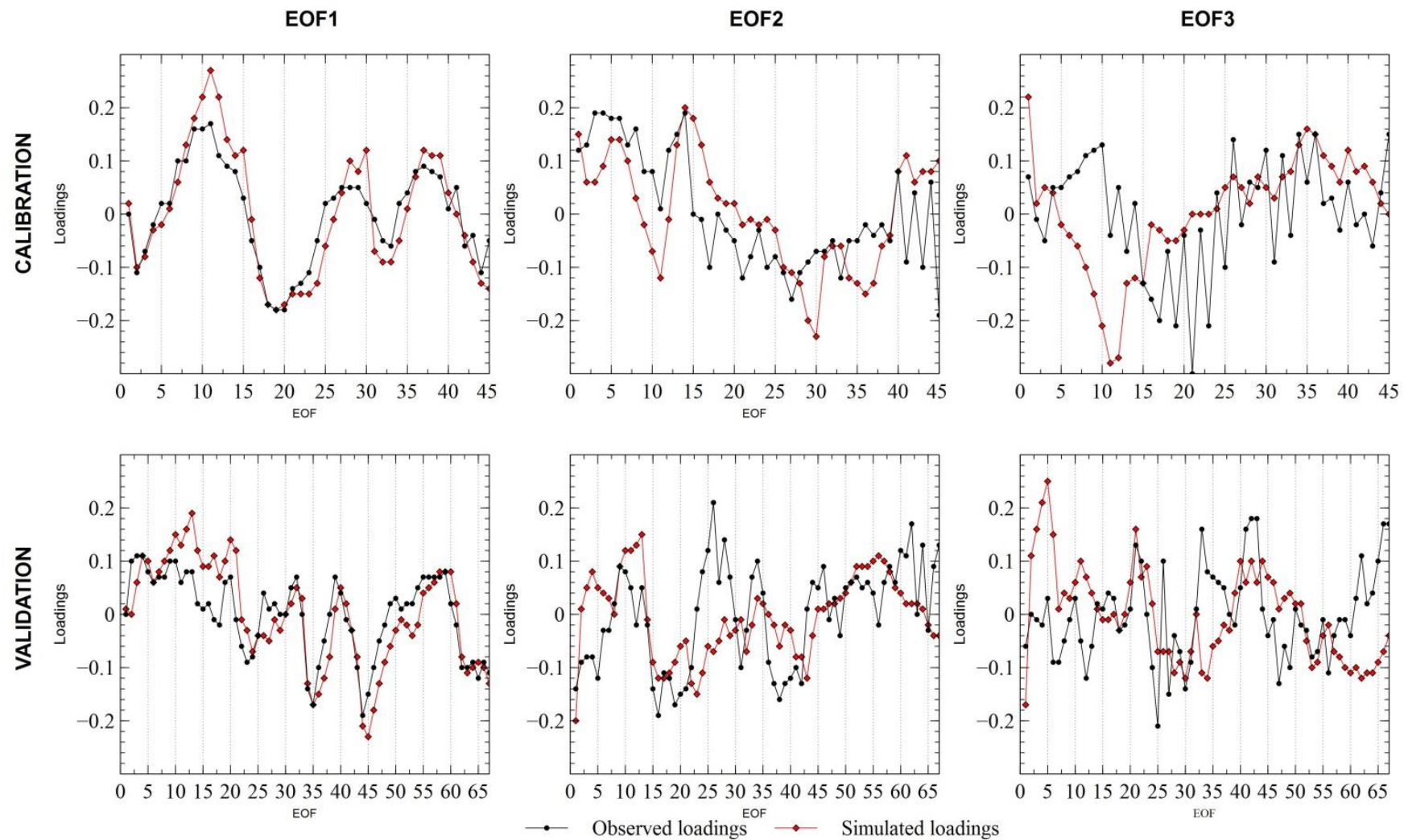

Figure 4-10.Comparison between the loadings of the normalized NDVI provided by satellite (observed loadings) and the normalized LAlr simulated by the model (simulated loadings) during the calibration period (year 2000, upper panels) and during the validation (year 2001, 2002 and 2003; lower panels). The yaxes reflect the unitless loadings of each EOF. The x-axes reflect the number of the analyzed maps (45 and 65 maps were used for model's calibration and validation respectively). 
The weakness of the proposed calibration methodology is that, although the associated weights to the loading deviation in equation [ 27 ] are needed, they are also misleading some spatial information. New ways to weight the loading deviations must be emerge in future works as proposed by Koch et al. (2015). In fact, due to the portion of variance explained by the EOF ${ }_{1}$, this main pattern controlled the calibration process. However, the variability captured in EOF 1 is predominant and explains more than $60 \%$ of the total variance and should thus be weighted more.

Actually, the calibration process works satisfactorily as shown by the fact that, in most of the basin, the temporal Pearson correlation coefficient between the observed NDVI and the simulated LAI r was higher than 0.4 (Figure 4-11). The weakest correlations were obtained in the two higher areas of the basin near to the Mount Kenya and Aberdare Mountains with zero to negative values.

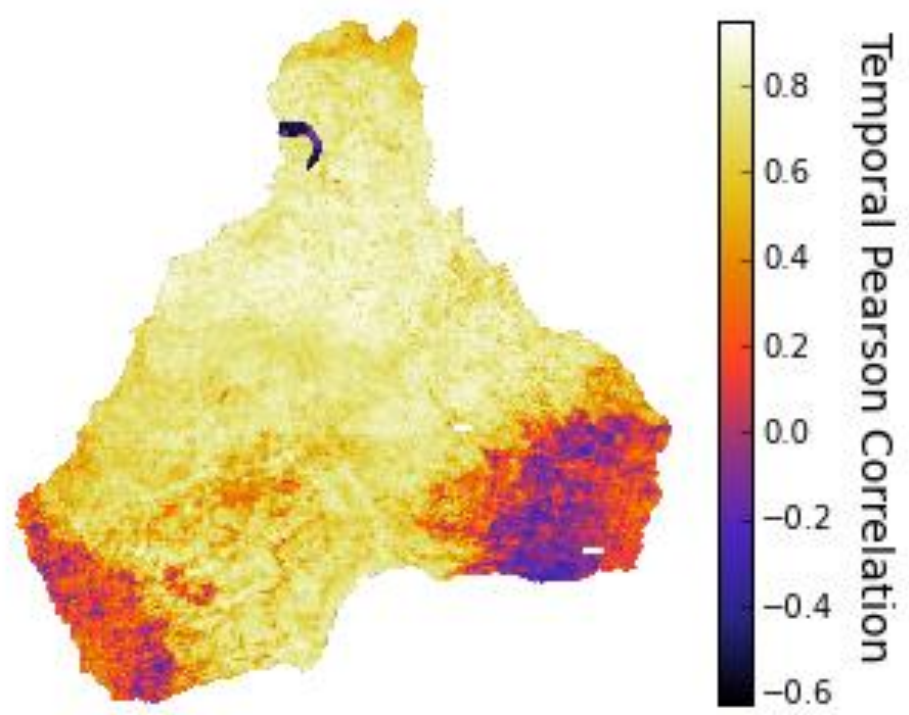

Figure 4-11. Temporal Pearson correlation coefficient between the NDVI provided by MODIS and the LAI simulated by the model during the calibration period (year 2000). The two areas with negative values correspond to the Mount Kenya and Aberdare Mountains.

Two reasons could explain such unsatisfying results. First, the observed NDVI in some pixels of those areas had a really bad quality and they were unrealistic. There were oscillations from NDVI equal to 0.8 to NDVI equal to 0.1 (even zero) 
in just one week. These unrealistic oscillations could be produced by the presence of clouds near to the mountains. The second reason is related to the conceptual limitation of the proposed model. The TETIS-VEG was designed to be used only in water-controlled areas. Franz (2007) combined the fractional woody cover and the mean annual precipitation (MAP) in order to provide some insights as to the limiting resources in the basin. Plotting MAP against the fractional woody, it could be observed that MAP and the fractional woody of this catchment were correlated linearly but with two different slopes. The point where the slope changes, is called the transition point. Up to this point, the slope is steeper (i.e.: small variations of MAP produce high variations of the fractional woody) indicating the situation in which water has bigger influence. The transition point occurred approximately around $800 \mathrm{~mm} /$ year. Physically, the transition point is believed to be a good approximation of the transition from a water-controlled ecosystem to a nutrient-controlled ecosystem. Franz (2007) affirmed that the high-latitudes (where Mount Kenya and Aberdare Mountains are included) were nitrogen limited ecosystems.

Without taking into account the regions with negative temporal Pearson correlation coefficient, the spatial Pearson correlation coefficients were calculated as explained in the methodology section. Although slightly worse than the obtained results in terms of temporal correlation, the mean spatial correlations were higher than 0.45 for all main land covers: trees, shrubs and grasses (Figure 4-12). We obtained the best results in the cells classified as trees. In fact the median was almost 0.6 and the variance was not high. Contrarily, the cells classified as grasses obtained the worst results with the lowest median and the highest variance.

Figure 4-13 shows the comparison between the maps which contain, in each cell, the difference between the temporal mean and the general mean (mean calculated with all dataset) of the observed NDVI and the simulated $\mathrm{LAI}_{\mathrm{r}}$ respectively. As can be seen, the spatial gradient was modelled properly by the model. These results, together with the fact than the temporal and spatial correlation coefficients were positive and acceptable in most of the catchment, highlight the soundness of the proposed automatic calibration methodology. 


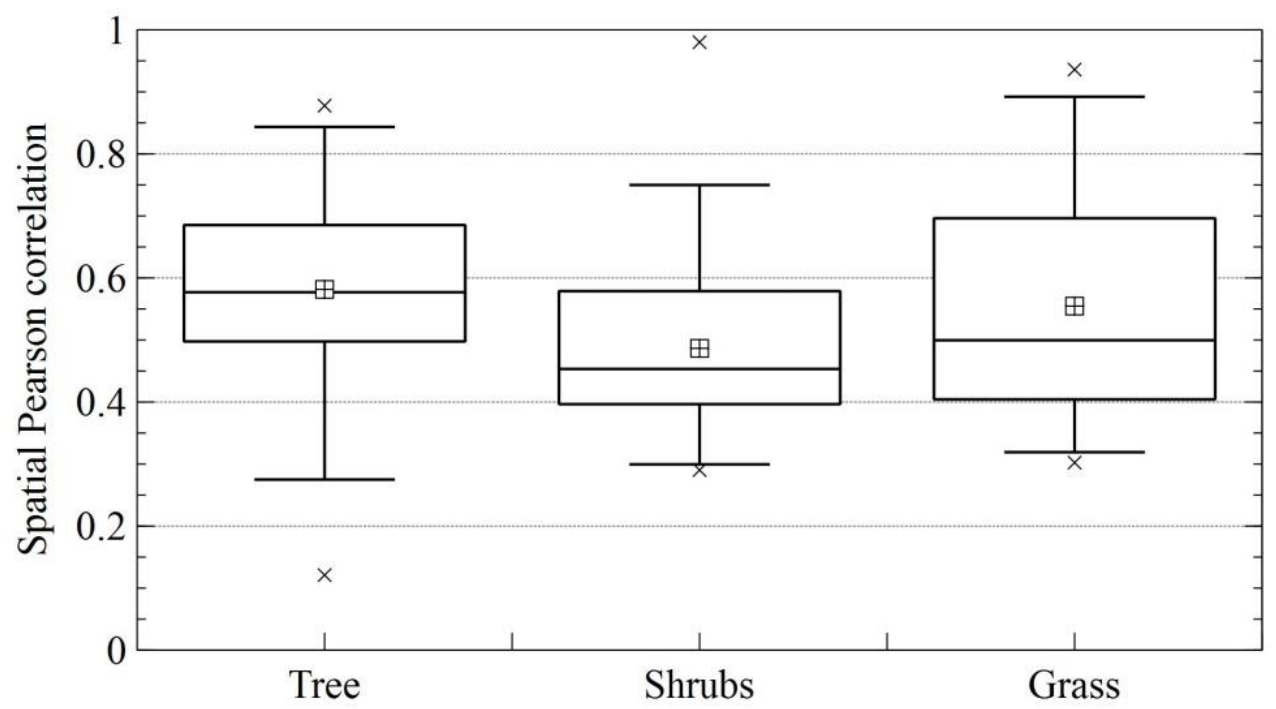

Figure 4-12 Spatial Pearson correlation coefficient during the calibration (year 2000) distinguishing between the main land uses: tree, shrubs and grass. The whiskers were calculated according to the $98 \%$ percentile and the outliers were plotted as $\mathrm{x}$. The median is the line inside boxplot and the mean is the quadrangle.
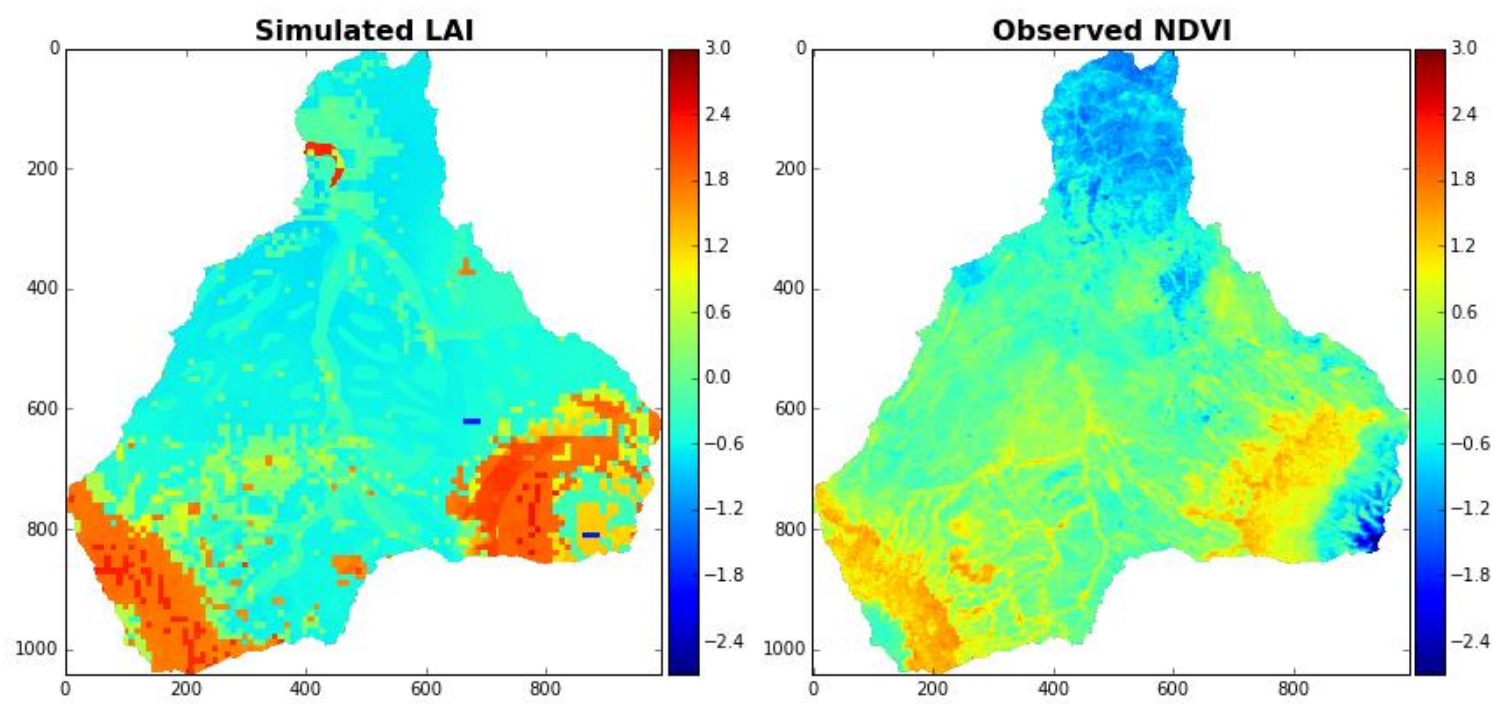

Figure 4-13 Comparison between the maps where each pixel contains the difference between the temporal mean calculated in this particular pixel and the general mean calculated using the all dataset of the simulated $\mathrm{LAI}_{\mathrm{r}}$ (left) and observed NDVI (right) for the calibration period (year 2000). This difference is a measure of spatial gradient of both variables ( $\mathrm{LAI}_{\mathrm{r}}$ and $\left.\mathrm{NDVI}\right)$. 
Finally, there were four parameters which changed substantially (in relative terms) in comparison to the values obtained during the manual calibration: the correction factor of the maximum static storage, the correction factor of the reference evapotranspiration, the factor related to the distribution of roots between the first and the second static storage layers and the maximum LAI sustainable by the system. These parameters affect directly the amount of available water to be consumed by the plants and, consequently, they also affect the transpiration process. All obtained values were consistent with the reviewed literature (embedded in the Table 4-1). Furthermore, all of them are completely included in the searching boundary used during the automatic calibration.

\subsubsection{Satellite validation}

As for the calibration process, in validation, the EOF 1 explained more than $60 \%$ of the spatial variance while the $\mathrm{EOF}_{2}$ and the $\mathrm{EOF}_{3}$ explained around $10 \%$. The remaining of EOF maps is not illustrated because they explained less than 3\% each (Figure 4-14). The simulated and observed loadings of the EOF 1 were almost equals while the obtained results in relation to the $\mathrm{EOF}_{2}$ and the $\mathrm{EOF}_{3}$ were slightly worse (lower part of the Figure 4-10), but showing the same clear temporal dynamics. Anyway, the obtained error for the validation period was 4.03 , just slightly worse than the obtained error for the calibration period. The error value was calculated considering all EOFs.

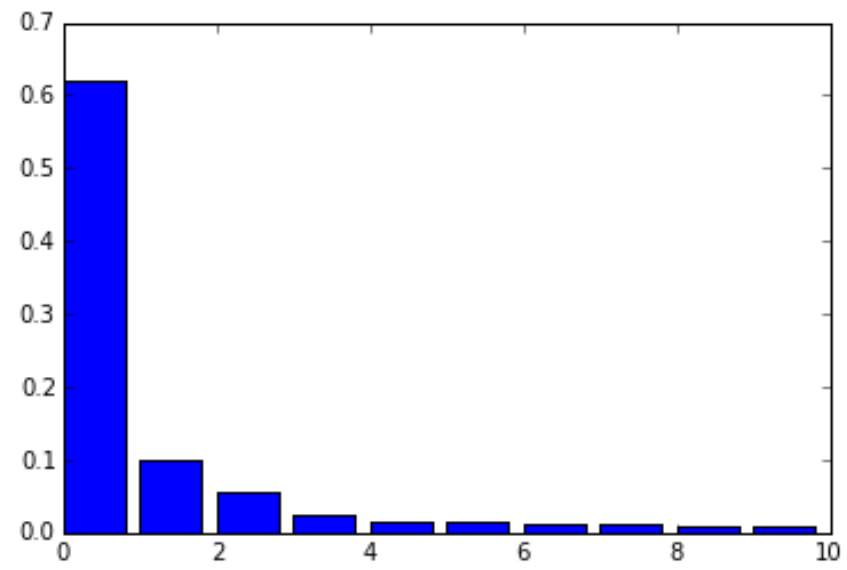

Figure 4-14. Variance explained by the first ten EOFs during the validation period (year 2001, 2002 and 2003)

The Pearson correlation map showed the same results as for the calibration period: in more than $80 \%$ of the catchment, this coefficient was between 0.3 and 
0.9 (Figure 4-15). In fact, only in two areas located near to the Mount Kenya and the Aberdare Mountains, the temporal correlation coefficient was zero or negative. In this two areas, the quality of the observed NDVI was low due to the presence of clouds probably and, again, these two areas were described as nutrient-controlled.

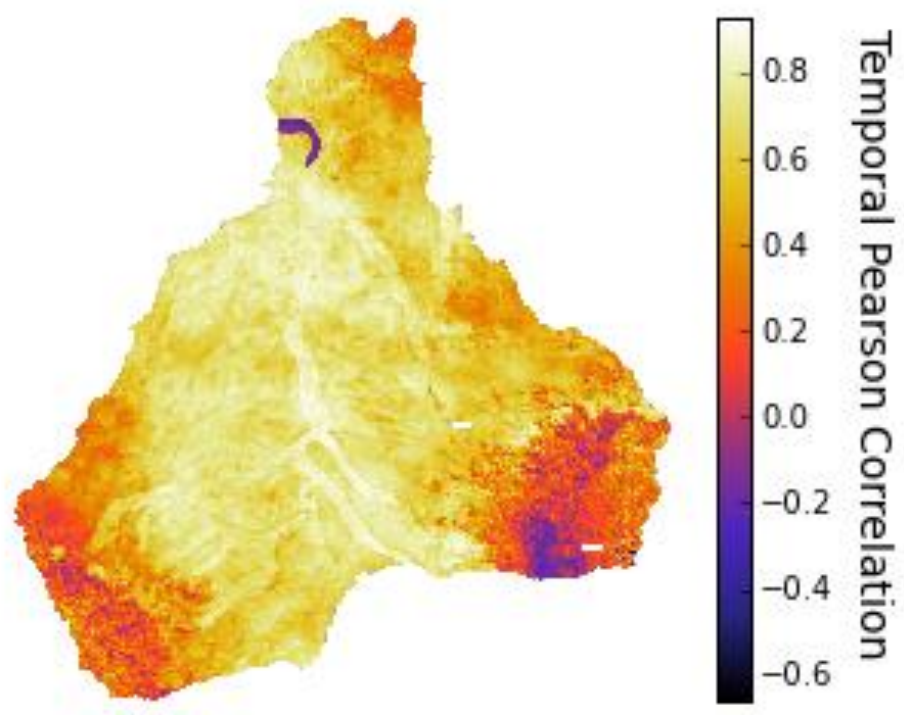

Figure 4-15. Temporal Pearson correlation coefficient between the NDVI provided by MODIS and the LAI simulated by the model during the validation period (years 2001, 2002 and 2003). The two areas with negative values correspond to the Mount Kenya and Aberdare Mountains.

Regarding to the spatial Pearson correlation coefficient, the results were not as good as the obtained in terms of temporal correlation. Nevertheless, there were no negative spatial correlation coefficients in any time step. In the case of shrubs and grasses, the mean and median were almost 0.4 while the corresponding ones for the trees were around 0.35 (Figure 4-16). The variance obtained during the validation period was narrower than the obtained during the calibration period in the three cases: trees, shrubs and grasses.

Furthermore, the spatial gradient was, as for the calibration period, well captured by the model during the validation (Figure 4-17). The cells with high differences between its own temporal mean and the general mean were consistent in both maps, observed NDVI and simulated LAI. 


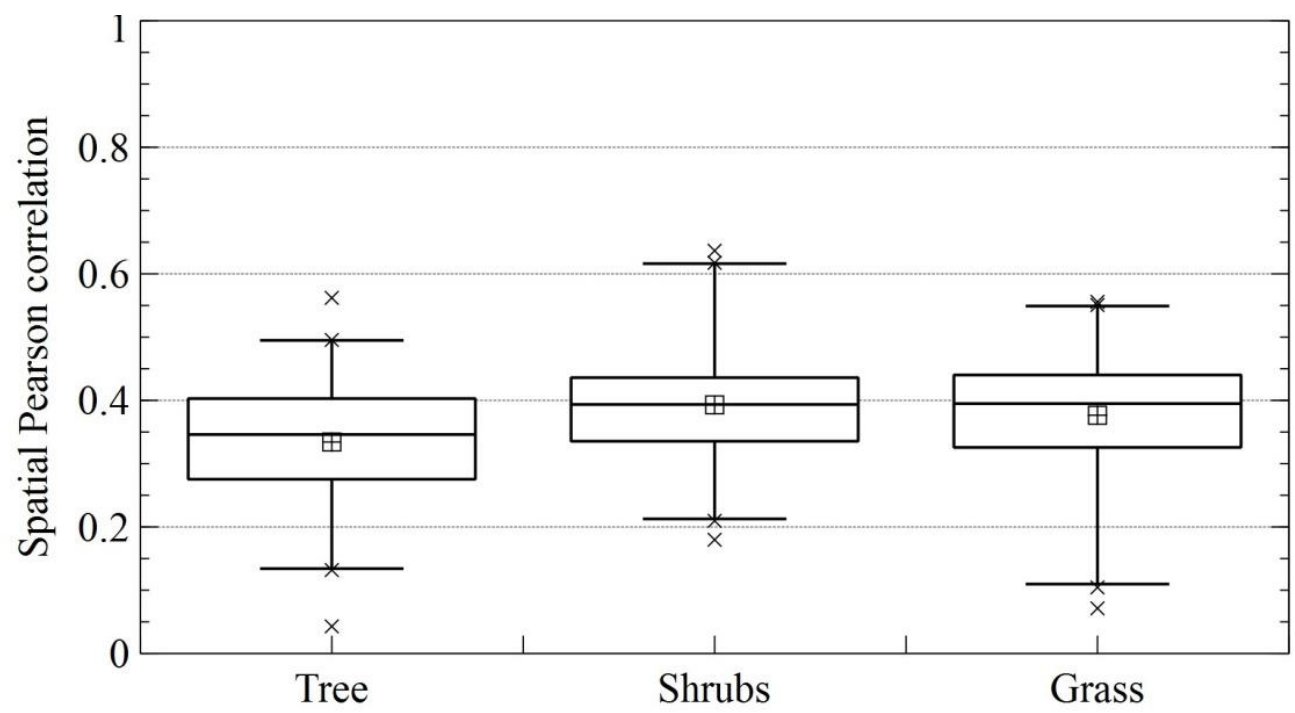

Figure 4-16 Spatial Pearson correlation coefficient during the validation distinguishing between the main land uses: tree, shrubs and grass. The whiskers were calculated according to the $98 \%$ percentile and the outliers were plotted as $\mathrm{x}$. The median is the line inside boxplot and the mean is the quadrangle.
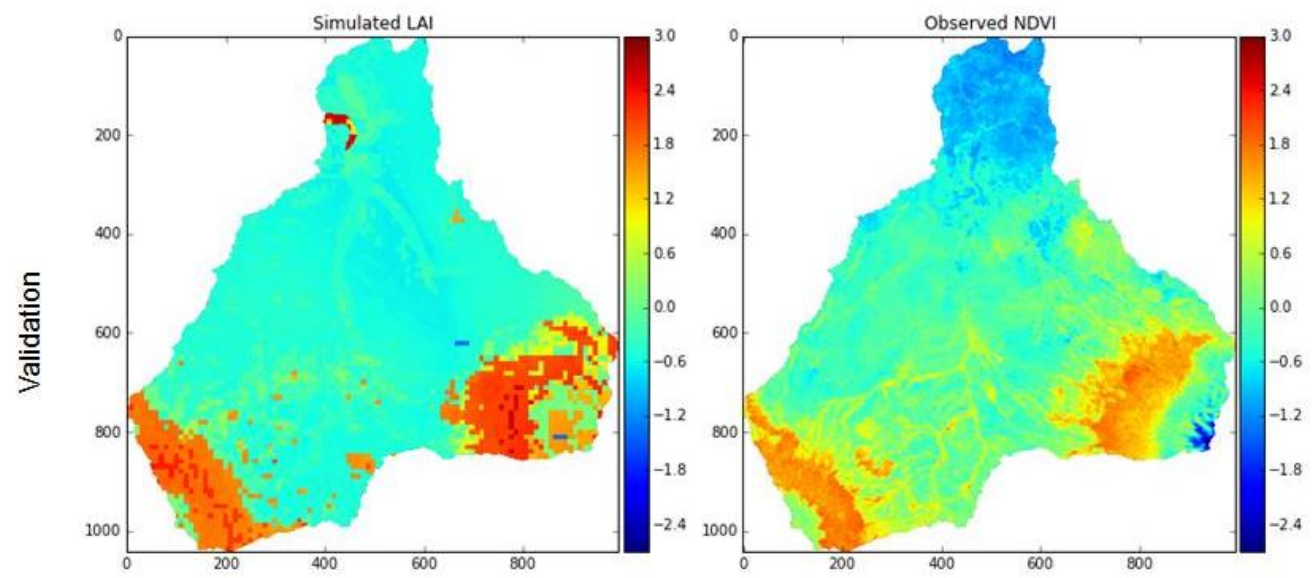

Figure 4-17. Comparison between the maps where each pixel contains the difference between the temporal mean calculated in this particular pixel and the general mean calculated using the all dataset of the simulated $\mathrm{LAI}_{\mathrm{r}}$ (left) and observed NDVI (right) in validation (years 2001, 2002 and 2003). This difference is a measure of spatial gradient of both variables ( $\mathrm{LAI}_{\mathrm{r}}$ and $\left.\mathrm{NDVI}\right)$. 


\subsubsection{Discharge validation}

Finally, since there was observed discharge at the basin outlet during the years 2000, 2001 and 2002, it could be possible to compare the discharge simulated by the model against the observations. The volume error $(E)$ was equal to -0.401 while the NS was equal to 0.321 . $E$ is strongly affected by the results obtained at the beginning of the validation period due to the absence of information regarding the initial conditions. Although we used a year as warming-up period, the simulations improved only from 2001. In fact, having calculated the performances indexes in each year, the $E$ decreased from -0.878 in 2000 to only -0.17 during the year 2002 (Figure 4-18). Regarding to the NS index, the worst result was also obtained for the first year and it improved from a negative value in 2000 to 0.354 during the year 2002. We did not expect a perfect agreement as long as the model was calibrated using the vegetation dynamics represented by the MODIS NDVI. But, in general terms, the model seems to fit well the discharge at the outlet point (Figure 4-18). Hence, the results can be considered satisfactory taking into account that the observed discharge was not included in the calibration process where only spatial patterns of the NDVI provided by MODIS and their temporal variation were addressed.

It is important to highlight the positive consequences of this last result particularly in ungauged basins because it means that satellite data could be used in order to obtain, at least, a proxy of the observed discharge. At the same time, this result also shows the key role played by vegetation in water-controlled areas such as the upper Ewaso Ngirio River basin in Kenya.

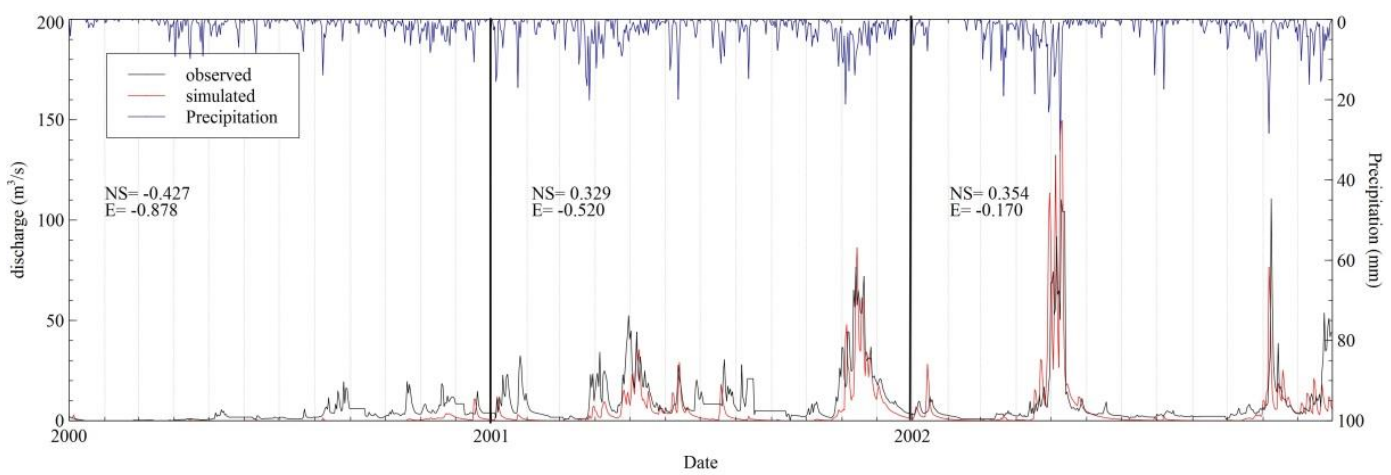

Figure 4-18. Time series of rainfall and observed and simulated daily discharge $\left(\mathrm{m}^{3} / \mathrm{s}\right)$ during the validation period $(2000,2001$ and 2002) 


\subsection{Conclusions}

Two were the main objectives of this chapter: (1) to explore if it is possible to calibrate and validate at catchment scale a parsimonious distributed ecohydrological model only using satellite information, and (2) to incorporate spatio-temporal data about a model state variable into an automatic calibration process. In order to tackle these two questions, a parsimonious distributed ecohydrological model was calibrated using exclusively NDVI data provided by MODIS. A methodology based on the EOF analysis was proposed to carry out the model calibration. Finally, the results were validated using satellite data referring to different periods and, also, the observed discharge at the basin outlet which was not used for calibration.

Regarding to the first objective of this chapter, the results highlighted the enormous utility of satellite data. It was possible to completely implement the hydrological and the vegetation components of TETIS-VEG daily model only using NDVI data and the model validation can be considered satisfactory. This fact is a promising conclusion particularly in ungauged basins such as most of the basins located in developing countries because it means that satellite data could be used in order to obtain, at least, a proxy of the observed discharge. At the same time, this result also shows the key role played by vegetation in watercontrolled areas such as the upper Ewaso Ngiro River basin in Kenya. The time step also was a relevant factor in the transfer of information from satellite NDVI to hydrological parameters: at daily time step the runoff propagation was not relevant in this case study.

The proposed automatic calibration was completely designed in order to incorporate spatio-temporal data in order to take the maximum advantage of the used satellite information. After calibrating, the simulated vegetation patterns display good agreement with measured NDVI in most of the basin except for the portion at higher altitudes. These non-satisfactory results may be due to the bad quality of the NDVI data and the limitation of the vegetation sub-model (that was specifically designed for semiarid regions). 
On the use of satellite data to calibrate a parsimonious ecohydrological model in ungauged basins Doctoral Thesis 


\section{CHAPTER 5. CONCLUSIONS}


On the use of satellite data to calibrate a parsimonious ecohydrological model in ungauged basins Doctoral Thesis 


\subsection{Concluding remarks}

As someone who was born and grown up in the Mediterranean region, I am familiar with the problematic and controversial task of water resources management. In my opinion, the decision making process depends absolutely on the use of appropriate models in order to model and simulate the available water and other ecosystem services. From the beginning of my research, I realized that most of the hydrological models had an accurate (more or less) description of the different fluxes of the water balance with the exemption of the actual evapotranspiration, even the model developed by the research group I belong to. This model, which is called TETIS, is a process-based distributed hydrological model with successful results around the world but it had not included the vegetation as state variable. That's why I felt soon drawn to the new, at least almost new, term of Ecohydrology and the integral vision of Hydrology and Ecology. Inspired by the contributions of Rodriguez-Iturbe, Porpotato, Laio and the doctoral thesis of one of my colleagues, Marta Pasquato (all of them cited along this thesis), I felt emboldened to continue their path and improve the TETIS model including the vegetation as state variable but keeping its simplicity.

In some areas, the vegetation key role on controlling the hydrological cycle is such that the actual evapotranspiration may account for more than $90 \%$ of the precipitation. The issue of climate change is (and will be) aggravating this situation. This raises the question of a loss of services that ecosystems provide to human and also the amount of available water to be used by vegetation due to the increasing temperatures around the world and variation of the precipitation in some regions. The question of the water cycle, therefore, should be considered in an integrated manner by taking into account both blue water (water in liquid form used for the human needs or which flows into the oceans) and green water (water for evaporation and transpiration processes).

In the last decades, the number of hydrological models which explicitly take into account the vegetation development as a state variable has increased substantially and considerable efforts have been made to understand and reproduce adequately the interactions between the vegetation and the water cycle. However, most of the time, these models are difficult to constrain because of the high number of parameters that are required to be estimated and/or calibrated. This represents a particularly challenging task, especially considering that in operational applications the available information is frequently quite 
limited, in particular for undeveloped and developing regions where there still exist a high amount of ungauged basins (even ungagged large basins).

Therefore, parsimonious models together with available remote sensing information can be valuable tools to predict vegetation dynamics. Up to now, remote sensing data has been employed in three different ways: (1) as forcing data, (2) as proxy data in order to obtain prior information of some parameters and (3) to calibrate and/or validate different models. In spite of the economical investment in new remote sensing technology and the deep interest shown by scientific community, the number of papers in which the model calibration was carried out explicitly and exclusively with this kind of information is really low as mentioned and referred in Section 2.4.3 and Table 2-4.

For all these reasons, my research group and I focused on the use of the parsimonious and dynamic vegetation LUE-Model and the NDVI data included in the MODIS products and provided by NASA. Firstly, the model was applied in a semi-arid experimental plot located in La Hunde (East of Spain). The climate is Mediterranean and the vegetation is characterized by Aleppo pine plantations of high tree density. Since the used ecohydrological model is parsimonious, some vegetation processes are neglected. It was important to check that the most relevant processes are being captured by the model. That's why the capability of this parsimonious model was compared against a physically-based model in reproducing the interaction between vegetation and water. Both models obtained really similar results and they could be considered satisfactory.

But, all this first part of this research was made at plot scale so only the temporal information of the satellite data could be exploited. There still existed one challenge proposed at the beginning of this research: the application of the model at basin scale and the exploitation of the spatio-temporal information of remotesensing data, i.e., not only the temporal dynamics but also the spatial patterns. In particular, the model was implemented in the upper Ewaso Ngiro River basin located in Kenya. It is a perfect example where we can be interested in modelling because the deeply demonstrated sensitivity of this region against climate change but we don't have a lot of information required by most of the current ecohydrological models. Precisely in these scarce data environments, the use of novel sources of information such as satellite imagery could be the unique alternative. 
In order to explore the potential applicability of the satellite data, we wanted to calibrate the model using exclusively the NDVI provided by NASA. Firstly, we had to deal with the fact that we were not calibrating the model with only one temporal series such as historical streamflow as usual. In fact, satellite data is composed by one temporal series per pixel. We had to identify how to use spatio-temporal (and not only temporal) data during models' calibration and validation. In that sense, unfortunately, there is still a deep lack in literature.

In fact, nowadays, there is a grand availability of remote sensing information (not only satellite) concerning spatial state variables and more information will be available in the future. Many efforts are being done to improve the quality and quantity of data (drones, better devices, etc.). And, the scientific community must also be ready to work with different kinds of data (temporal, spatial and spatiotemporal) simultaneously. If we want to be efficient, we have to identify the best way to use all of this new available information, not only for data assimilation, but more important for model calibration and validation.

A methodology based on the use of EOF analysis was proposed and successfully applied. This experience provided amazing and promising results. The model was capable to produce daily LAI (Leaf Area Index) maps (spatio-temporal series of LAI) and, also, discharge at the outlet point with a good accuracy in both cases. It is important to highlight the positive consequences of this last result particularly in ungauged basins because it means that satellite imagery can be used in order to obtain, at least, a proxy of the observed discharge.

\subsection{Future lines}

One of the possible future lines could be focused on the use of different satellite products. Among the multiple possibilities, soil moisture could be the most promising product in the future. However, it has some well- known disadvantages (Rakovec et al,. 2016): (1) there is limited information on the exact depth of the soil layer that is used, (2) the biases across the statistical moments are very typical for surface soil moisture data derived from satellite retrievals, ground measurements and models, and (3) the top thin first soil layer of most distributed models is not a good representation of actual soil moisture.

But, at the same time, soil moisture monitoring over large scales may be extremely useful, but it is limited by the fact that most of the available tools provides only surface measurements not representative of the effective amount 
of water stored in the subsurface as mentioned previously. Authors (such as Manfreda et al., 2014) have developed a methodology able to provide a formal description of the mathematical relationship between surface measurements and root-zone soil moisture. This advance opens new ways to use satellite information. In fact, Manfreda et al. (2014) used the new satellite near-surface moisture data (SMAP) together with this tool and a Kalman filter obtaining satisfactory results.

Other challenging task could be the development of new objective functions. Regarding to the EOF analysis, the proposed error index could be improved if we didn't want the EOF 1 to dominate the calibration process or we wanted to emphasize a particular EOF map. A popular method for deciding which EOF to keep and which to discard is to use 'selection rules'. Basically, there are three classes of selection rules depending on whether they focus on the amount of variance explained by each EOF, the loadings or the EOF maps. Those based on the amount of variance are called dominant variance rules as the rule used in this thesis. Secondly, the time-history rules examine the loadings. Thirdly, the spacemap rules select the EOF based on some pre-specified form of the maps. It could be really interesting to check the obtained results by applying different selection rules.

Other option would be to calibrate the model using a multi-objective approach in which different sources of information could be mixed. For example, one test could be to re-calibrate the model using both field measurements (historical streamflow for instance) and satellite data (e.g. NDVI). The proposed methodology should be able to prioritize those sources of information with less uncertainty. This experience should be done in a well-gauged basin.

The TETIS-VEG model could also be improved. Nowadays, the GIMHA group (research group in which this doctoral thesis was carried out) is incorporating nutrients, concretely nitrogen and carbon cycle, in the model conceptualization. In this way, the model performance would increase in nutrient-limited areas.

It could be also interesting to explore the impact of the variability of hydrologic drivers on the vegetation patterns formation (studied during this thesis) and sustainable functioning of natural and human systems that depends on them. The term variability of hydrologic drivers includes not only changes in the amount of rainfall but, also, changes in seasonality and spatial patterns. Special attention is required during the extreme weather conditions. Their occurrence is expected 
to increase and, still now, there exists a deep lack about how vegetation will respond. The unique sure knowledge is that vegetation and its productivity will be affected negatively in times of growing and consuming population. Repeating the words of Porporato and Rodriguez-Iturbe (Porporato and Rodriguez-Iturbe, 2013): '... our challenges that we have posed deal with understanding and predicting the origin of vegetation and biogeochemical patterns resulting from the interactions of stochastics hydrologic variability with the complex ecohydrological dynamics inherent in the soil-plant-atmosphere system'. To this end, processbased and stochastic models should be improved and not only in temporal terms but in spatio-temporal ones.

Finally, it should be explored how to adapt the current code to be run taking advantages of the parallel programming. To do that, the options are Open-MP and MPI because the code is written in Fortran. The main differences between these two options lie on: (1) shared/distributed memory and (2) process/thread. Particularly, MPI targets both distributed as well as shared memory system while Open-MP targets only shared memory system. On the other hand, Open-MP is designed for thread based parallelism and data racing is inherent in this option while MPI can be used for both thread and process based parallelism. In general, both have pros and cons and the hybrid alternative could be the best option. 
On the use of satellite data to calibrate a parsimonious ecohydrological model in ungauged basins Doctoral Thesis 


\section{SCIENTIFIC PUBLICATIONS DERIVED FROM THIS DOCTORAL THESIS}

\subsection{Publications in indexed journals (with peer-review)}

Ruiz-Pérez, G; Koch, J.; Manfreda, S.; Caylor, K.; Francés, F. Calibration of a parsimonious distributed ecohydrological daily model in a data scarce basin using exclusively the spatio-temporal variation of NDVI. Journal of Hydrology, peer review.

Ruiz-Pérez, G; González-Sanchis, M; del Campo, A.; Francés, F. Can a parsimonious model implemented with satellite data be used for modelling the vegetation dynamics and water cycle in water-controlled environments? Ecological Modelling, 324, 2016, 45-53. doi: 10.1016/j.ecolmodel.2016.01.002

\subsection{Conferences contributions and publications in proceedings}

Echeverría, C.; Ruiz-Pérez, G.; Francés, F. "How relevant is the interannual vegetation's dynamic in the water cycle at catchment scale?". Poster at the EGU General Assembly. Vienna (Austria), April, 2016.

Ruiz-Pérez, G.; Koch, J.; Manfreda, S.; Caylor, K.; Francés, F. "Automatic calibration of a parsimonious ecohydrological model in a sparse basin using the spatio-temporal variation of the NDVI". Oral presentation at the EGU General Assembly. Vienna (Austria), April, 2016.

Ruiz-Pérez, G.; Manfreda, S.; Caylor, K.; Francés, F. "On the use of satellite data to implement a parsimonious ecohydrological model in the upper Ewaso Ngiro River basin". Oral presentation at AGU Fall meeting 2015. San Francisco (USA), December, 2015.

Del Campo, A,; González-Sanchis, M; Lidón, A.; Bautista, I.; Lull, C.; GarcíaPrats, A.; Ruiz-Pérez, G.; Francés, F. "Ecohydrological-based forest management in semiarid forests". Oral presentation at 30th sesión of the EFC Working Party on the Management of Mountain Watersheds. Trento (Italy), September, 2015. 
Del Campo, A,; González-Sanchis, M; Lidón, A.; Bautista, I.; Lull, C.; GarcíaPrats, A.; Ruiz-Pérez, G.; Francés, F. "Hydrological response of pine saplings to forest management during the driest year on record". Oral presentation at XIV World Forestry Congress. Durban (South Africa), September, 2015.

Del Campo, A,; González-Sanchis, M; Lidón, A.; Bautista, I.; Lull, C.; GarcíaPrats, A.; Ruiz-Pérez, G.; Francés, F. "Addressing the eco-hydrological side of adaptive silviculture: effects on the water cycle components, tree growth, biogeochemical cycles and soil properties.". Oral presentation at 4th International Conference on Forests and Water in a Changing Environment. Kelowna (Canada), July,2015.

Ruiz-Pérez, G; González-Sanchis, M; del Campo, A.; Francés, F. "Mediterranean vegetation-water interactions: a model comparison at different complexity levels". Oral presentation at 36th IAHR World Congress: Deltas of the Future and what happens upstream. The Hague (The Netherlands), June, 2015.

Ruiz-Pérez, G; González-Sanchis, M; del Campo, A.; Francés, F. "On the use of satellite data to implement a distributed dynamic vegetation model in a Mediterranean catchment". Oral presentation at 26th General Assembly of the International Union of Geodesy and Geophysics (IUGG 2015). Prague (Czech republic), June, 2015.

Ruiz-Pérez, G.; Francés, F. "Influence of vegetation dynamic modeling on the allocation of Green and Blue waters". Oral presentation at European Geosciences Union General Assembly 2015. Vienna (Austria), April, 2015.

Ruiz-Pérez, G; González-Sanchis, M; del Campo, A.; Francés, F. "Interacciones bosque-agua en la región Mediterránea: comparación de modelos a diferentes escalas". Oral presentation at the III Reunión de grupo de trabajo de hidrología forestal de la Sociedad Española de ciencias Forestales. Valencia (Spain), March, 2015.

Ruiz-Pérez, G; Medici, C; González-Sanchis, M; García-Prats, A.; del Campo, A; Francés, F."Mediterranean vegetation-water interactions. A model comparison at different scales.". Oral presentation at the XXIV IUFRO 
World Congress - Sustaining Forests, Sustaining People: The Role of Research. Utah (USA) October 5-11, 2014.

Ruiz-Pérez, G; Medici, C; González-Sanchis, M; del Campo, A.; Francés, F. "On the importance of remote sensing data to validate a dynamic vegetation model applied to a semi-arid basin." Oral presentation at the 11th International Conference on Hydroinformatics. "Informatics and the Environment: Data and Model Integration in a Heterogeneous Hydro World". New York (USA), August, 2014.

Ruiz-Pérez, G; Pasquato, M.; Medici, C; González-Sanchis, M; Molina, A.; Fernándes, T.J.G.; del Campo, A.; Francés, F. "Application of a simple dynamic vegetation model to an experimental plot and validation through satellite data and field observations. Poster at the EGU General Assembly, Vienna (Austria), May, 2014.

Ruiz-Pérez, G; Pasquato, M.; Medici, C; González-Sanchis, M; Molina, A.; Fernándes, T.J.G.; del Campo, A.; Francés, F. " Using satellite-based remote sensing data and field measurements to validate a dynamic vegetation model implemented in a water-controlled catchment". Poster at Global Vegetation Monitoring and Modelling (GV2M), Avignon (France), February, 2014.

Ruiz-Pérez, G; Medici, C.; Latron, J.; Llorens, P.; Gallart, F.; Francés, F. "¿Heterogeneidad espacial o no-linealidad en los procesos? Análisis en una pequeña cuenca Mediterránea." Poster at the Jornadas de Ingeniería del Agua (JIA). Valencia (Spain), October, 2013.

Ruiz-Pérez, G; Medici, C.; Latron, J.; Llorens, P.; Gallart, F.; Francés, F. "Importance of the spatial heterogeneity in the non-linear response of a small Mediterranean catchment". Oral presentation at the International Symposium on Distributed Hydrological Modelling, Bologna (Italy), June, 2013.

Ruiz-Pérez, G; Medici, C.; Latron, J.; Llorens, P.; Gallart, F.; Francés, F. "Importance of the spatial heterogeneity in the non-linear response of a small Mediterranean catchment”. Poster at the EGU General Assembly, Viena (Austria), April, 2013. 
On the use of satellite data to calibrate a parsimonious ecohydrological model in ungauged basins Doctoral Thesis 


\section{REFERENCES}

Aarts, J., 2012. Will community-based water management solve Africa's water problems? The performance of Water Resource User Associations in the Upper Ewaso Ngiro River basin, Kenya. MA Thesis Radboud University.

Aber J., Neilson R.P., McNulty S., Lenihan J.M., Bachelet D., Drapek R.J., 2001. Forest processes and global environmental change: predicting the effects of individual and multiple stressors. BioScience, 51(9), 735- 751

Acland, J. 1971. East African Crops. Cambridge University Press

Aguiar, M.R., Paruelo, J.M, Sala, O.E., Lauenroth, W.K. 1996. Ecosystem responses to changes in plant functional type composition: an example from the Patagonian steppe. Journal of Vegetation Science, 7, 381-390.

Allen, R. G., Pereira, L. S., Raes, D., Smith, M., 1998. Crop evapotranspirationGuidelines for computing crop water requirements-FAO Irrigation and drainage paper 56. FAO, Rome, 300(9), D05109.

Allen R. G., Pruitt W.O., Wright J.L., Howell T.A., Ventura F., Snyder R., Itenfisu D., Steduto P., Berengena J., Yrisarry J.B., Smith M., Pereira L.s., Raes D., Perrier A., Alves I., Walter I., Elliott R., 2006. A recommendation on standardized surface resistance for hourly calculation of reference ETO by the FAO56 Penman-Monteith method. Agricultural Water Management, 81 (1-2), 1-22. doi: 10.1016/j.agwat.2005.03.007

Andersen, F.H. 2008. Hydrological modeling in a semi-arid area using remote sensing data. Doctoral Thesis, Department of Geography and Geology, University of Copenhagen (Denmark).

Arda Sorman A., Sensoy A., Tekeli A.E., Sorman A.Ü., Akyürek Z., 2009. Modelling and forecasting snowmelt runoff process using the HBV model in the Eastern part of Turkey. Hydrological Processes, 23, 1031-1040

Arnold J.G., Fohrer N., 2005. SWAT2000: current capabilities and research opportunities in applied watershed modelling. Hydrological Processes, 19, 563-572, doi: 10.1002/hyp.5611 
Arnold S., Attinger S., Frank K., Hildebrandt A., 2015. Assessing the structural adequacy of alternative ecohydrological models using a pattern-oriented approach. Ecological Modelling, 316, 52-61

Arnold, S., Lechner, A., Baumgartl, T., 2011. Merging modelling and experimental approaches to advance ecohydrological system understanding. In: Webb, A.A.,Bonell, M., Bren, L., Lane, P.N.J., McGuire, D., Neary, D.G., Nettles, J., Scott, D.F.,Stednick, J.D., Wang, Y. (Eds.), Revisiting Experimental Catchment Studies in Forest Hydrology, vol. 353. IAHS Publications, Wallingford, UK, pp. 117-124.

Arora V., 2002. Modeling vegetation as a dynamic component in soil-vegetationatmosphere transfer schemes and hydrological models. Reviews of Geophysics, 40(2), 1-26, doi:10.1029/2001RG000103

Asbjornsen H, Shepherd G, Helmers M., 2008. Seasonal patterns in depth ofwater uptake under contrasting annual and perennial systems in the Corn Belt Region of the Midwestern US. Plant Soil, 308,69-92.

Asbjornsen H., Goldsmith G.R., Alvarado-Barrientos M., Rebel K., Van Osch F.P., Rietkerk M., 2011. Ecohydrological advances and applications in plant-water relations research: a review. Journal of Plant Ecology, 4 (1-2), 3-22, doi: 10.1093/jpe/rtr005

Asner, G. P., Scurlock, J. M., Hicke, J., 2003. Global synthesis of leaf area index observations: implications for ecological and remote sensing studies. Global Ecology and Biogeography, 12(3), 191-205.

Asrar, G., Fuchs, M., Kanemasu, E. T., Hatfield, J. L., 1984. Estimating absorbed photosynthetic radiation and leaf area index from spectral reflectance in wheat. Agronomy journal, 76(2), 300-306.

Aydin, M.; Ynag, S.L.; Kurt, N.; Yano, T., 2005. Test of a simple model for estimating evaporation from bare-soils in different environments. Ecological Modelling, 182, 91-105

Baird, A. J., and R. L. Wilby (Eds.), 1999. Ecohydrology: Plants and Water in Terrestrial and Aquatic Environments, Routledge, Boca Raton, Fla. 
Band L.E., Patterson P., Nemani R., Running S.W. 1993. Forest ecosystem processes at the watershed scale: incorporating hillslope hydrology. Agricultural and Forest Meteorology, 63(1-2), 93-126

Bandaragoda, C., Tarboton, D. G., Woods, R., 2004. Application of TOPNET in the distributed model intercomparison project. Journal of Hydrology, 298(1), 178-201.

Baquedano, F. J., Castillo, F. J., 2006. Comparative ecophysiological effects of drought on seedlings of the Mediterranean water-saver Pinus halepensis and water-spenders Quercus coccifera and Quercus ilex. Trees, 20(6), 689-700.

Becker-Reshef, I., Vermote, E., Lindeman, M., Justice, C., 2010. A generalized regression-based model for forecasting winter wheat yields in Kansas and Ukraine using MODIS data. Remote Sensing of Environment, 114(6), 1312-1323.

Bennett, N. D., Croke, B. F., Guariso, G., Guillaume, J. H., Hamilton, S. H., Jakeman, A. J., Marsili-Libelli S., Newham L.T.H., Norton J.P., Perrin C., Pierce, S. A., Robson B., Seppelt R., Voinov A.A., Fath B.D., Andreassian V., 2013. Characterising performance of environmental models. Environmental Modelling and Software, 40, 1-20.

Beven K, 2001. How far can we go in distributed hydrological modelling? Hydrology and Earth System Sciences, 5(1), 1-12.

Birot, Y., Gracia, C., Palahi, M., 2011. Water for forests and people in the Mediterranean region: a challenging balance. European Forest Institute (EFI).

Bleby TM, Mcelrone AJ, Jackson RB, 2010. Water uptake and hydraulic redistribution across large woody root systems to $20 \mathrm{~m}$ depth. Plant Cell Environment, 33, 2132-2148.

Blöschl, G., Sivapalan, M., 1997. Process controls on regional flood frequency: coefficient of variation and basin scale. Water Resources Research, 33(12), 2967-2980. 
Bjornsson, H., Venegas SA., 1997. A manual for EOF and SVD analyses of climate data. CCGCR Rep. 97-1, McGill University, Montréal, QC, Canada, 52 pp.

Bond B. 2003. Hydrology and ecology meet - and the meeting is good. Hydrological Processes, 17, 2087 - 2089

Boyle, D. P., Gupta, H. V., Sorooshian, S., 2000. Toward improved calibration of hydrologic models: Combining the strengths of manual and automatic methods. Water Resources Research, 36(12), 3663-3674.

Breshears, D.D., Meyers, O.B., Johnson, S.R., Meyer, C.W., Martens, S.N. 1997. Differential water use of heterogeneous soil moisture by two semiarid woody species: Pinus edulis and Juniperus monosperma. Journal of Ecology, 85, 289-299.

Breshears, D.D., Nyhan, J.W. Heil, C.E., Wilcox, B.P. 1998. Effects of woody plants on microclimate in a semiarid woodland: soil temperature and soil evaporation in canopy and intercanopy patches. International Journal of Plant Sciences, 159, 1010-1017.

Breshears D.D., Barnes F.J., 1999. Interrelationship between plant functional types and soil moisture heterogeneity for semiarid landscapes within the grassland/forest continuum: a unified conceptual model. Landscape Ecology, 14, 465-478.

Burgess, S.S.SO.; Adams, M.A.; Turner, N.C.; Beverly, C.R.; Ong, C.K.; Jhan, A.A.H; Bleby, T.M., 2001. An improved heat pulse method to measure low and reverse rates of sap flow in woody plants. Tree Physiology, 21, 589598.

Calatayud V., Muñoz C., Hernández R., Sanz M.J., Pérez Fortea V., Soldevilla C., Sánchez G., 2000. Seguimiento de daños en acículas de Pinus halepensis en localidades de Teruel y Castellón (España), Ecología, 14, 129-140

Canfield, H. E., Lopes, V. L., 2004. Parameter identification in a two-multiplier sediment yield model 1. Journal of the American Water Resources Association, 40(2), 321. 
Campo L., Caparrini F., Castelli F., 2006. Use of multi-platform, multi-temporal remote-sensing data for calibration of a distributed hydrological model: an application in the Arno basin, Italy. Hydrological Processes, 20, 26932712

Cao, M., and Woodward, F.I.,1998. Net primary and ecosystem production and carbon stocks of terrestrial ecosystem and their response to climate change, Global Change Biology, 4, 185-198.

Carlson T.N., Ripley D.A., 1997. On the relation between NDVI, Fractional Vegetation Cover and Leaf Area Index. Remote Sensing of Environment, 62, 241-252

Caruana R., Niculescu-Mizil A., 2006. An empirical comparison of supervised learning algorithms. Proceedings of the $23^{\text {rd }}$ International Conference on Machine Learning, Pittsburg, PA.

Caylor, K. K., Manfreda, S., Rodriguez-Iturbe, I., 2005. On the coupled geomorphological and ecohydrological organization of river basins. Advances in Water Resources, 28(1), 69-86.

Caylor, K.K., D'Odorico P., Rodriguez-Iturbe I., 2006. On the ecohydrological organization of spatially heterogeneous semi-arid landscapes. Water Resources Research, 42(7), W07424, doi:10.1029/2005WR004683.

Ceballos Y, Ruiz de la Torre J. 1979. Árboles y arbustos de la España peninsular. ETSI Montes Publications: Madrid.

Cervelló Royo, J., 2008. Estudio climatológico del monte V-1007 de La Hunde y la Palomera en el término municipal de Ayora (Valencia). Proyecto Final de Carrera. Universitat Politècnica de València.

Chapin III, F. S., McGuire, A. D., Randerson, J., Pielke Sr, R., Baldocchi, D., Hobbie, S. E., Zimov, S. A., 2000. Feedbacks from arctic and boreal ecosystems to climate. Global Change Biol., 6(Suppl 1), 211-223.

Chen, X. L., Zhao, H. M., Li, P. X., Yin, Z. Y., 2006. Remote sensing imagebased analysis of the relationship between urban heat island and land use/cover changes. Remote sensing of environment, 104(2), 133-146. 
Chen L., Wang L., Ma Y., Liu P., 2015. Overview of ecohydrological models and systems at the watershed scale. IEEE SYSTEMS JOURNAL, 9(3), 10911099

Chen, J. M., \& Cihlar, J.,1996. Retrieving leaf area index of boreal conifer forests using Landsat TM images. Remote Sensing of Environment, 55, 153 162.

Chiesi, M., Maselli, F., Bindi, M., Fibbi, L., Bonora, L., Raschi, A., Nadezhdina, N., 2002. Calibration and application of FOREST-BGC in a Mediterranean area by the use of conventional and remote sensing data. Ecological Modelling, 154(3), 251-262.

Chiesi, M., Maselli, F., Moriondo, M., Fibbi, L., Bindi, M., Running, S. W., 2007. Application of BIOME-BGC to simulate Mediterranean forest processes. Ecological Modelling, 206(1), 179-190.

Clapp, R. B., Hornberger, G. M., 1978. Empirical equations for some soil hydraulic properties. Water Resources Research, 14(4), 601-604.

Cohen J. 1968. Weighted kappa: nominal scale agreement provision for scaled disagreement or partial credit. Psychological Bulletin, 70(4), 213-220. DOI: $10.1037 / \mathrm{h} 0026256$.

Cohen, W. B., Maiersperger, T. K., Gower, S. T., \& Turner, D. P., 2003. An improved strategy for regression of biophysical variables and Landsat ETM+data. Remote Sensing of Environment, 84, 561 - 571.

Corbari C., Mancini M., Li J., Su Z., 2015. Can satellite land Surface temperatura data be used similarly to river discharge measurements for distributed hydrological model calibration?, Hydrological Sciences Journal, 60(2), 202-217, doi: 10.1080/02626667.2013.866709

Dalsgaard L, Mikkelsen TN, Bastrup-Birk A., 2011. Sap flow for beech (Fagus sylvatica) in a natural and managed forest - effect of spatial heterogeneity. Journal of Plant Ecology, 4, 23-35.

Davenport, D.W., Breshears, D.D., Wilcox, B.P., Allen, C.D., 1998. Viewpoint: Sustainability of piñon-juniper ecosystems - a unifying perspective of soil erosion thresholds. Journal of Range Management. 51: 231-240. 
Dawson, T.P.; Curran, P.J.; Plummer, S.E., 1998. LIBERTY-modeling the effect of leaf biochemical contration on reflectance spectra. Remote Sensing of Environment, 65, 50-60

Del Campo A.D., Aguilella A., Lidón A., Segura G., 2008. Influencia del tipo y dosis de hidrogel en las propiedades hidrofísicas de tres suelos forestales de distinta textura. Cuadernos de la Sociedad Española de Ciencias Forestales, 25, 137-143

Del Campo, A.D.; Fernandes, T.J.G.; Molina, A.J., 2014. Hydrology-oriented (adaptive) silviculture in a semiarid pine plantation: How much can be modified the water cycle through forest management?. European Journal of Forest Research, 133, 879-894.

Domec JC, King JS, Noormets A, 2010. Hydraulic redistribution of soil water by roots affects whole-stand evapotranspiration and net ecosystem carbon exchange. New Phytology, 187, 171-83.

Drewry D.T., Albertson J.D., 2006. Diagnosing model error in canopy-atmosphere exchange using empirical orthogonal function analysis. Water Resources Research, 42, W06421, doi: 10.1029/2005WR004496

Eagleson PS. 1978. Climate, soil and vegetation. 1. Introduction to water balance dynamics. Water Resources Research, 14, $705-712$.

Eagleson PS. 2002. Ecohydrology: Darwinian Expression of Vegetation Form and Function. Cambridge University Press: Cambridge.

Eckhardt, K., Arnold, J. G., 2001. Automatic calibration of a distributed catchment model. Journal of hydrology, 251(1), 103-109.

Engler, A., 1919. Untersuchungen Uber den Einfluss des Waldes anf den Stand der Gewässer. Swiss Federal Institute Forest, Snow and Landscape Research, Birmensdorf, Mitteilungen, Report, 12: i-626.

Fang Z., Bogena H., Kollet S., Koch J., Vereecken H., 2015. Spatio-temporal validation of long-term 3D hydrological simulations of a forested catchment using empirical orthogonal functions and wavelet coherence analysis. Journal of Hydrology, 529, 1754-1767 
FAO, 2005. Organización de las Naciones Unidas para la Agricultura y la Alimentación. Evaluación de los recursos forestales mundiales. Roma,

Fatichi S., Ivanov V.Y., Caporali E., 2012. A mechanistic ecohydrological model to investigate complex interactions in cold and warm water-controlled environments: 1. Theoretical framework and plot-scale analysis. Journal of advances in Modeling Earth Systems, 4, M05002, doi: $10.1029 / 2011 \mathrm{MS} 000086$

Field, C.B.; Randerson, J.T.; Malmstrom, C.M., 1995. Global net primary production: combining ecology and remote sensing. Remote Sensing of Environment, 51, 74-88

Francés F., Benito J., 1995. La modelación distribuida con pocos parámetros de las crecidas. Ingeniería del Agua, 2, 7-24

Francés F., Vélez J. I., Vélez J. J., 2007. Split.-parameter structure for the automatic calibration of distributed hydrological models. Journal of Hydrology, 332:226-240

Franz K.J., Karsten L.R., 2013. Calibration of a distributed snow model using MODIS snow covered area data. Journal of hydrology, 494, 160-175

Franz T.E, 2007. Ecohydrology of the upper Ewaso Ngiro river basin, Kenia. Doctoral Thesis. Princeton University, Princeton, NJ, USA.

Franz TE, Caylor KK, Nordbotten JM, Rodríguez-Iturbe I., Celia MA., 2010. An ecohydrological approach to predicting regional woody species distribution patterns in dryland ecosystems. Advances in Water Resources, 33(2), 215-230

Friedl, M. A., Michaelsen, J., Davis, F. W., Walker, H., \& Schimel, D. S., 1994. Estimating grassland biomass and leaf area index using ground and satellite data. International Journal of Remote Sensing, 15, 1401 - 1420.

Funk, C., Budde, M. E., 2009. Phenologically-tuned MODIS NDVI-based production anomaly estimates for Zimbabwe. Remote Sensing of Environment, 113(1), 115-125. 
Gamon, J.A.; Serrano, L.; Surfus, J.S., 1997. The photochemical reflectance index: an optical indicator of photosynthetic radiation use efficiency across species, functional types, and nutrient levels. Oecologia, 112, 492-501

García-Arias A., 2015. Desarrollo de un modelo ecohidrológico para el análisis de la dinámica de ecosistemas riparios. Doctoral Thesis. Universitat Politècnica de València.

Gerten D., Schaphoff S., Haberlandt U., Lucht W., Sitch S., 2004. Terrestrial vegetation and water balance - hydrological evaluation of a dynamic global vegetation model. Journal of Hydrology, 286, 249-270

Gibbon, P., 2011. Experiences of plantation and large-scale farming in 20th century Africa (No. 2011: 20). DIIS Working Paper.

GIMHA team (Vélez I., Vélez J., Puricelli M., Montoya JJ., Camilo JC., Bussi G., Medici C., Orozco I., Ruiz-Pérez G.), 2014. Description of the distributed conceptual hydrological model TETIS v.8. Universitat Politècnica de València.

Giorgi, F., Lionello, P., 2008. Climate change projections for the Mediterranean region. Global and Planetary Change, 63(2), 90-104.

Gitelson, A. A., Viña, A., Verma, S. B., Rundquist, D. C., Arkebauer, T. J., Keydan, G., Suyker, A. E., 2006. Relationship between gross primary production and chlorophyll content in crops: Implications for the synoptic monitoring of vegetation productivity. Journal of Geophysical Research: Atmospheres, 111(D8).

Giuggiola, A., Bugmann, H., Zingg, A., Dobbertin, M., Rigling, A., 2013. Reduction of stand density increases drought resistance in xeric Scots pine forests. Forest Ecology and Management, 310, 827-835.

Gobron, N., 2008. Leaf area index (LAI). Terrestrial essential climate variable for climate change assessment, mitigation and adaptation, FAO.

González-Sanchis, M., Del Campo, A. D., Molina, A. J. 2015. Modeling adaptive forest management of a semi-arid Mediterranean Aleppo pine plantation. Ecological Modelling, 308, 34-44. 
Gracia CA, Tello E, Sabaté S, Bellot J., 1999. GOTILWA: an integrated model of water dynamics and forest growth. In: "Ecological Studies 137: Ecology of Mediterranean Evergreen Oak Forest” (Rodà F, Retana J, Gracia C, Bellot J eds). Springer Berlin, Heidelberg, Germany, 163-179.

Graf A., Bogena H.R., Drüe C., Hardelauf H., Pütz T., Heinemann G., Vereecken H., 2014. Spatiotemporal relations between water budget components and soil moisture in a forested tributary catchment. Water Resources Research, 50(6), 4837-4857. doi: 10.1002/2013WR014516

Granier, A., 1987. Evaluation of transpiration in a Douglas-fir stand by means of sap flow measurements. Tree physiology, 3(4), 309-320.

Guswa, A.J.; Celia, M.A.; Rodriguez-Iturbe, I., 2004. Effect of vertical resolution on predictions of transpiration in water-limited ecosystems, Advances in Water Resources, 27, 467-480

Gutmann E.D., Small E.E., 2010. A method for the determination of the hydraulic properties of soil from MODIS surface temperature for use in land-surface models. Water Resources Research, 46, W06520, doi: 10.1029/2009WR008203

Hannah D.N., Wood P.J., Sadler J.P., 2004. Ecohydrology and hydroecology: A 'new paradigm'?. Hydrological Processes, 18, 3439-3445, doi: 10.1002/hyp.5761

Hack J.T., Goodlett J.C., 1960. Geomorphology and forest ecology of a mountain region in the central Appalachians. United States Geological Survey Professional Papers, 347

Hatfield, J. L., Kanemasu, E. T., Asrar, G., Jackson, R. D., Pinter Jr, P. J., Reginato, R. J., Idso, S. B, 1985. Leaf-area estimates from spectral measurements over various planting dates of wheat†. International Journal of Remote Sensing, 6(1), 167-175.

Hernandez-Santana, V.; Asbjornsen, H.; Sauer, T.; Isenhart, T.; Schilling, K.; Schultz, R., 2011. Enhanced transpiration by riparian buffer trees in response to advection in a humid temperature agricultural landscape. Forest Ecology Management, 261, 1415-1427. 
Hobbs, T. J., 1995. The use of NOAA-AVHRR NDVI data to assess herbage production in the arid rangelands of Central Australia. International Journal of Remote Sensing, 16(7), 1289-1302.

Hursh CR., Brater EF., 1941. Separating storm-hydrographs from small drainage areas into surface and subsurface flow. Transactions AGU, 22, 862-870

Huxman, T.E.; Wilcox, B.P.; Breshears, D.D.; Scott, R.L.; Snyder K.A.; Small, E.E.; Hultine, K.; Pockman, W.T.; Jackson, R.B. 2005. Ecohydrological implication of woody plant encroachment, Ecological Society of America, 86(2), 308-319.

Ichoku, C., Remer, L. A., Kaufman, Y. J., Levy, R., Chu, D. A., Tanré, D., Holben, B. N., 2003. MODIS observation of aerosols and estimation of aerosol radiative forcing over southern Africa during SAFARI 2000. Journal of Geophysical Research: Atmospheres, 108(D13).

Intergovernmental Panel on Climate Change (IPCC), 2007. General guidelines on the use of scenario data for climate impact and adaptation assessment. Version 2. Intergovernmental Panel on Climate Change.

Istanbulluoglu E., Wang T., Wedin D.A., 2012. Evaluation of ecohydologic model parsimony at local and regional scales in a semiarid grassland ecosystem. Ecohydrology, 5, 121-142

Ito, A., and Oikawa, T., 2000. A model analysis of the relationship between climate perturbations and carbon budget anomalies in global terrestrial ecosystems: 1970 to 1997, Climate Research, 15(3), 161-183.

Jamal, V., Weeks, J., 1993. Africa misunderstood: or whatever happened to the rural-urban gap?. Macmillan Press Ltd., for International Labour Organisation.

Jasechko S., Sharp Z.D., Gibson J.J., Birks S.J., Yi Y., Fawcett P.J., 2013. Terrestrial water fluxes dominated by transpiration. Nature, 496, 347-350, doi: $10.1038 /$ nature11983

Jolly, W. M., Running, S. W., 2004. Effects of precipitation and soil water potential on drought deciduous phenology in the Kalahari. Global Change Biology, 10(3), 303-308. 
Keenan, T., Garcia, R., Friend, A. D., Zaehle, S., Gracia, C., Sabaté i Jorba, S., 2009. Improved understanding of drought controls on seasonal variation in Mediterranean forest canopy $\mathrm{CO} 2$ and water fluxes through combined in situ measurements and ecosystem modelling. Biogeosciences, 6, 14231444.

Khakbaz B., Imam B., Hsu K., Sorooshian S., 2012. From lumped to distributed via semi-distributed: Calibration strategies for semi-distributed hydrologic models. Journal of Hydrology, 418-419: 61-77

Kim G., Barros A.P., 2002. Space-time characterization of soil moisture from passive microwave remotely sensed imagery and ancillary data. Remote Sensing of Environment, 81, 393-403

King E.G., Caylor K.K., 2011. Ecohydrology in practice: strengths, conveniences and opportunities. Ecohydrology, 4, 608-612, doi: 10.1002/eco.248

Klein, T., Shpringer, I., Fikler, B., Elbaz, G., Cohen, S., Yakir, D., 2013. Relationships between stomatal regulation, water-use, and water-use efficiency of two coexisting key Mediterranean tree species. Forest ecology and management, 302, 34-42.

Koch J., Jensen K.H., Stisen S., 2015. Toward a true spatial model evaluation in distributed hydrological modeling: Kappa statistics, Fuzzy theroy, and EOF-analysis benchmarked by the human perception and evaluated against a modeling case study. Water Resources Research, 51, 12251246, doi: 10.1002/2014WR016607

Krysanova, V.; Hatterman, F.; Wechsung, F. 2005. Development of the ecohydrological model SWIM for regional impact studies and vulnerability assessment. Hydrological Processes, 19, 763-783

Kunnath-Poovakka A., Ryu D., Renzullo L.J., George B., 2016. The efficacy of calibrating hydrologic model using remotely sensed evapotranspiration and soil moisture for streamflow prediction. Journal of hydrology, 535, 509-524

Laio, F.; Porporato, A.; Ridolfi, L; Rodriguez-Iturbe, I, 2001. Plants in watercontrolled ecosystems: active role in hydrologic processes and response 
to water stress. II. Probabilistic soil moisture dynamics. Advances in Water Resources, 24, 707-723.

Landsberg, J.J; Waring, R.H., 1997. A generalised model of forest productivity using simplified concepts of radiation-use efficiency, carbon balance and partiotioning. Forest Ecolological Management, 95, 209-228

Law, B. E., Waring, R. H., 1994. Remote sensing of leaf area index and radiation intercepted by understory vegetation. Ecological Applications, 4, 272 279.

Le Roux X., Bariac t., Mariotti A., 1995. Spatial partitioning of the soil water resource between grass and shrub components in a West African humid savanna. Oecologia, 104, 147-155.

Liu Y., 2003. Spatial patterns of soil moisture connected to monthly-seasonal precipitation variability in a monsoon region. Journal of Geophysical Resources, 108 (D22), 8856. doi: 10.1029/2002JD003124

Liu, H., Huete, A., 1995. A feedback based modification of the NDVI to minimize canopy background and atmospheric noise. Geoscience and Remote Sensing, IEEE Transactions on, 33(2), 457-465.

Lo, M.H.; Famiglietti, J.S.; Yeh, P.J; Syed, T.H., 2010. Improving parameter estimation and water table depth simulation in a land surface model using GRACE water storage and estimated base flow data. Water Resources Research (46), W05517. doi:10.1029/2009WR007855

López-Serrano FR, Landete-Castillejos T, Martínez-Millán J, Cerro-Barja A. 2000. LAl estimation of natural pine forest using a non-standard sampling technique. Agricultural and Forest Meteorology, 101, 95-111. DOI: 10.1016/S0168-1923(99)00171-9

Lu N, Chen S, Wilske B, 2011. Effects of land use practices on ET- soil water relationships in semi-arid Inner Mongolia. Journal of Plant Ecology, 4, 4960.

Lubczynski M.W., 2009. The hydrogeological role of trees in water-limited environments. Hydrogeology Journal, 17, 247-259 
Lüdeke M. K. B., Badeck F.W., Otto R.D.,1994. The Frankfurt Biosphere Model: A global process oriented model of seasonal and long-term $\mathrm{CO} 2$ exchange between terrestrial ecosystems and the atmosphere, I, Model description and illustrative results for cold deciduous and boreal forests, Climate Research, 4, 143-166.

Ludwig, J.A., Tongway, D.J. 1995. Spatial organization of landscapes and its function in semi-arid woodlands, Australia. Landscape Ecology, 10, 5163.

Manfreda S., Caylor K.K., 2013. On the vulnerability of water limited ecosystems to climate change. Water, 5(2), 819-833, doi: 10.3390/w5020819

Manfreda S., Pizzolla T., Caylor K.K., 2013. Modelling vegetation patterns in semiarid environments. Procedia Environmental Sciences, 19, 168-177

Martínez-Vilalta, J., Prat, E., Oliveras, I., \& Piñol, J., 2002. Xylem hydraulic properties of roots and stems of nine Mediterranean woody species. Oecologia, 133(1), 19-29.

Mas J.F., 2011. Aplicaciones del sensor MODIS para el monitoreo del territorio. E-book. ISBN: 978-607-7908-55-5

Maselli, F., 2004. Monitoring forest conditions in a protected Mediterranean coastal area by the analysis of multiyear NDVI data, Remote Sensing of Environment, 89, 4, 423-433.

Maselli, F., Chiesi, M., Moriondo, M., Fibbi, L., Bindi, M., Running, S. W., 2009. Modelling the forest carbon budget of a Mediterranean region through the integration of ground and satellite data. Ecological Modelling, 220(3), 330342.

McCree, K.J., 1972. The action spectrum, absorptance and quantum yield of photosynthesis in crop plants. Agricultural Meteorology, 9, 191-216.

Mo X. G., Lin Z. H., Liu S. X., 2007. Climate change impacts on the ecohydrological processes in the Wuding River basin. Acta Ecol. Sin., 27(12), 4999-5007. 
Molina A., 2010. Aproximación al ciclo hidrológico de una masa de Pinus Halepensis con diferentes grados de cobertura vegetal. Trabajo Fin de Máster. Universitat Politècnica de València.

Molina, A., Del Campo, A. D., 2011. Estimación del Índice de área foliar en pinares de repoblación con LAI-2000 bajo radiación solar directa: relación con variables de inventario e hidrológicas. Forest systems, (1), 108-121.

Molina, A. J., del Campo, A. D., 2012. The effects of experimental thinning on throughfall and stemflow: a contribution towards hydrology-oriented silviculture in Aleppo pine plantations. Forest ecology and management, 269, 206-213.

Montaldo N., Rondena R., Albertson J.D., Mancini M., 2005. Parsimonious modeling of vegetation dynamics for ecohydrologic studies of waterlimited ecosystems. Water Resources Research, 41, W10416, doi: 10.1029/2005WR004094

Monteith, J. L., 1965. Evaporation and environment. In Symp. Soc. Exp. Biol , 19, 205-23.

Monteith, J. L., Unsworth M. H., 2008. Principles of Environmental Physics, 3rd Edition. Burlington, MA, Academic Press.

Mouton, A. M., De Baets, B., Goethals, P. L., 2010. Ecological relevance of performance criteria for species distribution models. Ecological Modelling, 221(16), 1995-2002.

Mu Q., Zhao M., Running S.W., 2011. Improvement to a MODIS global terrestrial evapotranspiration algorithm. Remote Sensing of Environment, 115, 1781-1800. DOI: 10.1016/j.rse.2011.02.019

Naiman R.J., Magnuson J.J., McKnight D.M., Stanford J.A., and other members of the FWI Steering Committee, 1995. The freshwater imperative: $A$ research agenda. Island Press, Washington D.C., Covelo, California.

Nash J.E. and Sutcliffe J.V., 1970. River flow forecasting through conceptual models part I - A discussion of principles. Journal of Hydrology, 10 (3), 282-290 
Newman B.D., Wilcox B.P., Archer S.R., Breshears D.D., Dahm C.N., Duffy C.J., McDowell N.G., Phillips F.M., Scanlon B.R., Vivoni E.R., 2006. Ecohydrology of water-limited environments: A scientific vision. Water Resources Research, 42, W06302, doi: 10.1029/2005WR004141

Ngigi S., Savenije H.H.G., Gichuki F.N., 2008. Hydrological impacts of flood storage and management on irrigation water abstraction in Upper Ewaso Ngiro River basin, Kenya. Water Resources Management, 22, 1859-1879. DOI: $10.1007 /$ s11269-008-9257-5

Niu, G.Y.; Seo, K.; Yang, Z-L; Wilson, C.; Su, H.; Chen, J.; Rodell, M.; 2007. Retrieving snow mass from GRACE terrestrial water storage change with a land surface model. Geophysical research letter, 34 (15), LI5704, doi:10.1029/2007GL030413.

Nuttle, W. K. 2002. Eco-hydrology's past and future in focus, Eos Transaction AGU., 83, 205-212.

Oliveira RS, Dawson TE, Burgess SSO, 2005. Hydraulic redistribution in three Amazonian trees. Oecologia, 145, 354-63.

Ollinger, S.V.; Richardson, A.D.; Martin, M.E.; Hollinger, D.Y.; Frolking, S.; Reich, P.B.; Plourde, L.C.; Katul, G.; Munger, J.W.; Oren, R.; Smith, M.L.; Paw, U.; Bolstad, K.T.; Cook, P.V.; Day, B.; Martin, M.C.; Monson, T.A.; Schmidt, R.K.H.P., 2008. Canopynitrogen, carbon assimilation, and albedo in temperate and boreal forests: functional relations and potential climate feedbacks. Proc. Natl. Acad. Sci. USA., 105, 19335-19340

Oya, C. 2012. Contract Farming in Sub-Saharan Africa: A Survey of Approaches, Debates and Issues. Journal of Agrarian Change, 12(1), 1-33.

Pande S., Savenije H.H.G., Bastidas L.A., Gosain A.K., 2012. A parsimonious hydrological model for a data scarce dryland region. Water Resources Management, 26, 909-926, doi: 10.1007/s11269-011-9816-z

Padien, D.J., Lajtha, K. 1992. Plant spatial pattern and nutrient distribution in pinyon-juniper woodlands along an elevational gradient in northern New Mexico. International Journal of Plant Sciences, 153, 425-433. 
Parajka J., Blöschl G., 2008. The value of MODIS snow cover data in validating and calibrating conceptual hydrologic models. Journal of Hydrology, 358, 240-258.

Pasquato M., 2013. Comparison of parsimonious dynamic vegetation modeling approaches for semiarid climates. PhD Thesis, Universitat Politècnica de València,

Pasquato, M.; Medici, M.; Friend A.D.; Francés, F., 2015. Comparing two approaches for parsimonious vegetation modelling in semiarid regions using satellite data. Ecohydrology, 8(6), 1024-1036. DOI: 10.1002/eco. 1559

Parsons A.J., Abrahams A.D., 1994. Geomorphology of desert environments. Chapman and Hall, London, ISBN 978-94-015-8256-8

Perone C.S., 2009. Pyevolve: a Python open-source framework for genetic algorithms. ACM SIGEVOlution, 4 (1), 12-20, doi: $10.1145 / 1656395.1656397$

Pettorelli N, Vik JO, Mysterud A, Gaillard JM, Tucker CJ, Stenseth NC, 2005. Using the satellite-derived Normalized Difference Vegetation Index (NDVI) to assess ecological effects of environmental change. Trends in Ecology and Evolution, 20:503-510

Piedallu C., Gégout J.C., Perez V., Lebourgeois F., 2013. Soil water balance performs better than climatic water variables in tree species distribution modelling. Global Ecology and Biogeography, 22, 470-482.

Pielke R.A., Avissar S.R., Raupach M., Dolman A.J., 1998. Interactions between the atmosphere and terrestrial ecosystems: influence on weather and climate. Global Change Biology, 4(5), 461-475.

Pietsch, S. A., Hasenauer, H., Kučera, J., Čermák, J., 2003. Modeling effects of hydrological changes on the carbon and nitrogen balance of oak in floodplains. Tree physiology, 23(11), 735-746.

Pilgrim, D.H.; Chapman, T.G.; Doran, D.G. 1988. Problems of rainfall-runoff modelling in arid and semiarid regions, Hydrological Sciences Journal des Sciences Hydrologiques, 33, 379-400. 
Pokhrel, P., Gupta, H. V., Wagener, T., 2008. A spatial regularization approach to parameter estimation for a distributed watershed model. Water Resources Research, 44(12).

Pokhrel P., Gupta H.V., 2010. On the use of spatial regularization strategies to improve calibration of distributed watershed models. Water Resources Research, 46, doi: 10.1029/2009WR008066

Polley, H. W., Phillips, R. L., Frank, A. B., Bradford, J. A., Sims, P. L., Morgan, J. A., Kiniry, J. R., 2011. Variability in light-use efficiency for gross primary productivity on Great Plains grasslands. Ecosystems, 14(1), 15-27.

Porporato A., Laio F., Ridolfi L., Rodriguez-Iturbe I., 2001. Plants in watercontrolled ecosystems: active role in hydrologic processes and response to water stress: III. Vegetation water stress. Advances in Water Resources, 24(7), 725-744.

Porporato, A., Rodriguez-lturbe I., 2002. Ecohydrology-A challenging multidisciplinary research perspective, Hydrological Sciences Journal, 47, $811-821$.

Porporato, A., Rodriguez-Iturbe, I., 2013. From random variability to ordered structures: a search for general synthesis in ecohydrology. Ecohydrology, 6(3), 333-342.

Preisendorfer, R. W., Mobbley C.D., 1988. Principal component analysis in meteorology and oceanography (Vol. 425). (Ed.). Amsterdam: Elsevier.

Price, J. C., 1992. Estimating vegetation amount from visible and near infrared reflectances. Remote Sensing of Environment, 41(1), 29-34.

Prince, S. D., 1991. Satellite remote sensing of primary production: comparison of results for Sahelian grasslands 1981-1988. International Journal of Remote Sensing, 12(6), 1301-1311.

Prince, S. D., Goward, S. N., 1995. Global primary production: a remote sensing approach. Journal of biogeography, 815-835.

Quevedo, D.I.; Francés, F., 2008. A conceptual dynamic vegetation-soil model for arid and semiarid zones. Hydrology and Earth System Science, 12, 11751187 
Quevedo, D.I., 2010. Desarrollo de un modelo conceptual dinámico suelovegetación para zonas áridas y semi-áridas. Doctoral thesis, Universitat Politècnica de València.

Reynolds, J.F., Virginia, R.A., Schlesinger, W.H. 1997. Defining functional types for models of desertification. In Plant functional types: their relevance to ecosystem properties and global change. pp. 195-216. Edited by T.M. Smith, H.H. Shugart and F.I. Woodward. Cambridge University Press, New York, N.Y.

Rientjes, T.H.M., Muthuwatta, L.P., Bos, M. G., Booij, M.J., Bhatti, H.A., 2013. Multi-variable calibration of a semi-distributed hydrological model using streamflow data and satellite-based evapotranspiration. Journal of Hydrology, 505, 276-290

Rigon, R.; Bertoldi, G.; Over, T.M. 2006. GEOTOP: A distributed hydrological model with coupled water and energy budgets. Journal of Hydrometeorology, 7, 371-388.

Rodriguez-Iturbe I., 2000. Ecohydrology: A hydrologic perspective of climate-soilvegetation dynamics, Water Resources Research, 36, 3-9.

Rodriguez-Iturbe, I., D'odorico, P., Porporato, A., Ridolfi, L., 1999. On the spatial and temporal links between vegetation, climate, and soil moisture. Water Resources Research, 35(12), 3709-3722.

Rodriguez-Iturbe, I.; Porporato, A.; Laio, F; Ridolfi, L. 2001. Plants in watercontrolled ecosystems: active role in hydrologic processes and response to water stress. I. Scope and general outline. Advances in Water Resources, 24, 695-705

Ruiz-Pérez G., González-Sanchis M., Del Campo AD., Francés F., 2016b. Can a parsimonious model implemented with satellite data be used for modelling the vegetation dynamics and water cycle in water-controlled environments?. Ecological modelling, 324, 45-53

Ruiz-Pérez G., Medici C., Latron J., Llorens P., Gallart F., Francés F., 2016a. Investigating the behaviour of a small Mediterranean catchment using three different hydrological models as hypotheses. Hydrological Processes, online version, DOI: 10.1002/hyp.10738 
Running, S.W.; Nemani, R.R.; Heinsch, F.A.; Zhao, M.; Reeves, M.; Hashimoto, $\mathrm{H}$., 2004. A continouos satellite-derived measure of global terrestrial primary production. BioScience, 54, 547-560.

Sabaté, S.; Gracia, C.A.; Sánchez, A., 2002. Likely effects of climate change on growth of Quercus ilex, Pinus halepensis, Pinus pinaster, Pinus sylvestris and Fagus sylvatica forests in the Mediterranean region. Forest Ecology and Management, 162, 23-37

Samaniego L., Kumar R., Jackisch C., 2011. Predictions in a data-sparse region using a regionalized grid-based hydrologic model driven by remotely sensed data. Hydrology Research, 42(5), 338-355, doi: 10.2166/nh.2011.156

Scanlon, T. M., Albertson, J. D., 2003. Inferred controls on tree/grass composition in a savanna ecosystem: Combining 16-year normalized difference vegetation index data with a dynamic soil moisture model. Water resources research, 39(8).

Schimel, D. S., Braswell, B. H., Holland, E. A., McKeown, R., Ojima, D. S., Painter, T. H.,Townsend, A. R.,1994. Climatic, edaphic, and biotic controls over storage and turnover of carbon in soils. Global biogeochemical cycles, 8(3), 279-293.

Schulze, E.D., Beck E., Müller-Hohenstein K., 2005. Plant Ecology. Springer Berlin- Heidelberg. ISBN: 3-540-20833-X

Schulze, E.D., Mooney, H.A., Sala, O.E., Jobbagy, E., Buchmann, N., Bauer, G., Canadell, J., Jackson, R.B., Loreti, J., Oesterheld, M., Ehleringer, J.R. 1996. Rooting depth, water availability, and vegetation cover along an aridity gradient in Patagonia. Oecologia, 108, 503-511

Schwinning S., Sala O.E., 2004. Hierarchy of responses to resource pulses in arid and semi-arid ecosystems. Oecologia, 141, 211-220, doi: $10.1007 / \mathrm{s} 00442-004-1520-8$

Schwinning S., 2010. The ecohydrology of roots in rocks. Ecohydrology, 3, 238245, doi: $10.1002 /$ eco. 134 
Sender, J., Johnston, D., 2004. Searching for a weapon of mass production in rural Africa: unconvincing arguments for land reform. Journal of Agrarian Change, 4(1-2), 142-164.

Sellers, P. J., 1985. Canopy reflectance, photosynthesis and transpiration. International Journal of Remote Sensing, 6(8), 1335-1372.

Silleos, N.G.; Alexandridis, T.K.; Gitas, I.Z.; Perakis, K, 2006. Vegetation Indices: Advances made in biomass estimation and vegetation monitoring in the last 30 years. Geocarto International , 21(4), 21-28

Sims, D.A.; Luo, H.; Hastings, S.; Oechel, W.C.; Rahman, A.F.; Gamon, J.A., 2006. Parallel adjustments in vegetation greenness and ecosystem $\mathrm{CO} 2$ exchange in response to drought in a Southern California chaparral ecosystem. Remote Sensing of Environment, 103, 289-303

Sitch, S., Smith, B., Prentice, I. C., Arneth, A., Bondeau, A., Cramer, W., Thonicke, K. 2003. Evaluation of ecosystem dynamics, plant geography and terrestrial carbon cycling in the LPJ dynamic global vegetation model. Global Change Biology, 9(2), 161-185.

Smalley, R. 2013. Plantations, contract farming and commercial farming areas in Africa: a comparative review. Land and Agricultural Commercialization in Africa. Future Agricultures Consortium. University of Sussex, Brighton, UK.

Snyder, R.L.; Bali, K.; Ventura, F.; Gómez-MacPherson, H., 2000. Estimating evaporation from bare and nearly bare soil. Journal of Irrigation and Drainage Engineering - ASCE, 126, 399-403.

Sprintsin, M.; Karnieli, A.; Berliner, P.; Rotenberg, E.; Yakir, D.; Cohen, S., 2007. The effect of spatial resolution on the accuracy of leaf area index estimation for a forest planted in the desert transition zone. Remote Sensing of Environment, 109, 416-428

Stisen, S., McCabe, M.F., Refsgaard, J.C., Lerer, S. and Butts, M.B., 2011. Model parameter analysis using remotely sensed pattern information in a multi-constraint framework. Journal of Hydrology, 409(1), 337-349. 
Sun A.Y., Green R., Swenson S., Rodell M., 2012. Toward calibration of regional groundwater models using GRACE data. Journal of Hydrology, 422-423, $1-9$

Sun W.C., Ishidaira H., Bastola S., 2010. Towards improving river discharge estimation in ungauged basins: calibration of rainfall-runoff models based on satellite observations of river flow width at basin outlet. Hydrology and Earth System Sciences, 14, 2011-2022, doi: 10.5194/hes-14-2011-2010

Tague, C.L.; Band, L.E. 2004. RHESSyS: Regional Hydro-Ecologic Simulation System- An object-oriented approach to spatially distributed modeling of carbon, water and nutrient. Earth Interactions, 8, 1-42.

Tanner, C.B. and Fuchs, M., 1968. Evaporation from unsaturated surfaces: a generalized combination method. Journal of Geophysical Research, 73, 1299-1304.

Tatarinov, F. A., Cienciala, E., 2006. Application of BIOME-BGC model to managed forests: 1. Sensitivity analysis. Forest Ecology and Management, 237(1), 267-279.

Thompson, E. T. 1941. The climatic theory of the plantation. Agricultural History, 15(1), 49-60.

Thorton, P.; Law, B.; Gholz, H.L.; Clark, K.L.; Falge, E.; Ellsworth, D.; Goldstein, A.; Monson, R.; Hollinger, D.; Falk, M.; Chen, J.; Sparks, J, 2002. Modeling and measuring the effects of disturbance history and climate on carbon and water budgets in evergreen needleleaf forests. Agricultural and Forest Meteorology, 113, 185-222

Tolba, M. K., 1982. Development without destruction: evolving environmental perceptions. Natural Resources and Environmental, 12: 197-203.

Tromp-van Meerveld H.J., McDonnell J.J., 2006. On the interrelations between topography, soil depth, soil moisture, transpiration rates and species distribution at the hillslope scale. Advances in Water Resources, 29, 293310

Tucker CJ., 1979. Red and photographic infrared linear combinations for monitoring vegetation. Remote Sensing of Environment, 8, 127-150, doi:10.1016/0034-4257(79)90013-0 
Tucker, C. J., Townshend, J. R., \& Goff, T. E., 1985. African land-cover classification using satellite data. Science, 227(4685), 369-375.

Turner, D. P., Cohen, W. B., Kennedy, R. E., Fassnacht, K. S., \& Briggs, J. M., 1999. Relationships between leaf area index and Landsat TM spectral vegetation indices across three temperate zone sites. Remote Sensing of Environment, 70, 52 - 68 .

van der Molen M.K., Dolman A.J., Ciais P., Eglin T., Gobron N., Law B.E., Meir P., Peters W., Phillips O.L., Reichstein M., Chena T., Dekker S.C., Doubková M., Friedl M.A., Jung M., van den Hurk B.J.J.M., de Jeu R.A.M., Kruijt B., Ohta T., Rebel K.T., Plummer S., Seneviratne S.I., Sitch S., Teuling A.J., van der Werf G.R., Wang G., 2011. Drought and ecosystem carbon cycling. Agricultural and Forest Meteorology, 151(7), 765-773. Doi: 10.1016/j.agrformet.2011.01.018

van Dijk A.I.J.M., Renzullo L.J., 2011. Water resource monitoring systems and the role of satellite observations. Hydrology and Earth system Sciences, 15, 39-55. doi: 10.5194/hess-15-39-2011

van Vliet, J., Hagen-Zanker, A., Hurkens, J., van Delden, H., 2013. A fuzzy set approach to assess the predictive accuracy of land use simulations. Ecological modelling, 261, 32-42.

Velpuri N.M., Senay G.B., Asante K.O., 2012. A multi-source satellite data approach for modelling Lake Turkana water level: calibration and validation using satellite altimetry data. Hydrology and Earth System Sciences, 16, 1-8, doi: 10.5194/hess-16-1-2012

Vermeulen, S., Cotula, L., 2010. Making the most of agricultural investment: $A$ survey of business models that provide opportunities for smallholders. lied.

Vertessy R. A., Dawes W. R., Zhang L., Hatton T. J., Walker J., 1996. Catchment-scale hydrologic modelling to assess the water and salt balance behavior of eucalypt plantations. CSIRO Div. Water Resour., Black Mountain, Australia, Tech. Memo. No. 96/2.

Vicente-Serrano, S.M.; Lasanta, T.; Gracia, C., 2010. Aridification determines changes in forest growth in Pinus halepensis forests under semiarid 
Mediterranean climate conditions. Agricultural and Forest Meteorology, $150,614-628$.

Vieux, B. E., Cui, Z., Gaur, A., 2004. Evaluation of a physics-based distributed hydrologic model for flood forecasting. Journal of Hydrology, 298(1), 155177.

Viña, A., Gitelson, A. A., Nguy-Robertson, A. L., Peng, Y., 2011. Comparison of different vegetation indices for the remote assessment of green leaf area index of crops. Remote Sensing of Environment, 115(12), 3468-3478.

Von Storch, H., Navarra, A. (1995). Analysis of Climate Variability, 334 pp.

Wang L., D’Odorico P., Evans J.P., Elridge D.J., McCabe M.F., Caylor K.K., King E.G., 2012. Dryland ecohydrology and climate change: critical issues and technical advances. Hydrology and Earth System Sciences, 16, 25852603, doi: 10.5194/hess-16-2585-2012

Wang, Y., Woodcock, C. E., Buermann, W., Stenberg, P., Voipio, P., Smolander, H., ... \& Myneni, R. B., 2004. Evaluation of the MODIS LAI algorithm at a coniferous forest site in Finland. Remote sensing of Environment, 91(1), 114-127.

Wang Q, Adiku S, Tenhunen J, Granier A, 2005. On the Relationship of NDVI with leaf area index in a deciduous forest site. Remote Sensing of Environment, 94, 244-255

Waring, R. H., Running S. W., 2007. Forest Ecosystems: Analysis at Multiple Scales. San Francisco, CA, Elsevier Academic Press.

Watts, M. J., Little, P. D., 1994. Life under contract: contract farming, agrarian restructuring, and flexible accumulation. Living under contract: contract farming and agrarian transformation in sub-Saharan Africa., 21-77.

Wi S., Yang Y.C.E., Steinschneider S., Khalil A., Brown C.M., 2015. Calibration approaches for distributed hydrologic models in poorly gaged basins: implication for streamflow projections under climate change. Hydrology and Earth System Sciences, 19, 857-876 
Williams, C.A.; Albertson, J.D., 2005. Contrasting short and long-timescale effects of vegetation dynamics on water and carbon fluxes in water-limited ecosystems. Water Resources Research, 41, W06005

Williams, D.G.; Cable, W.; Hultine, K.; Hoedjes, J.C.B; Yepez, E.A.; Simonneaux, V.; Er-Raki, S.; Boulet, G.; Bruin, H.A.R.; Chehbouni A.; Hartogensis, O.K.; Timouk, F., 2004. Evapotranspiration components determined by stable isotopes, sap flow and eddy covariance techniques. Agricultural and Forest Meteorology, 125, 241-258.

Winsemius, H.C., Savenije, H.H.G., Bastiaansen, W.G.M., 2008. Constraining model parameters on remote sensed evaporation: justificacion for distribution in ungauged basins? Hydrology Earth System Science, 12, 1403-1413.

Wolf, A ., 2011. Estimating the potential impact of vegetation on the water cycle requires accurate soil water parameter estimation. Ecological Modelling, 222, 2595-2605.

Xiao X., Zhang Q., Braswell B., Urbanski S., Boles S., Wofsy S., Moore B., Ojima D., 2004. Modeling gross primary production of temperate deciduous broadleaf forest using satellite images and climate data. Remote Sensing of Environment, 91(2), 256-270

Yang S., Liu C. M., Wen Z. Q., Wang X. L., Wang Y. J., Li Q., Sheng H. R., 2009. Development of ecohydrological assessment tool and its application, Sci. Chin. Ser. E-Technol. Sci., vol. 52(7), 1947-1957.

Yatheendradas, S., Wagener, T., Gupta, H., Unkrich, C., Goodrich, D., Schaffner, M., Stewart, A., 2008. Understanding uncertainty in distributed flash flood forecasting for semiarid regions. Water Resources Research, 44(5).

Yuan W, Liu S, Zhou G, Zhou G, Tieszen LL, Baldocchi D, Bernhofer C, Gholz H, Goldstein AH, Goulden ML, Hollinger DY, Hu Y, Law BE, Stoy PC, Vesala T, Wofsy SC, other AmeriFlux collaborators. 2007. Deriving a light use efficiency model from eddy covariance flux data for predicting daily gross primary production across biomes. Agricultural and Forest Meteorology, 143, 189-207. DOI: 10.1016/j.agrformet.2006.12.001

Yuan W., Liu S., Yu G., Bonnefond J-M, Chen J., Davis K., Desai AR., Goldstein A.H., Gianelle D., Rossi F., Suyker AE., Verma SB., 2010. Global 
estimates of evapotranspiration and gross primary production based on MODIS and global meteorology data. Remote Sensing of Environment, 114(7), 1416-1431

Zalewski M., Borkowski W., Migal W., Salacinki S., 1992. Rybniki, st. 1" Krzemianka", gm. Wasilków, woj. białostockie, AZP 34-86/1. Informator Archeologiczny: badania, 26.

Zalewski M., Janauer G.A., Jolankai G., 1997. Ecohydrology: a new paradigm for the sustainable use of aquatic resources

Zhang Y.Q., Francis H.S., Chiew H.S., Zhang L., Li H., 2009. Use of remotely sensed actual evapotranspiration to improve rainfall-runoff modeling in southeast Australia. American Meteorological Society, 10, 969-980

Zhang Y.Q., Viney N.R., Chiew F.H.S., van Dijk A.I.J.M., Liu Y.Y., 2011. Improving hydrological and vegetation modelling using regional model calibration schemes together with remote sensing data. 19th International Congress on Modelling and Simulation, Perth, Australia, 12-16 December

Zhang C., Kovacs J.M., 2012. The application of small unmanned aerial systems for precision agriculture: a review. Precision Agriculture, 13, 693-712.

Zhao K.G., Shi J.C., Zhang L.X., Jiang L.M., Zhang Z.J., Qin J., Yao Y.J., Hu J.C., 2003. Retrieval of bare soil surface parameters from simulated data using neural networks combined with IEM. Geoscience and Remote Sensing Symposium, 6, 3881-3883, doi: 10.1109/IGARSS.2003.1295301

Zhen-Ming, G., Xiao, Z., Seppo, K., Heli, P., Kai-Yun, W., 2011. Climate, canopy conductance and leaf area development controls on evapotranspiration in a boreal coniferous forest over a 10-year period: A united model assessment. Ecological Modelling, 222(9), 1626-1638.

Zreda, M., Desilets, D., Ferre, T. P. A., Scott, R. L., 2008. Measuring soil moisture content non-invasively at intermediate spatial scale using cosmic-ray neutrons, Geophysical Research letters, 35, L21402, doi:10.1029/2008GL035655. 
On the use of satellite data to calibrate a parsimonious ecohydrological model in ungauged basins Doctoral Thesis 